\section{Pacific Northwest}

National Laboratory

Operated by Battelle for the

U.S. Department of Energy

\title{
Updated Site Response Analyses for the Waste Treatment Plant, DOE Hanford Site, Washington
}

\author{
R. R. Youngs
}

June 2007

Prepared by Geomatrix Consultants, Inc. for the Pacific Northwest National Laboratory under Contract DE-AC05-76RL01830 with the U.S. Department of Energy 


\title{
DISCLAIMER
}

This report was prepared as an account of work sponsored by an agency of the United States Government. Neither the United States Government nor any agency thereof, nor Battelle Memorial Institute, nor any of their employees, makes any warranty, express or implied, or assumes any legal liability or responsibility for the accuracy, completeness, or usefulness of any information, apparatus, product, or process disclosed, or represents that its use would not infringe privately owned rights. Reference herein to any specific commercial product, process, or service by trade name, trademark, manufacturer, or otherwise does not necessarily constitute or imply its endorsement, recommendation, or favoring by the United States Government or any agency thereof, or Battelle Memorial Institute. The views and opinions of authors expressed herein do not necessarily state or reflect those of the United States Government or any agency thereof.

\author{
PACIFIC NORTHWEST NATIONAL LABORATORY \\ operated by \\ BATTELLE \\ for the \\ UNITED STATES DEPARTMENT OF ENERGY \\ under Contract DE-AC05-76RL01830
}

Printed in the United States of America
Available to DOE and DOE contractors from the
Office of Scientific and Technical Information,
P.O. Box 62, Oak Ridge, TN 37831-0062; ph: (865) 576-8401
fax: (865) 576-5728
email: reports@adonis.osti.gov

\author{
Available to the public from the National Technical Information Service, \\ U.S. Department of Commerce, 5285 Port Royal Rd., Springfield, VA 22161 \\ ph: (800) 553-6847 \\ fax: (703) 605-6900 \\ email: orders@ntis.fedworld.gov \\ online ordering: http://www.ntis.gov/ordering.htm
}


GMX-9995.002-001: Updated Site Response Analyses for WTP, Rev 00

Page No.:- i. -

UPDATED SITE RESPONSE ANALYSES FOR THE WASTE TREATMENT PLANT DOE HANFORD SITE, WASHINGTON

Document GMX-9995.002-001 Rev 00

Prepared by:

Date:
Robert R Young

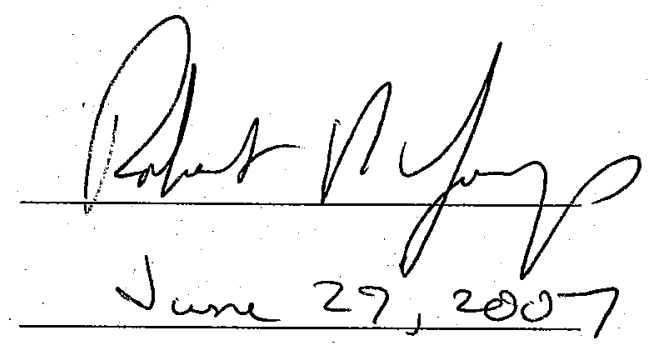

Project 9995.002.

Geomatrix Consultants, Inc.

Oakland, CA 94612 


\begin{tabular}{|c|c|l|}
\hline Revision & Date & Purpose of Revision \\
\hline 00 & $6 / 29 / 2007$ & Original issue \\
\hline
\end{tabular}




\section{TABLE OF CONTENTS}

1.0

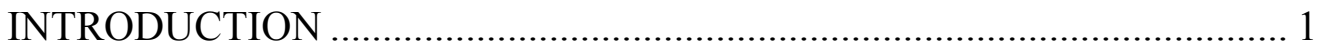

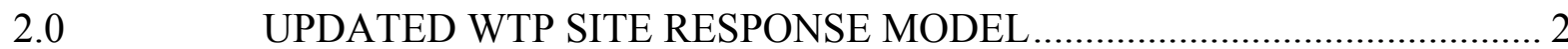

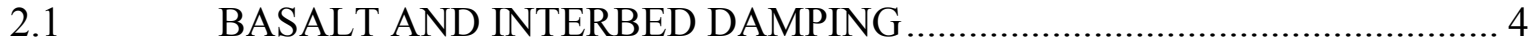

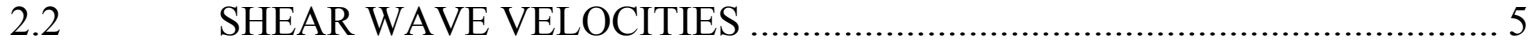

2.2.1 Supra-basalt Sediment Velocities ..................................................................... 5

2.2.2 Basalt and Interbed Velocities ............................................................... 6

2.3 MODULUS REDUCTION AND DAMPING RELATIONSHIPS FOR SUPRA-BASALT SEDIMENTS …..................................................... 8

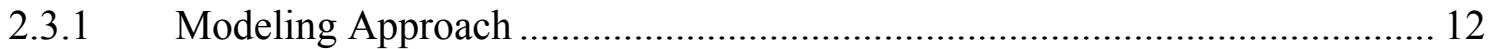

2.3.2 H2 Unit $\mathrm{G} / \mathrm{G}_{\max }$ and Damping Relationships............................................ 13

2.3.3 H3 Unit $\mathrm{G} / \mathrm{G}_{\max }$ and Damping Relationships........................................... 15

2.3.4 CCU G/G $\mathrm{G}_{\max }$ and Damping Relationships ............................................. 16

2.3.5 Ringold Unit A G/G $\mathrm{G}_{\max }$ and Damping Relationships................................. 18

2.4 SUMMARY OF CHANGES TO SITE RESPONSE MODEL .................... 18

RELATIVE SITE RESPONSE ANALYSIS ............................................. 19

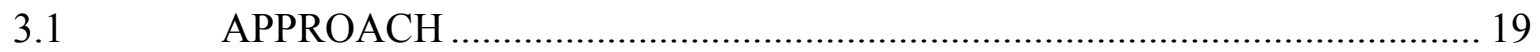

3.1.1 Rock Motions.......................................................................................... 20

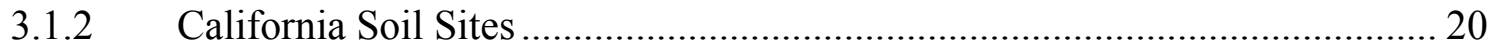

3.1.3 Randomized Velocity Profiles for the WTP Site ...................................... 20

3.1.4 Randomized Modulus Reduction and Damping Relationships ..................... 24

3.2 SITE RESPONSE ANALYSIS RESULTS ............................................ 26

3.2.1 Summary of 2005 Results and Sensitivity Using 2005 Site Response Model 26

3.2.2 Sensitivity Analyses Using Updated Site Velocities Only .......................... 28

3.2.3 Sensitivity Analyses Using Complete Updated WTP Site Model .................. 31

3.2.4 Statistics of Relative Amplification Functions ........................................... 35

3.3 EFFECT OF PEER-NGA GROUND MOTION MODELS ON SITE HAZARD .............................................................................................. 36

4.0 DEVELOPMENT OF WTP SITE-SPECIFIC DESIGN RESPONSE

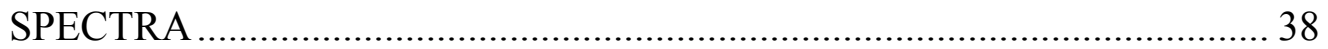

Horizontal Spectrum ........................................................................ 38

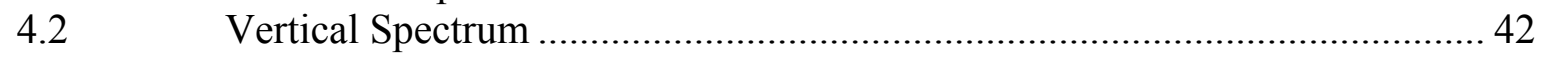

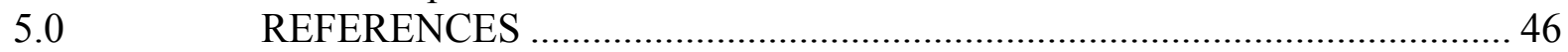

\section{List of Tables}

Table 1: Members of the Site Response Model Expert Panel ............................................... 3

Table 2: Grain Size Parameter Distributions for Hanford Supra-Basalt Sediments ............... 13

Table 3: Comparison of 2005 and 2007 Site Response Models for the WTP site................. 19

Table 4: Velocity Variability Model Parameters Used for the Supra-basalt Sediments at the

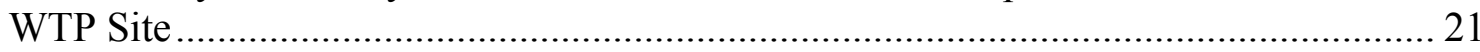

Table 5: Updated WTP Site-Specific Design Response Spectra ....................................... 43

\section{List of Figures}

Figure 1: Site Response Model Logic Tree for the WTP Site Developed by Rohay and Reidel (2005). (Numbers in parentheses below branches indicate assigned weight.) ................ 2

Figure 2: Updated site response model logic tree for the WTP. (Numbers in parentheses

below branches indicate assigned weight.) ........................................................ 3

Figure 3: Geometric mean velocity profiles for supra-basalt sediments. ........................... 6

Figure 4: Geometric mean velocity profiles for basalts and interbeds. ................................ 8 
Figure 5: Comparison of resonant column (RC) and torsional shear (TS) test results for one specimen from the $\mathrm{H} 2$ unit at its estimated in-situ mean effective stress with $\mathrm{G} / \mathrm{G}_{\max }$ and damping relationships developed from Menq's (2003) model based on test specimen $C_{U}$ and $\mathrm{D}_{50}$

Figure 6: Comparison of resonant column (RC) and torsional shear (TS) test results for one specimen from the $\mathrm{H} 3$ unit at its estimated in-situ mean effective stress with $\mathrm{G} / \mathrm{G}_{\max }$ and damping relationships developed from Menq's (2003) model based on test specimen $C_{U}$ and $\mathrm{D}_{50}$.

Figure 7: Comparison of resonant column (RC) and torsional shear (TS) test results for one specimen from CCU at its estimated in-situ mean effective stress with $\mathrm{G} / \mathrm{G}_{\max }$ and damping relationships developed from Menq's (2003) model based on test specimen $C_{U}$ and $\mathrm{D}_{50}$.

Figure 8: Modulus reduction and damping relationships for the 0-40 $\mathrm{ft}$ depth range of the $\mathrm{H} 2$ unit used in the updated site response analysis.

Figure 9: Modulus reduction and damping relationships for the $>40$ to $110 \mathrm{ft}$ depth range of the $\mathrm{H} 2$ unit used in the updated site response analysis.

Figure 10: Modulus reduction and damping relationships for the $>110-250 \mathrm{ft}$ depth range of the $\mathrm{H} 2$ unit used in the updated site response analysis.

Figure 11: Modulus reduction and damping relationships for the H3 unit developed using the model of Menq (2003) compared to those of Rollins et al. (1998) and the Peninsula Ranges model (Silva et al. 1998). Relationships developed using Menq (2003) and Rollins et al. (1998) are used for the H3 unit in the updated analysis.

Figure 12: Modulus reduction and damping relationships for the CCU layer developed using the model of Menq (2003) compared to those of Rollins et al. (1998) and the Peninsula Ranges model (Silva et al. 1998). Relationships developed using Menq (2003) and Rollins et al. (1998) are used for the CCU layer in the updated analysis.

Figure 13: Effect of confining pressure difference on modulus reduction and damping relationships using the model of Menq (2003) with $\mathrm{C}_{U}=20$ and the mid-point depths of the $\mathrm{H} 3$ and $\mathrm{CCU}$ units.

Figure 14: Thirty randomized velocity profiles (five per panel) for the supra-basalt sediments

Figure 15: Statistics of randomized velocity profiles for the supra-basalt sediments.

Figure 16: Thirty randomized velocity profiles (five per panel) for the basalts and interbeds.

Figure 17: Statistics of randomized velocity profiles for the basalts and interbeds.

Figure 18: Percentiles of randomized $\mathrm{G} / \mathrm{G}_{\max }$ and damping relationships based on EPRI (1993) 21-50 ft depth curves. $\mathrm{G} / \mathrm{G}_{\max }$ is randomized using a beta distribution with strain-dependent parameters and damping is randomized using a lognormal distribution with strain-dependent sigma.

Figure 19: Percentiles of randomized $\mathrm{G} / \mathrm{G}_{\max }$ and damping relationships based on EPRI (1993) 21-50 ft depth curves. Curves are first fit with Darendeli (2001) model parameters $\gamma_{R}, a$, and $\mathrm{D}_{\min }$. $\mathrm{G} / \mathrm{G}_{\max }$ and damping are randomized using randomization of Darendeli (2001) model parameters fit to base case curves.

Figure 20: Distribution of relative amplification functions for the WTP site developed by Rohay and Reidel (2005).

Figure 21: Rohay and Reidel (2005) logic tree reduced to branches consistent with updated site response model.

Figure 22: Distribution of relative amplification functions for the WTP site computed using the Rohay and Reidel (2005) site response model logic tree reduced to include only 
those parameters that are comparable to the updated site response model. (The reduced logic tree is shown in Figure 21.)

Figure 23: Distribution of relative amplification functions computed using the updated WTP velocity models and the Rohay and Reidel (2005) sets of modulus reduction and damping relationships (without randomization of $\mathrm{G} / \mathrm{G}_{\max }$ and damping)...

Figure 24: Comparison of distributions of relative amplification functions computed using the updated WTP velocity models and the Rohay and Reidel (2005) sets of modulus reduction and damping relationships with and without randomization. Ratios are shown for the $\mathrm{CCU}=\mathrm{H} 3$ velocity case.

Figure 25: Comparison of relative amplification functions computed using the updated WTP basalt and interbed velocity models based on down-hole velocity measurements and those computed with basalt and interbed velocities based on the suspension logging data. Ratios are shown for the CCU=H3 velocity case with EPRI (1993) and Rollins et

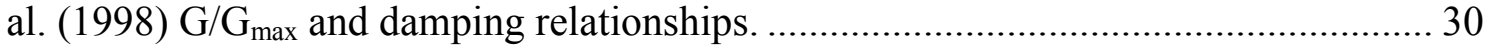

Figure 26: Effect of $\kappa$ on relative response for the updated site response model (Figure 2). . 31 Figure 27: Effect of $\mathrm{H3} / \mathrm{CCU}$ velocity model on relative response for the updated site

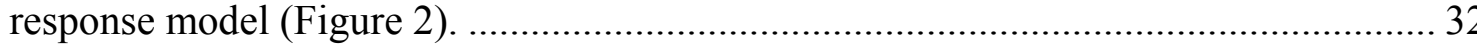

Figure 28: Effect of basalt and interbed velocity model on relative response for the updated site response model (Figure 2)

Figure 29: Effect of alternative approaches for specification of the $\mathrm{G} / \mathrm{G}_{\max }$ and damping relationships for the supra-basalt sediments on relative response for the updated site response model (Figure 2).

Figure 30: Effect of alternative $\mathrm{G} / \mathrm{G}_{\max }$ and damping relationships for the $\mathrm{H} 2$ unit on relative response for the updated site response model (Figure 2).

Figure 31: Effect of alternative $\mathrm{G} / \mathrm{G}_{\max }$ and damping relationships for the $\mathrm{H} 3$ unit on relative response for the updated site response model (Figure 2)......................................... 34

Figure 32: Effect of alternative $\mathrm{G} / \mathrm{G}_{\max }$ and damping relationships for $\mathrm{CCU}$ layer on relative response for the updated site response model (Figure 2)......................................... 35

Figure 33: Distribution of relative amplification functions for the WTP site computed using the updated site response model (Figure 2).

Figure 34: Comparison of total hazard curves (peak ground acceleration [PGA] and spectral acceleration [SA]) computed for: the 200 West site location using 1996 ground motion models, the WTP site location using 1996 ground motion models, and the WTP site location using PEER-NGA and new subduction zone earthquake ground motion models.

Figure 35: Development of 2005 interim WTP horizontal design response spectrum (2005 Interim DRS) presented in Rohay and Reidel (2005) compared to the original horizontal design response spectrum (1996 DRS)

Figure 36: Mean and 84th percentile response spectra developed using 2005 and 2007 relative amplification functions. The 2005, 2007, and Case 1a relative amplification functions are shown in Figures 20, 33, and 23, respectively.

Figure 37: Development of updated site-specific horizontal design response spectrum for the WTP site. Also shown are the original design response spectrum (1996 DRS), the original design response spectrum multiplied by the 2005 84th-percentile RAF, and the 2005 interim DRS.

Figure 38: Comparison of the updated WTP site-specific horizontal design response spectrum to spectra developed using the Newmark and Hall (1978) median and $84^{\text {th }}-$ percentile spectral amplification factors. 
Figure 39: The updated WTP site-specific design response spectra compared to the interim design response spectra developed by Rohay and Reidel (2005). 


\subsection{INTRODUCTION}

This document describes the calculations performed to develop updated relative amplification functions for the Waste Treatment and Immobilization Plant (WTP) facility at the DOE Hanford Site, Washington State and the development of updated WTP site specific design response spectra. The original 2,000-year return period design spectra for the WTP were based on the results of a probabilistic seismic hazard analysis (PSHA) performed for the DOE Hanford Site by Geomatrix (1996). Geomatrix (1996) performed the PSHA using empirical soil-site ground motion models based primarily on recordings from California. As part of that study, site response analyses were performed to evaluate ground motions at the Hanford sites and California deep soil sites. As described in Appendix A of Geomatrix (1996), characteristic site profiles and dynamic soil properties representative of conditions at various Hanford sites and California deep soil strong motion recording stations were defined. Relative site responses of the Hanford profiles and California profiles were then compared. Based on the results of those site response analyses, it was concluded that ground motions at the Hanford sites underlain by deep soil deposits are similar in character to those on California deep soil sites and it was judged appropriate to use empirical deep soil site attenuation relationships based primarily on California ground motion data to develop design spectra for the Hanford sites. In a subsequent analysis, Geomatrix (2003) updated the site response analyses of Geomatrix (1996, Appendix A) to incorporate randomization of the California and Hanford profiles. The results of that analysis also led to the conclusion that the response of the Hanford profiles was similar to the response of deep soil sites in California.

Rohay and Reidel (2005) developed an updated characterization of the subsurface conditions beneath the WTP site based partly on data obtained during studies of the WTP site and based partly on reanalysis of data obtained in earlier studies. Figure 1 shows the site response model logic tree developed by Rohay and Reidel (2005) to characterize the uncertainty in the WTP site dynamic soil properties. Rohay and Reidel (2005) presented the results of site response analyses using the updated characterization and used these analyses to develop a relative amplification function (RAF) that defines the relative site response of the WTP site compared to typical California soil sites to the same level of shaking. This RAF was used by Rohay and Reidel (2005) to develop interim design response spectra for the WTP facility. The site response calculations used to develop the Rohay and Reidel (2005) RAF were documented in Geomatrix (2006).

Subsequent to the analysis of Rohay and Reidel (2005) additional data were gathered on the dynamic properties of the subsurface materials at the WTP site from four new boreholes that were drilled in 2006. These data consist of down-hole shear and compression wave velocity and density measurements that extend through the Saddle Mountains Basalt sequence. The new data were analyzed to produce an updated velocity and density model for the WTP site which is documented in Rohay and Brouns (2007). The overall geologic characteristics of the WTP site are documented in Barnett et al. (2007). In addition to velocity and density data, dynamic laboratory tests on reconstituted samples of the supra-basalt sediments were performed to evaluate the modulus reduction and damping behavior ${ }^{1}$. These new data were used to refine the site response model for the WTP site. This document describes the

\footnotetext{
${ }^{1}$ Dynamic testing was performed by the University of Texas at Austin under contract to the U.S. Army Corps of Engineers.
} 
updated site response model, the results of relative response analyses conducted using the updated site response model, and the updated WTP site-specific response spectra.

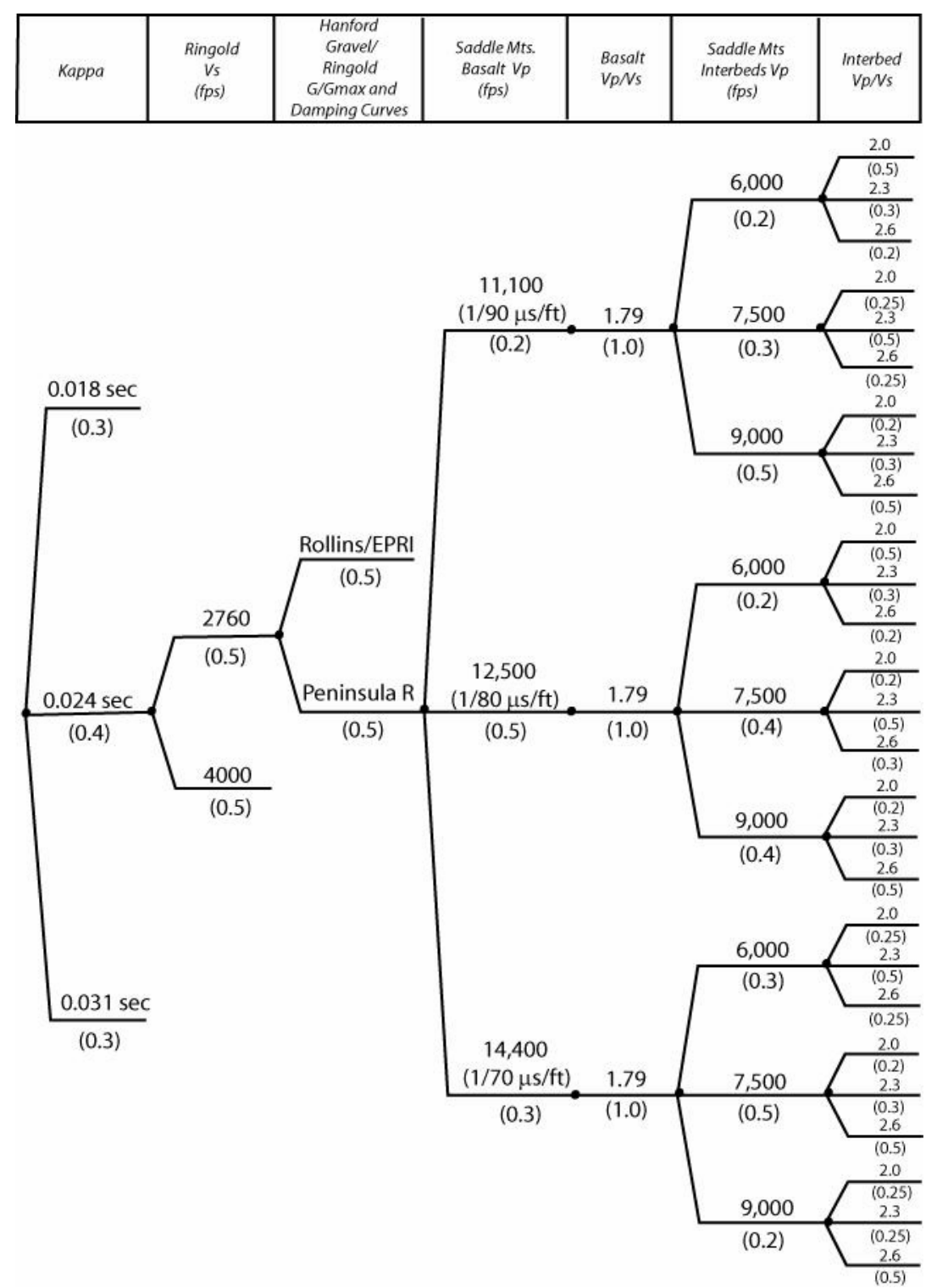

Figure 1: Site Response Model Logic Tree for the WTP Site Developed by Rohay and Reidel (2005). (Numbers in parentheses below branches indicate assigned weight.)

\subsection{UPDATED WTP SITE RESPONSE MODEL}

An updated site response model for the WTP site was developed by PNNL and Geomatrix. This effort was supported by an expert panel composed of the individuals listed in Table 1. The expert panel provided guidance on the interpretation of the data and recommendations on formulating the updated site response model. Figure 2 shows the site response model logic tree developed to represent the uncertainties in the site dynamic properties. The parameters and assigned weights for the model components are discussed below.

A few points should be made to assist the reader in understanding the structure of the logic trees shown in this report. For the sake of visual clarity, the logic tree figures do not display 
all of the branches that exist in the actual logic tree used in the analysis. Those branches that are repeated at multiple nodes of the tree are not shown. For example, note that at the first node for the value of "kappa" there are three branches for alternative values. The next level (node) of the logic tree indicate alternative models for $\mathrm{H} 3 / \mathrm{CCU}$ velocities. The alternative $\mathrm{H} 3 / \mathrm{CCU}$ velocity models are only shown for a single kappa branch. This is only for the sake of keeping the figure uncomplicated. In the hazard calculation, all nodes of the logic tree are assigned the relevant branches such that all possible sets of site parameters are used.

Table 1: Members of the Site Response Model Expert Panel

\begin{tabular}{|c|c|}
\hline Panel Member & Affiliation \\
\hline Dr. Carl Costantino & CJC\&A \\
\hline Dr. Richard Lee & LANL \\
\hline Dr. Alan Rohay & PNNL \\
\hline Dr. Walt Silva & Pacific Engineering and Analysis \\
\hline Dr. Ken Stokoe & University of Texas at Austin \\
\hline Dr. Robert Youngs & Geomatrix Consultants, Inc. \\
\hline Dr. Farhang Ostadan & Bechtel \\
\hline Dr. Kevin Coppersmith & Coppersmith Consulting, Inc. \\
\hline
\end{tabular}

\begin{tabular}{|c|c|c|c|c|c|c|}
\hline Kappa & $\begin{array}{c}H 3 / C C U \\
V / s \\
\text { (fos) }\end{array}$ & $\begin{array}{c}\text { Saddle Mt. } \\
\text { Basalt/ } \\
\text { Interbeds } \\
\text { Vs }\end{array}$ & $\begin{array}{l}\text { Approach for } \\
\text { C/Cmax and } \\
\text { Darnping Curves }\end{array}$ & $\begin{array}{c}\text { H2 Unit } \\
\text { G/Gmax and } \\
\text { Damping Curves }\end{array}$ & $\begin{array}{c}\text { H3 Unit } \\
\text { C/Cmax and } \\
\text { Damping Curves }\end{array}$ & $\begin{array}{c}C C U \\
G / \text { Cmax and } \\
\text { Damping Curves }\end{array}$ \\
\hline
\end{tabular}

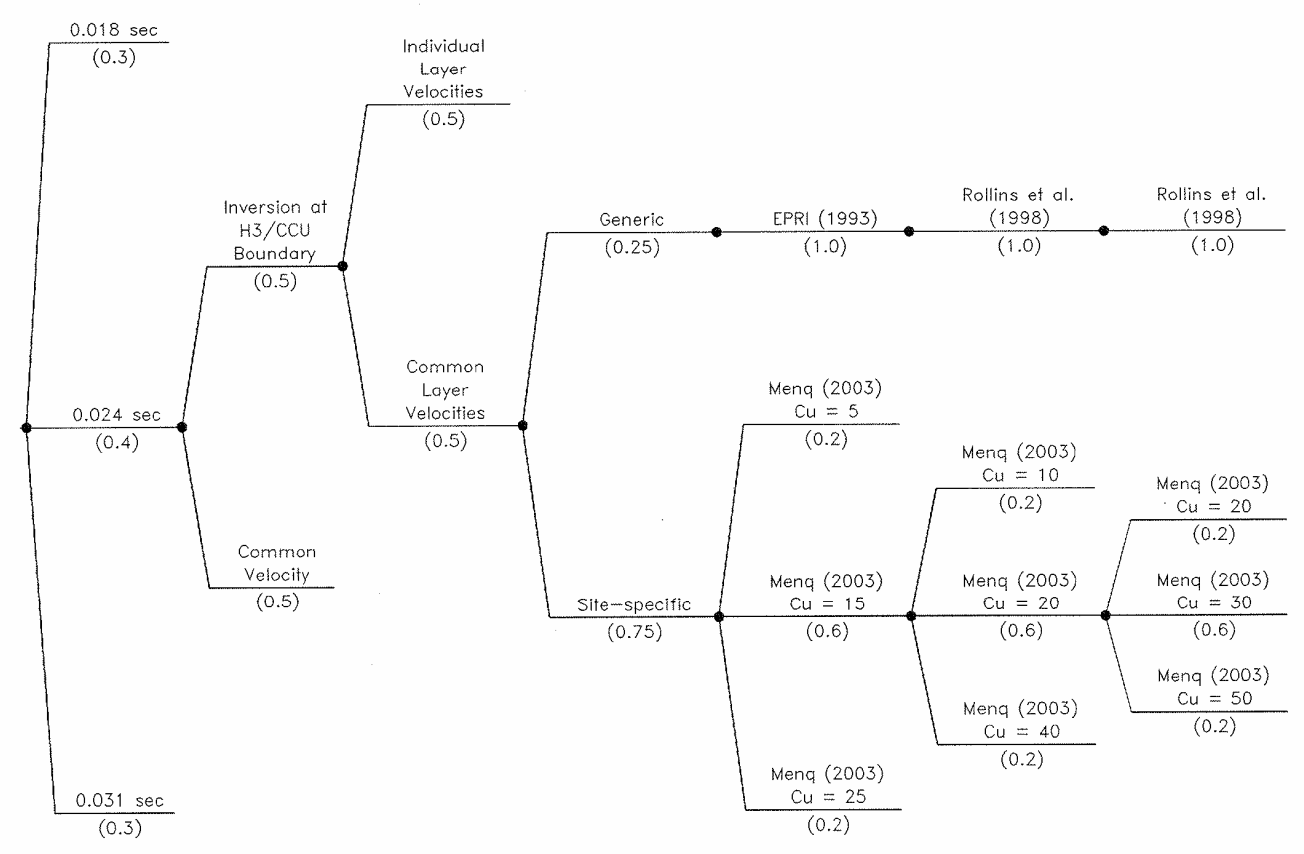

Figure 2: Updated site response model logic tree for the WTP. (Numbers in parentheses below branches indicate assigned weight.) 


\subsection{BASALT AND INTERBED DAMPING}

The first level of the logic tree addresses the uncertainty in the damping within the basalt/interbed sequence. As described in Rohay and Reidel (2005), the basalts and interbeds are assumed to remain linear during shaking levels corresponding to the 2,000-year return period ground motions. The amount of damping in the linear basalt and interbed materials was estimated from the ground motion parameter $\kappa$ in the same manner as Geomatrix (1996) and Geomatrix (2003). Parameter $\kappa$ is related to material damping, $\xi$, by the relationship

$$
\xi=\frac{\kappa V_{S}}{2 H}
$$

where $H$ is the thickness of the layer with shear wave velocity $\mathrm{V}_{\mathrm{S}}$. Material damping, $\xi$, is in turn related to the energy loss parameter $Q_{S}$ by the relationship

$$
\xi=\frac{1}{2 Q_{S}}
$$

Silva and Darragh (1995) find that $Q_{S}$ is proportional to shear-wave velocity $\left(Q_{S}=\gamma V_{S}\right)$. Using this assumption, the amount of high-frequency attenuation in the $i^{\text {th }}$ layer of a velocity profile, $\kappa_{i}$, is given by the relationship:

$$
\kappa_{i}=\frac{H_{i}}{\gamma V_{S i}^{2}}
$$

Where $H_{i}$ is the layer thickness and $V_{S i}$. Is the layer shear wave velocity. Given the total value of $\kappa$ appropriate for the site, one can solve for the value of $\gamma$ that will produce the appropriate damping values (see Geomatrix, 2003).

Rohay and Reidel (2005) estimated value of $\kappa$ for the basalts from shear wave spectra of recordings for 10 small, deep earthquakes located at distances of 25 to $90 \mathrm{~km}$. The signals were recorded on the horizontal components of broadband seismic station HAWA, located at the top of the Saddle Mountains basalt in a nearby (20 km SSW) exposure. These data were limited in bandwidth to $15 \mathrm{~Hz}$. Past experience with the inversion of the quality and quantity of data available suggested that the uncertainty of the estimate of site $\kappa$ was on the order of \pm 30 percent, leading to the three values of $0.018,0.024$, and 0.031 seconds assigned to the median value of $\kappa$ by Rohay and Reidel (2005). Because of the limited high-frequency content of the recordings, Rohay and Reidel (2005) assigned weights of 0.3, 0.4, and 0.3, respectively, to the three $\kappa$ values to reflect greater uncertainty than the typical assumption that the \pm 30 -percent factor represents a 90 -percent confidence interval. As no additional data were available, the uncertainty distribution for $\kappa$ developed by Rohay and Reidel (2005) was adopted for the updated site response model (Figure 2).

The basalt/interbed velocity contrasts and the randomization of velocity profiles (discussed in Section 3.1.3) produce scattering and reflection of high-frequency motions. This effect is considered part of the total site $\kappa$ estimated from surface recordings. The scattering $\kappa$ of the updated basalt profile was estimated by comparing the response of the layered velocity model without material damping to an equivalent uniform velocity profile with varying amounts of material damping. The layered velocity profile was found to produce high frequency damping equivalent to a $\kappa$ value of $0.006 \mathrm{sec}$. An additional scattering $\kappa$ of 0.001 sec is introduced by soil randomization. This value was estimated by comparing the median response of randomized soil profiles on an undamped uniform rock layer to that of the base case profile on a uniform rock layer with varying amounts of material damping. As a result, 
material damping in the basalts and interbeds was computed using $\kappa$ values reduced by 0.007 seconds from the total $\kappa$ values listed in Figure 2 in order to maintain the total kappa values (material plus scattering) assigned in the logic tree. A similar process was used in the Rohay and Reidel (2005) study. The scattering $\kappa$ of $0.007 \mathrm{sec}$ found in this study is similar to values reported in Rohay and Reidel (2005) for comparable velocity profiles.

\subsection{SHEAR WAVE VELOCITIES}

The second level and third levels of the updated site response model logic tree address uncertainty in the velocity model for the WTP site.

\subsubsection{Supra-basalt Sediment Velocities}

Figure 3 compares the 2007 velocity model for the supra-basalt sediments with the velocity models developed in Rohay and Reidel (2005). The actual ground surface varies in elevation in the area around the WTP and there is a thin layer of loess in some areas. For the updated site response model, the surface elevation of the site model is taken to be 670 feet and represents the top of the Hanford sand-dominated $\mathrm{H} 2$ unit of the supra-basalt sediments. The median velocities developed for the $\mathrm{H} 2$ unit in the 2007 model are similar to those used in Rohay and Reidel (2005). One difference is in the shallowest layers Rohay and Reidel (2005) used a nominal velocity of 1,000 fps to represent the backfill around the WTP. In this analysis, the profile is intended to represent free field conditions away from the influence of the WTP where backfill is not present. The elevation of $670 \mathrm{ft}$ corresponds to the bottom of the foundation of the Pretreatment (PT) facility of the WTP.

The second supra-basalt sediment unit is the Hanford gravel-dominated H3 unit encountered at an average depth of $166 \mathrm{ft}$ below elevation $670 \mathrm{ft}$. The computation of the median velocity profile by averaging of the data from specific elevations produces a relatively smooth trend in velocity with depth. However, the six individual down-hole velocity profiles (both $\mathrm{V}_{\mathrm{S}}$ and $\mathrm{V}_{\mathrm{P}}$ in three new boreholes) that extend into the $\mathrm{H} 3$ unit all show a significant step in velocity at the $\mathrm{H} 2 / \mathrm{H} 3$ boundary. Four preconstruction Vs profiles across this boundary also show this step (Rohay and Reidel, 2005; Rohay and Brouns, 2007). Therefore, this velocity step was maintained in the base case profile and the variation in the depth to the $\mathrm{H} 2 / \mathrm{H} 3$ boundary was accounted for in profile randomization.

The third sediment layer is the Cold Creek (CCU) unit considered to consist of reworked Ringold unit gravel-dominated material. It is encountered at an average depth of $249 \mathrm{ft}$ below elevation $670 \mathrm{ft}$. Velocity data for this layer at the WTP site were not previously available and Rohay and Reidel (2005) developed two alternative velocity models for the entire Ringold unit based on data from other locations. Three down-hole velocity surveys were conducted in this unit in 2006 and 2007 (Rohay and Brouns, 2007). These data show that the reworked Ringold unit (CCU) has shear wave velocities that are either similar to or slightly lower than the $\mathrm{H} 3$ unit. The data from two boreholes show the small inversion while the data from the third does not show a velocity inversion. Therefore, two models for the $\mathrm{H} 3$ and CCU velocities are used, one in which there is a small velocity inversion at the $\mathrm{H} 3 / \mathrm{CCU}$ boundary $\left(\mathrm{V}_{\mathrm{S}} \mathrm{H} 3=2,350 \mathrm{fps}, \mathrm{V}_{\mathrm{S}} \mathrm{CCU}=2,126 \mathrm{fps}\right)$ and one in which the two units have the same average velocity of 2,200 fps. At the level of uncertainty in the $\mathrm{V}_{\mathrm{S}}$ measurements, it is considered equally plausible that an inversion may or may not be present and the two models are assigned equal weight (Figure 2).

The fourth sediment layer is the Ringold Unit A encountered at an average depth of $309 \mathrm{ft}$ below elevation $670 \mathrm{ft}$. Three down-hole velocity measurements were obtained in this layer 
during the 2006-2007 data gathering effort and all three indicated high shear wave velocities, with a geometric mean velocity of $7,150 \mathrm{fps}$.

The comparison shown in Figure 3 indicates that the major difference in the characterization of the supra-basalt sediments is in the velocities of the Ringold unit. In the 2005 model the Ringold unit was modeled as a single layer with an average velocity of 2,760 or 4,000 fps. Based on the new site-specific data, the model for the Ringold unit now consists of two layers, a gravel-dominated layer (CCU) with velocities similar to the gravel-dominated H3 unit, and a layer of the original consolidated Ringold Unit A with much higher velocity.

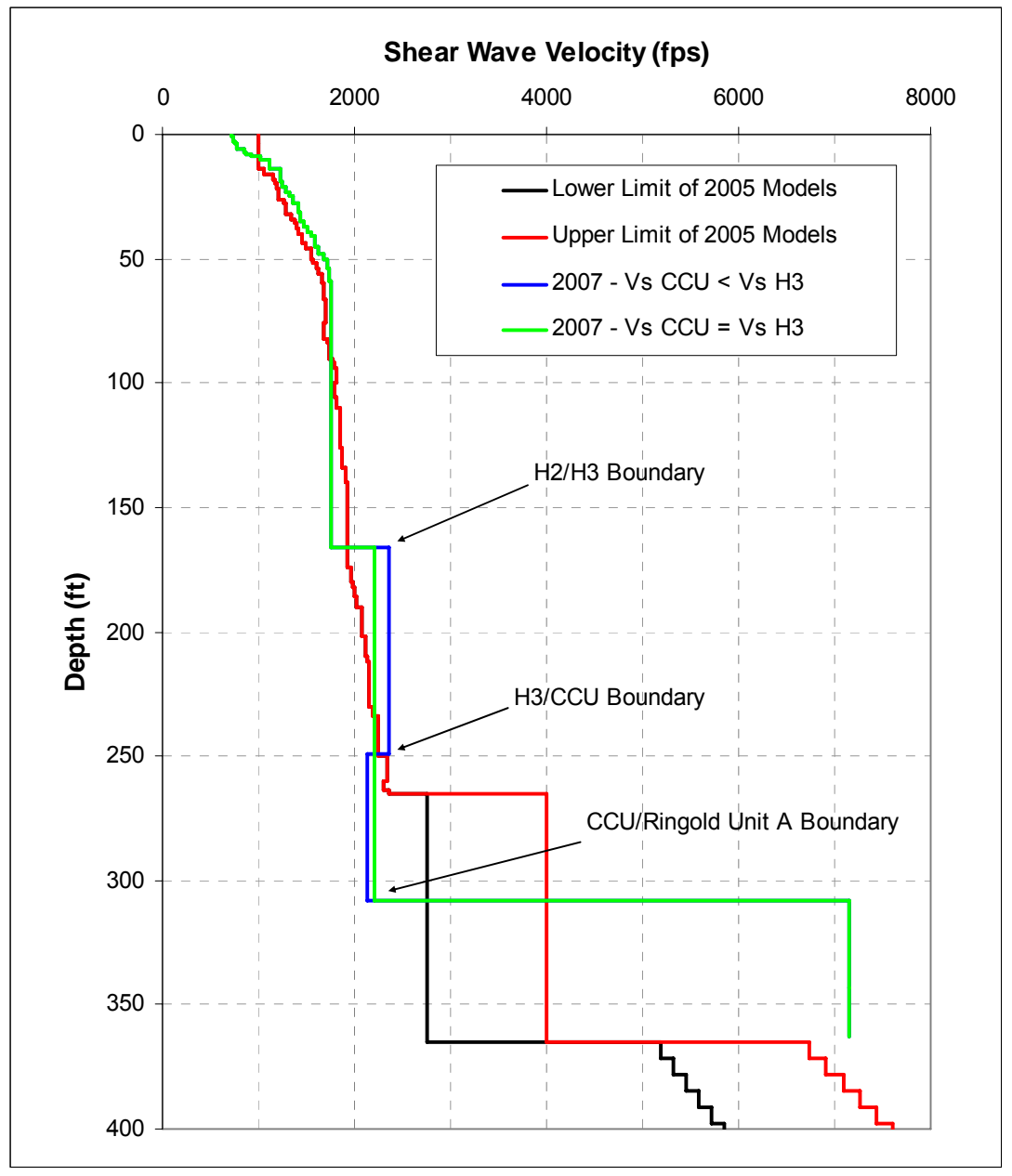

Figure 3: Geometric mean velocity profiles for supra-basalt sediments.

\subsubsection{Basalt and Interbed Velocities}

The third level of the logic tree addresses alternative models for the basalt and interbed shear wave velocities. Figure 4 compares the updated velocity profiles for the basalts and interbeds with the range of velocities used in Rohay and Reidel (2005). Rohay and Reidel (2005) developed a wide range of basalt and interbed velocities based on alternative interpretation of the limited data available at that time. The estimated median shear wave velocity of the four Saddle Mountains basalts ranged from 6,201 to 8,045 fps and the median shear wave velocity of the four interbeds ranged from $2,308 \mathrm{fps}$ to $4,500 \mathrm{fps}$. The median velocity assigned to the upper portion of the Wanapum basalts was $\sim 9,300 \mathrm{fps}$. These estimated velocities were based on interpretations of compression wave velocity data and assumptions about Poisson's ratio. 
The data gathered in 2006 included down-hole and suspension logging of both shear and compression wave velocities in the Saddle Mountains basalts and the interbed sediments. The down-hole surveys extended through the entire Saddle Mountains basalt/interbed sequence into the upper portion of the Wanapum basalts, the Priest Rapids member. Based on these site-specific data, Rohay and Brouns (2007) developed two alternative interpretations of the median velocities for the basalts and interbeds. One interpretation developed median velocities for each individual basalt unit and each individual interbed. The basis of this interpretation is that the basalt flows and sedimentary interbeds were laid down over millions of years and some variability in properties (e.g., density, velocity, etc.) from one unit to the other would be a reasonable expectation. However, the resulting individual layer values indicated that the four interbeds have very similar estimated median velocities. Similarly, the three lower Saddle Mountains basalt units also have very similar estimated median velocities. Therefore, an alternative interpretation was developed in which the three lower units of the Saddle Mountains basalts are assigned the same median velocity and the four interbeds are assigned the same median velocity. This composite velocity alternative, shown by the green line in Figure 4, produces slightly smaller basalt/interbed velocity contrasts at the Cold Creek interbed/Umatilla member interface and at the Umatilla member/Mabton interbed interface. Separate median velocities were assigned to the Elephant Mountain member and the Priest Rapids member. The two alternative models are judged to be equally plausible given the small differences in the individual unit velocities and they were given equal weight in the updated site response model (Figure 2).

Rohay and Brouns (2007) used only the down-hole velocity data to develop their estimates of median velocity in the basalts. The suspension-logging data indicated shear wave velocities that were approximately 25 percent greater that the down-hole velocity data. Given that the two sets of down-hole velocity measurements obtained by different investigators were very similar and the down-hole velocity data was obtained for waves at frequencies closer to the range of interest for earthquake shaking, the $\sim 10,000 \mathrm{fps} \mathrm{V}_{\mathrm{S}}$ values obtained from the suspension logging measurements in the basalts were not incorporated into the updated site response model. The suspension-logging data do provide higher resolution information on velocity variation within the basalts and interbeds and the data were used in a relative sense to develop velocity gradients in the basalts, as described below. In addition, a sensitivity analysis was performed using median $\mathrm{V}_{\mathrm{S}}$ values for the basalt based on suspension logging data to assess the impact of these higher velocities on the site response (see Section 3.2.2 and Figure 25.

As indicated in Figure 4, the measured shear wave velocities in the basalts are slightly higher than the largest value estimated by Rohay and Reidel (2005) and the measured shear wave velocities in the interbeds are in the lower range of the values estimated by Rohay and Reidel (2005). Rohay and Reidel (2005) included an estimated velocity gradient at the top of each basalt flow to represent the expected effects of brecciation and vesiculation at the top of basalt flows. In the updated velocity model, suspension logging velocity and density data were used to develop flow top velocity gradients for each basalt flow (Rohay and Brouns, 2007). These measured gradients were typically sharper than the assumed gradients used in the 2005 model. In addition, inter-flow gradients were found within the Umatilla and Priest Rapids members. 


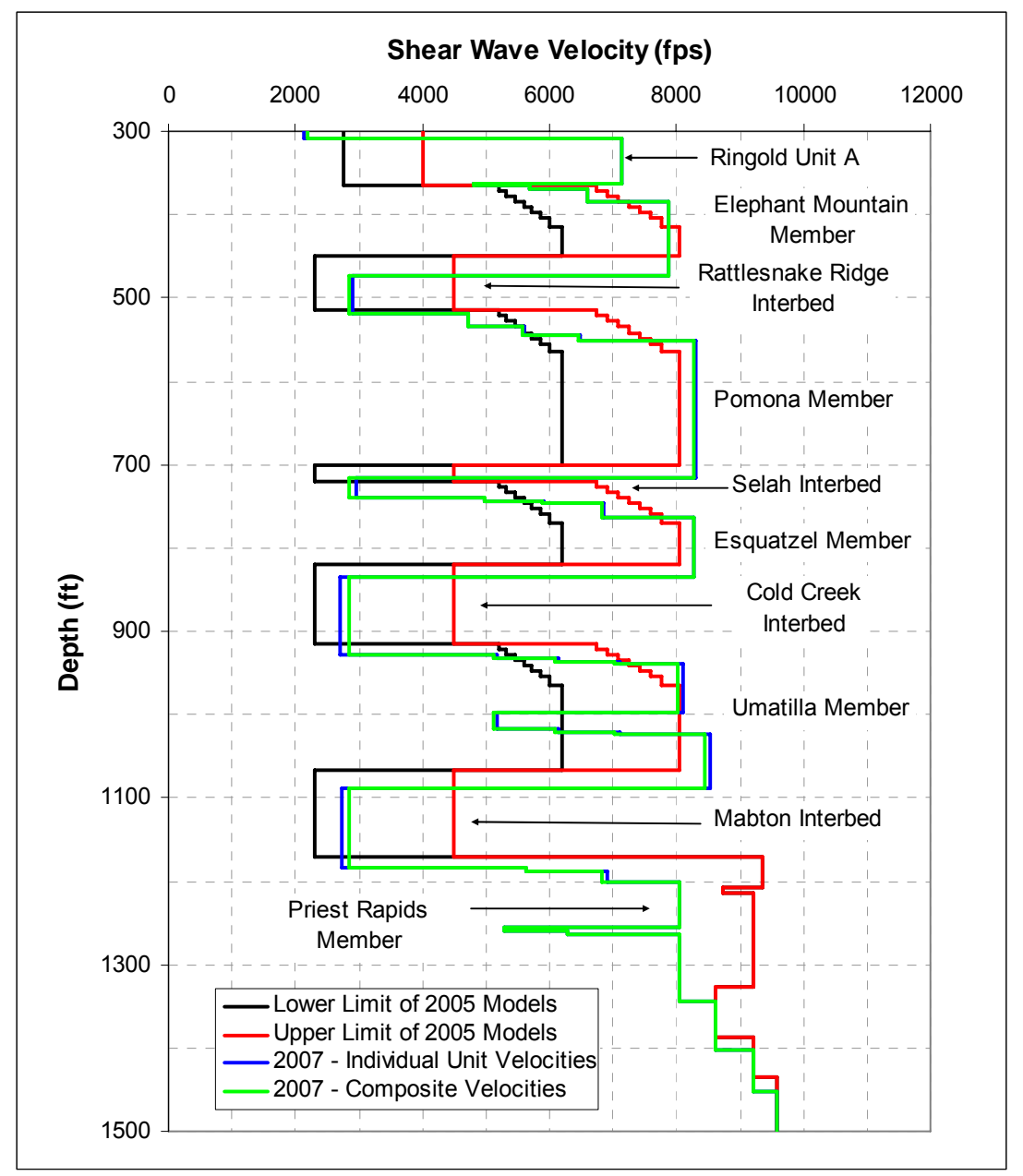

Figure 4: Geometric mean velocity profiles for basalts and interbeds.

\subsection{MODULUS REDUCTION AND DAMPING RELATIONSHIPS FOR SUPRA-BASALT SEDIMENTS}

The remaining levels of the updated site response model logic tree address uncertainty in the modulus reduction and damping relationships for the supra-basalt sediments. Rohay and Reidel (2005) used published generic modulus reduction and damping relationships to represent the non-linear behavior of the supra-basalt sediments. During the field investigation conducted in 2006, bulk samples of the sediments were obtained. Dynamic resonant column/torsional shear (RCTS) tests were performed on reconstituted samples by the University of Texas at Austin (UTA). The bulk samples obtained by UTA were scalped to remove large particle sizes before testing.

Figures 5, 6, and 7 show preliminary results of this testing program for one sample each from the H2, H3, and CCU layers, respectively, provided by Dr. Farn-Yuh Menq. Dr. Menq showed on the figures that the test data can be well represented by the function forms for $\mathrm{G} / \mathrm{G}_{\max }$ and damping developed by Darendeli (2001). Menq (2003) developed a model that defined the parameters of the Darendeli (2001) equations for granular soils in terms of the coefficient of uniformity, $\mathrm{C}_{\mathrm{U}}$, the median grain size, $\mathrm{D}_{50}$, and the mean effective stress, $\sigma_{\mathrm{M}}{ }^{\prime}$. As, shown on Figures 5, 6, and 7, G/ $\mathrm{G}_{\max }$ and damping relationships developed using the Menq (2003) model and the sample values of $\mathrm{C}_{\mathrm{U}}, \mathrm{D}_{50}$, and $\sigma_{\mathrm{M}}{ }^{\prime}$ also provide a reasonable match to the test data. 

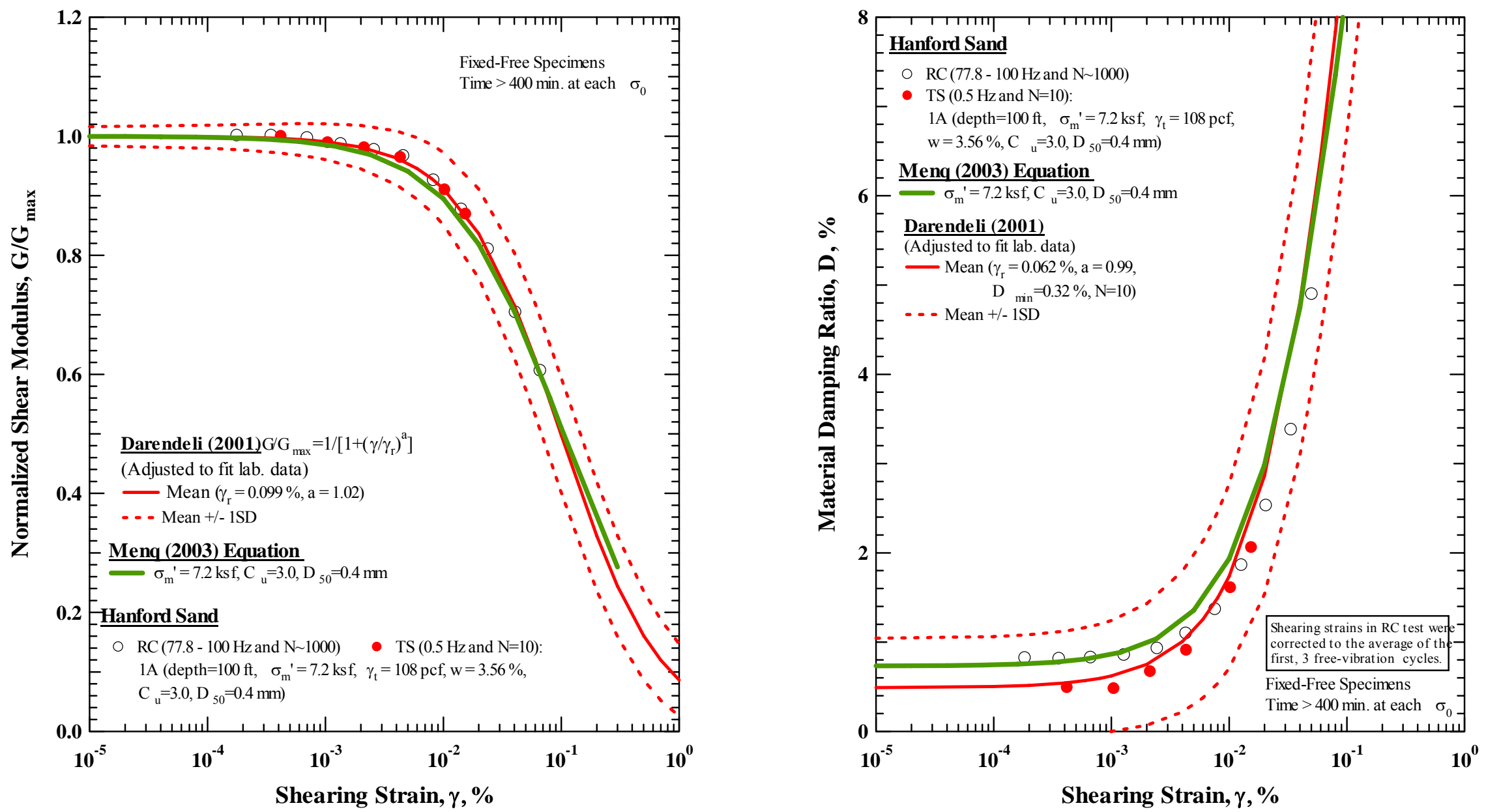

Figure 5: Comparison of resonant column (RC) and torsional shear (TS) test results for one specimen from the H2 unit at its estimated in-situ mean effective stress with $\mathrm{G} / \mathrm{G}_{\max }$ and damping relationships developed from Menq's (2003) model based on test specimen $\mathrm{C}_{\mathrm{U}}$ and $\mathrm{D}_{50}{ }^{2}$.

${ }^{2}$ Preliminary data transmitted from Dr. Farn-Yuh Menq, UTA to Robert R. Youngs, May 30, 2007. 

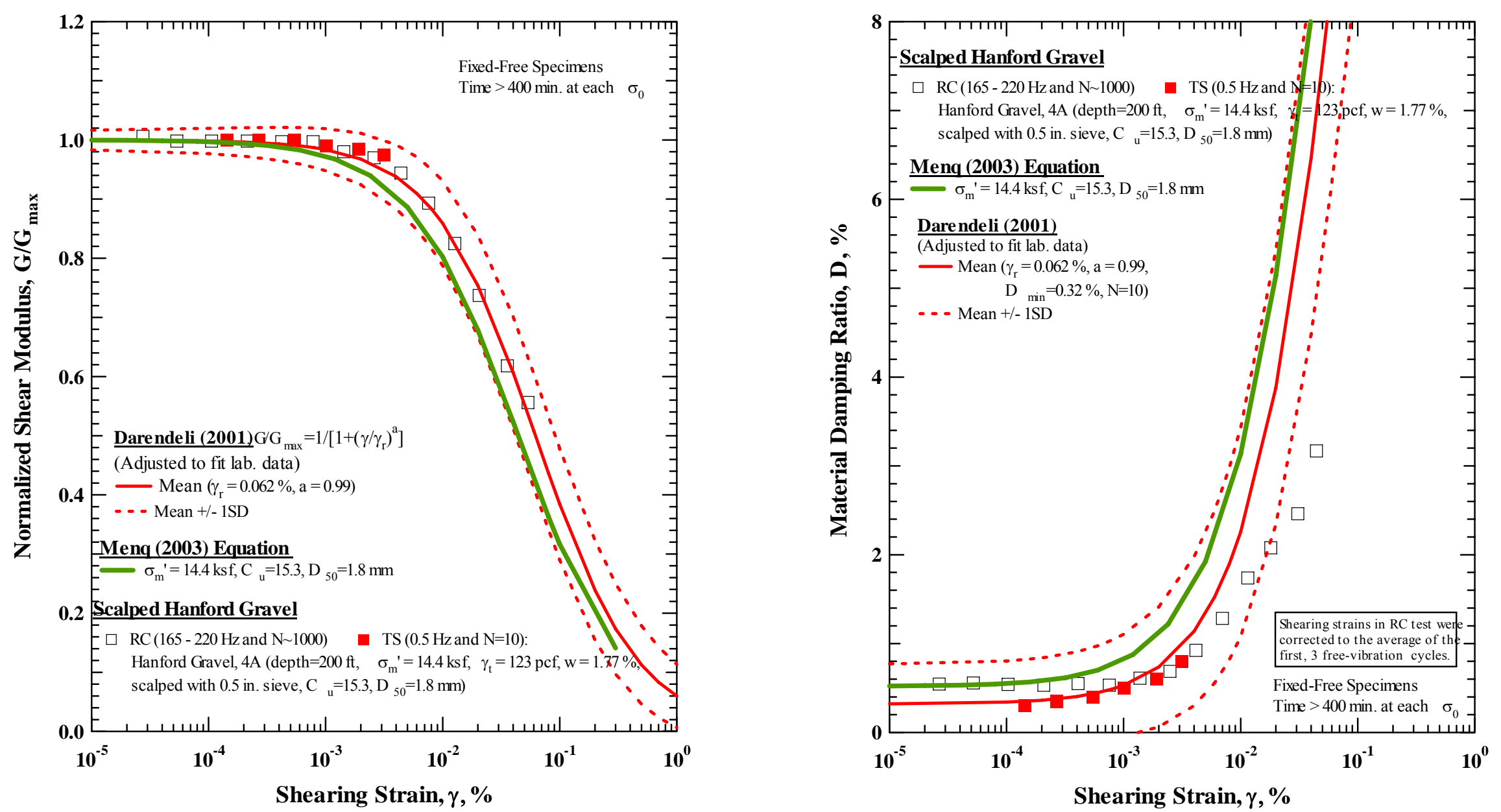

Figure 6: Comparison of resonant column (RC) and torsional shear (TS) test results for one specimen from the H3 unit at its estimated in-situ mean effective stress with $\mathrm{G} / \mathrm{G}_{\max }$ and damping relationships developed from Menq's (2003) model based on test specimen $\mathrm{C}_{\mathrm{U}}$ and $\mathrm{D}_{50}{ }^{3}$.

\footnotetext{
${ }^{3}$ Preliminary data transmitted from Dr. Farn-Yuh Menq, UTA to Robert R. Youngs, May 30, 2007.
} 



Figure 7: Comparison of resonant column (RC) and torsional shear (TS) test results for one specimen from CCU at its estimated in-situ mean effective stress with $\mathrm{G} / \mathrm{G}_{\max }$ and damping relationships developed from Menq's (2003) model based on test specimen $\mathrm{C}_{\mathrm{U}}$ and $\mathrm{D}_{50}{ }^{4}$.

\footnotetext{
${ }^{4}$ Preliminary data transmitted from Dr. Farn-Yuh Menq, UTA to Robert R. Youngs, May 30, 2007.
} 


\subsubsection{Modeling Approach}

The fact that the Menq (2003) model provides a reasonably good match to the scalped test data indicated that the model could be used to develop appropriate $G / G_{\max }$ and damping relationships for the in-situ grain size distributions of the $\mathrm{H} 2, \mathrm{H} 3$, and $\mathrm{CCU}$ layers. Therefore, two modeling approaches for specification of the $G / G_{\max }$ and damping relationships for the sediments were incorporated into the site response model, one based on the use of generic curves and one based on development of site-specific curves using the model developed by Menq (2003) (see Figure 2). The site-specific approach using the Menq (2003) model was favored (weight 0.75 ) over the generic curve approach because it provides a means of accounting for the differences in the grain size distributions of the WTP site sediments compared to the samples represented by the generic curves and because the Menq (2003) relationships provided a good match to the test data.

The Menq (2003) model defines the parameters of the $\mathrm{G} / \mathrm{G}_{\max }$ and damping relationships in terms of $C_{U}$ and $D_{50}$ of granular soil. To estimate the average $C_{U}$ and $D_{50}$ values for the $H 2$, $\mathrm{H} 3$, and CCU layers, PNNL reviewed all relevant available soil gradation testing data from on or near the WTP site from Shannon \& Wilson (2000), 2007 U.S. Army Corps of Engineers (USACE)-directed testing ${ }^{5}$, and earlier studies (Rockhold et al, 1993). The review concluded that only a few measurements of $\mathrm{C}_{\mathrm{U}}$ and $\mathrm{D}_{50}$ from $\mathrm{H} 3$ and $\mathrm{CCU}$ gravel-dominated layers have been made from WTP site samples, so the confidence in mean measured values for these units was low. For the $\mathrm{H} 2$ unit, approximately two-thirds of the data indicated a low mean $\mathrm{C}_{\mathrm{u}}(<5)$ and one-third of the data indicated a much higher $\mathrm{C}_{\mathrm{u}}(>10)$. Upon further review, it was determined that some samples were analyzed using wet sieving methods (corresponding to the higher mean $\mathrm{C}_{\mathrm{u}}$ ), and the rest were analyzed using dry sieving. Dry sieving is more commonly used, but has been shown to underestimate the fines (lowering the $\mathrm{C}_{\mathrm{u}}$ ) with Hanford sediments. Based on inconsistencies and/or inadequacies in gradation test methods used historically on WTP Site $\mathrm{H} 2$ sand-dominated unit, it was concluded that there is also significant uncertainty in the average value of $\mathrm{C}_{\underline{U}}$ for the $\mathrm{H} 2$ unit.

A Hanford site geologist and expert in the supra-basalt sediments provided best estimates of the upper, lower, and midpoint means for $\mathrm{C}_{\mathrm{U}}$ and $\mathrm{D}_{50}$ for the three units based on his review of 1) gradation testing results from current and historic WTP site borings, 2) the documented impact of sampling methods on these sands and gravels, and 3) first hand observations from assessment of samples from the WTP and overall Hanford sites. The best estimate distributions for the three soil units are summarized in Table 2. The three pairs of $C_{U}$ and $D_{50}$ are intended to represent the $5^{\text {th }}$-percentile, the $50^{\text {th }}$-percentile, and the $95^{\text {th }}$-percentle values of the distribution for the average properties of the soil unit and weights of $0.2,0.6$, and 0.2 , respectively, were assigned to the three values.

The selected modulus reduction and damping relationships used in the updated site response analysis for each soil unit are described below.

\footnotetext{
${ }^{5}$ Professional Service Industries, Inc. Letter Report from Tony Dean, PSI to Sonya Kuhns, USACE, Dated January 16, 2007
} 
Table 2: Grain Size Parameter Distributions for Hanford Supra-Basalt Sediments

\begin{tabular}{|c|c|c|c|}
\hline \multirow{2}{*}{ Soil Unit } & \multicolumn{3}{|c|}{ Grain Size Distribution Parameters } \\
\cline { 2 - 4 } & $\mathbf{C}_{\mathbf{U}}$ & $\mathbf{D}_{\mathbf{5 0}} \mathbf{( \mathbf { m m } )}$ & Weight \\
\hline \multirow{2}{*}{ Sand-dominated H2 } & 5 & 0.2 & 0.2 \\
Unit & 15 & 0.4 & 0.6 \\
& 25 & 1.0 & 0.2 \\
\hline \multirow{2}{*}{ Gravel-dominated H3 } & 10 & 2 & 0.2 \\
Unit & 20 & 6 & 0.6 \\
& 40 & 10 & 0.2 \\
\hline \multirow{2}{*}{ Gravel-dominated } & 20 & 3 & 0.2 \\
CCU & 30 & 6 & 0.6 \\
& 50 & 9 & 0.2 \\
\hline
\end{tabular}

\subsubsection{H2 Unit $\mathbf{G} / \mathbf{G}_{\max }$ and Damping Relationships}

Figures 8,9 , and 10 compare site-specific $G / G_{\max }$ and damping relationships developed using Menq's (2003) model and the soil parameters listed in Table 2 for the H2 unit with the EPRI (1993) relationships for three depth ranges. The EPRI (1993) relationships were selected as the generic model for the $\mathrm{H} 2$ unit because this model has been found to work well for sandy soils (Silva et al., 1998). As discussed above, the reference surface for the WTP site used in the relative response analyses was set at elevation 670. There are additional soils above this elevation and the effect of the additional confining pressure was accounted for in developing the site-specific relationships from Menq's (2003) model. In applying the EPRI (1993) relationships, the effect of the additional confining pressure was accounted for by using the EPRI (1993) curves for depth ranges that are approximately $10 \mathrm{ft}$ shallower than the nominal depth ranges assigned to the curves. As indicated in the figures, the relationships developed using the $5^{\text {th }}$-percentile soil grain size properties are essentially the same as the EPRI (1993) relationships for the same depth range. 

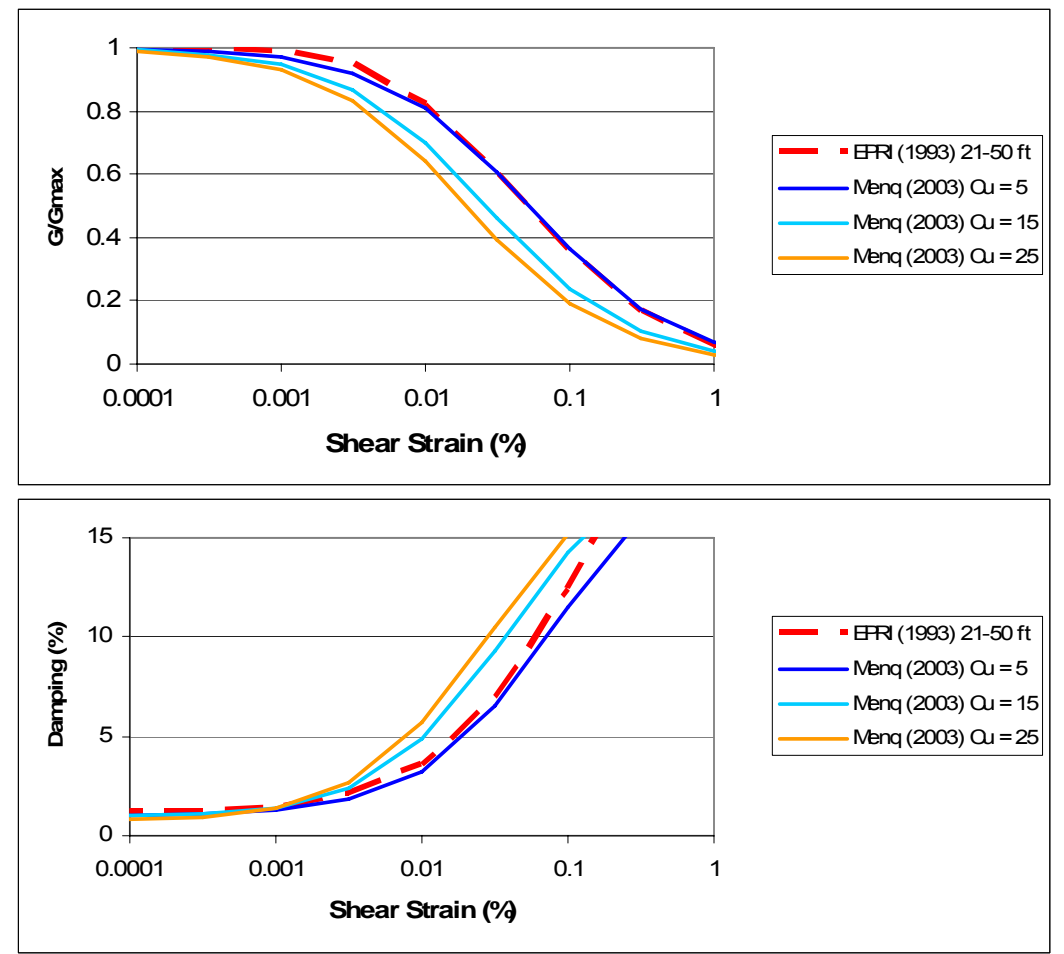

Figure 8: Modulus reduction and damping relationships for the $0-40 \mathrm{ft}$ depth range of the $\mathrm{H} 2$ unit used in the updated site response analysis.
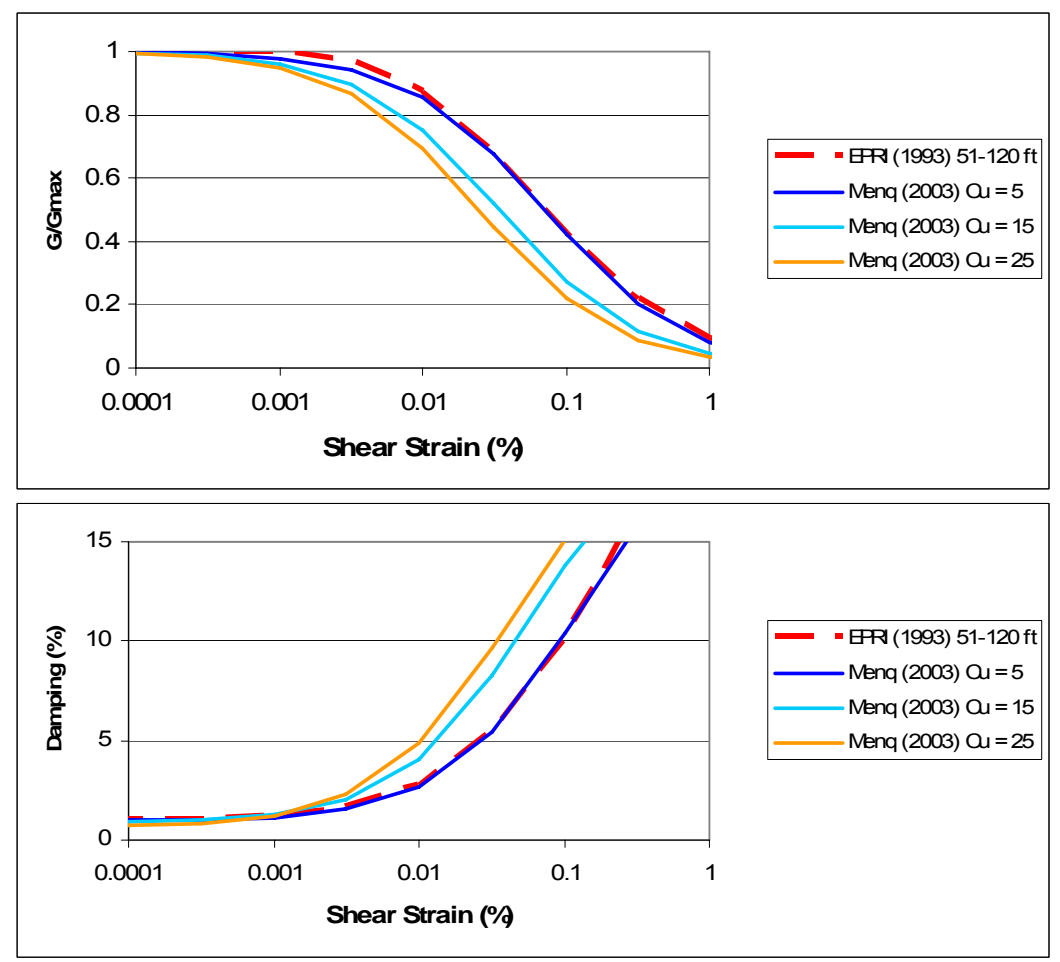

Figure 9: Modulus reduction and damping relationships for the $>40$ to $110 \mathrm{ft}$ depth range of the $\mathrm{H} 2$ unit used in the updated site response analysis. 

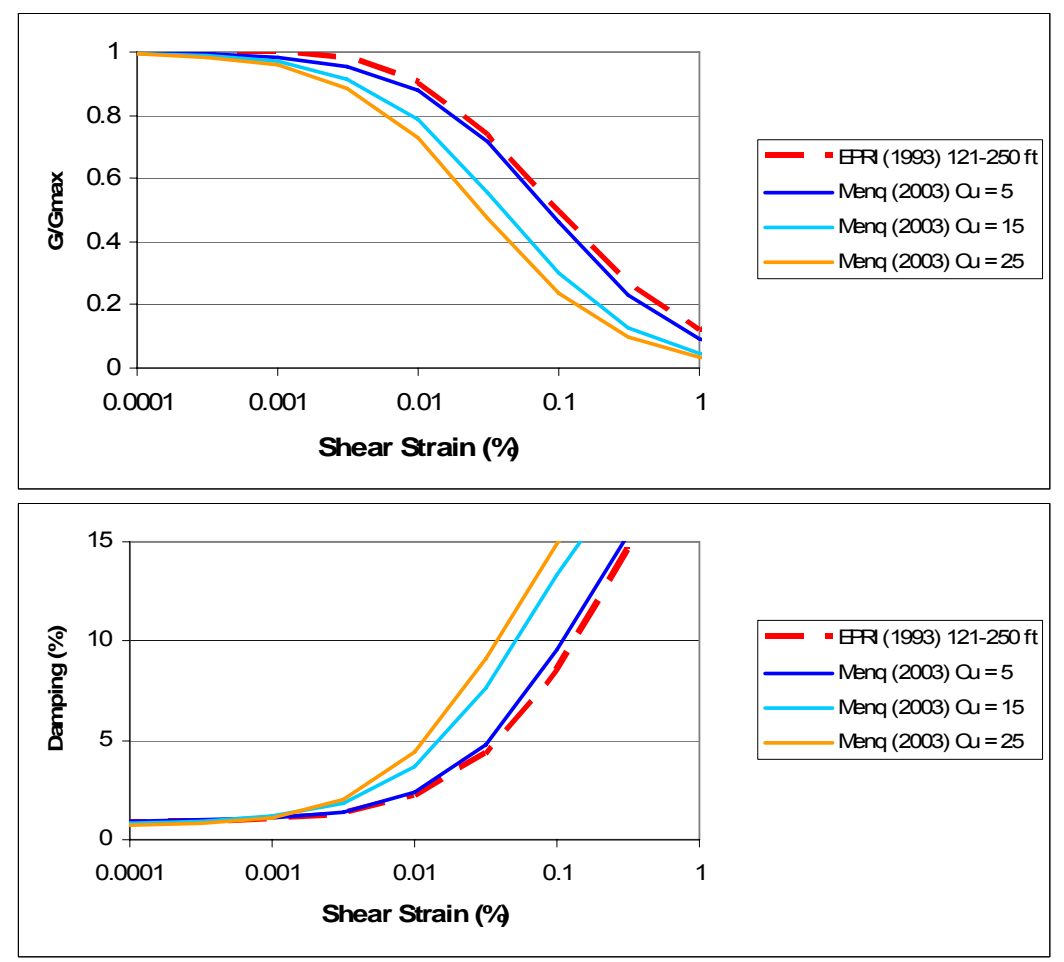

Figure 10: Modulus reduction and damping relationships for the $>110-250 \mathrm{ft}$ depth range of the $\mathrm{H} 2$ unit used in the updated site response analysis.

\subsubsection{H3 Unit $G / G_{\max }$ and Damping Relationships}

Figure 11 compares site-specific $\mathrm{G} / \mathrm{G}_{\max }$ and damping relationships computed using the model developed by Menq (2003) and the soil parameters listed in Table 2 for the H3 unit with the relationships used by Rohay and Reidel (2005) for gravels. Rohay and Reidel (2005) used two alternatives. One set consisted of the relationships developed by Rollins et al. (1998) for gravels. Rohay and Reidel (2005) used the mean plus one $\sigma \mathrm{G} / \mathrm{G}_{\max }$ relationship and the mean minus one $\sigma$ damping relationship to account for confining pressure effects. The second set consisted of the Peninsula Ranges $\mathrm{G} / \mathrm{G}_{\max }$ and damping relationships developed by Silva et al. (1998). The Rollins et al. (1998) relationships indicate more linear behavior than the relationships developed using Menq's (2003) model and the parameters in Table 2. These relationships are used as the generic model for the graveldominated H3 unit. The Peninsula Ranges relationships are interpreted to be too linear to be considered for the $\mathrm{H} 3$ unit and were not incorporated in the updated site response model (Figure 2). 


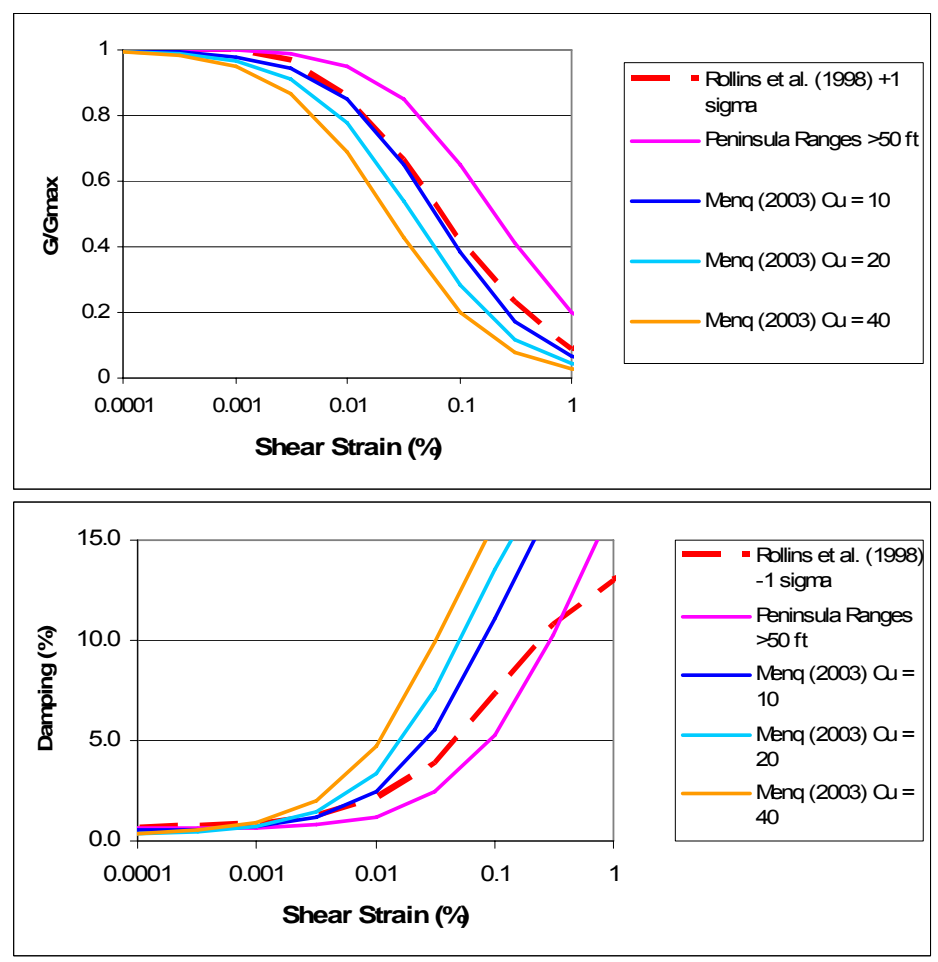

Figure 11: Modulus reduction and damping relationships for the $\mathrm{H} 3$ unit developed using the model of Menq (2003) compared to those of Rollins et al. (1998) and the Peninsula Ranges model (Silva et al. 1998). Relationships developed using Menq (2003) and Rollins et al. (1998) are used for the H3 unit in the updated analysis.

\subsubsection{CCU $\mathbf{G} / \mathrm{G}_{\max }$ and Damping Relationships}

Figure 12 compares site-specific $\mathrm{G} / \mathrm{G}_{\max }$ and damping relationships computed using the model developed by Menq (2003) and the soil parameters listed in Table 2 for the CCU layer with the relationships used by Rohay and Reidel (2005) for gravels. As was the case for the H3 unit, the Rollins et al. (1998) relationships indicate more linear behavior than the relationships developed using Menq's (2003) model and the parameters in Table 2. These relationships are used as the generic model for the gravel-dominated CCU. The Peninsula Ranges relationships are considered to be too linear for the CCU unit and were not incorporated in the updated site response model (Figure 2).

The Rollins et al. (1998) mean plus one $\sigma \mathrm{G} / \mathrm{G}_{\max }$ relationship and the mean minus one $\sigma$ damping relationship are used as the generic relationships for both the gravel-dominated $\mathrm{H} 3$ and the CCU layers. The effect of the difference in confining pressure in the two soil layers was examined using the Menq (2003) model and the $50^{\text {th }}$-percentile soil grain size properties. As indicated by the comparison shown in Figure 13, the effect of differences in confining pressure between the midpoint of the $\mathrm{H} 3$ layer and the mid-point of the CCU layer are small and were neglected when the Rollins et al. modulus reduction and damping relationships were used. 


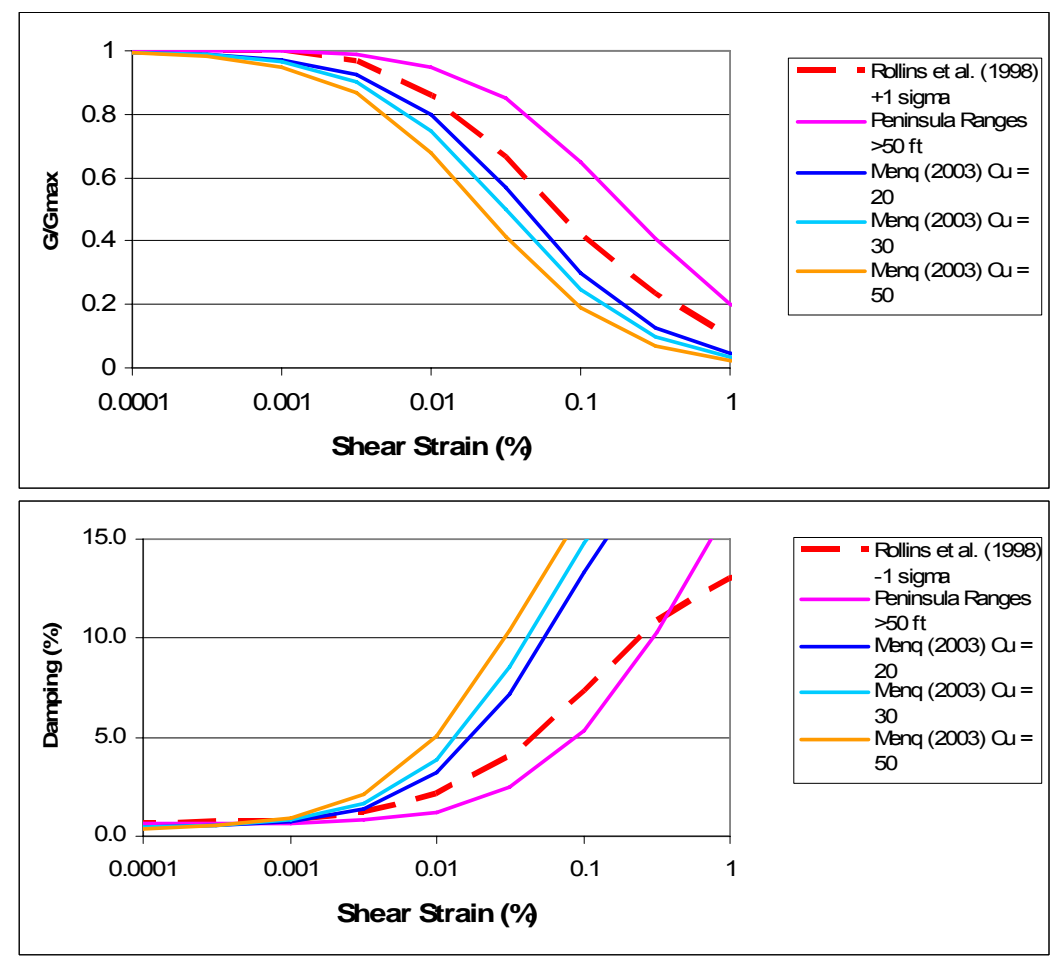

Figure 12: Modulus reduction and damping relationships for the CCU layer developed using the model of Menq (2003) compared to those of Rollins et al. (1998) and the Peninsula Ranges model (Silva et al. 1998). Relationships developed using Menq (2003) and Rollins et al. (1998) are used for the CCU layer in the updated analysis.

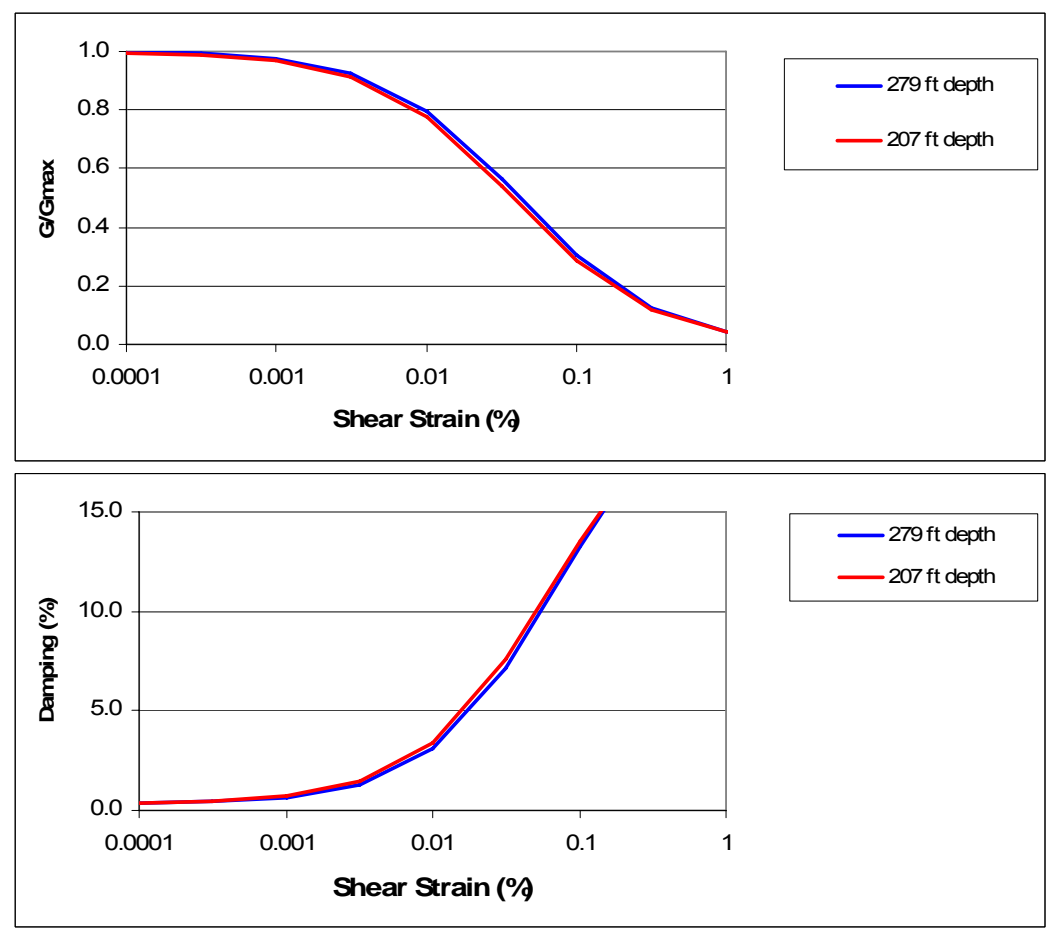

Figure 13: Effect of confining pressure difference on modulus reduction and damping relationships using the model of Menq (2003) with $\mathrm{C}_{\mathrm{U}}=20$ and the mid-point depths of the $\mathrm{H} 3$ and CCU units. 


\subsubsection{Ringold Unit $A \mathrm{G} / \mathrm{G}_{\max }$ and Damping Relationships}

The Ringold Unit A at the WTP site is highly consolidated with a shear wave velocity in excess of 7,000 fps. The shaking levels anticipated for the 2,000-year return period ground motions are expected to induce strain levels on the order of 0.001 percent or less. Therefore, it is expected that these materials will remain essentially linear and the Peninsula Ranges relationships for depths greater that 50 feet were used for the Ringold Unit A materials. As indicated in Figures 11 and 12, the Peninsula Ranges relationships remain essentially linear up to strain levels of 0.003 percent, with a low-strain damping of 0.6 percent.

\subsection{SUMMARY OF CHANGES TO SITE RESPONSE MODEL}

Table 3 lists the major elements of the site response model and indicates the changes in the characterization of the dynamic properties of the WTP site as a result of the additional data collection, testing, and analysis in 2006 and 2007. 
Table 3: Comparison of 2005 and 2007 Site Response Models for the WTP site

\begin{tabular}{|c|c|}
\hline Parameter & 2005 Model Versus 2007 Model \\
\hline $\mathrm{H} 2$ Unit Median $V_{S}$ & $\begin{array}{l}\text { - Updated median velocities with three additional down-hole } \\
\text { velocity surveys - Results in small change in velocity. } \\
\text { - } \quad \text { Removed backfill from model }\end{array}$ \\
\hline $\mathrm{H} 2$ Unit $\mathrm{G} / \mathrm{G}_{\max }$ and Damping & $\begin{array}{l}\text { - } 2005 \text { - EPRI (1993), no randomization } \\
\text { - } 2007 \text { - Two alternatives, randomization (see Sec 3.1.3) } \\
\text { o EPRI (1993) } \\
\text { o Site-specific based on soil grain size }\end{array}$ \\
\hline $\mathrm{H} 3$ Unit Median $V_{S}$ & $\begin{array}{l}\text { - Updated median velocities with three additional down-hole } \\
\text { velocity surveys - Results in small change in velocity. }\end{array}$ \\
\hline H3 Unit $G / G_{\max }$ and Damping & 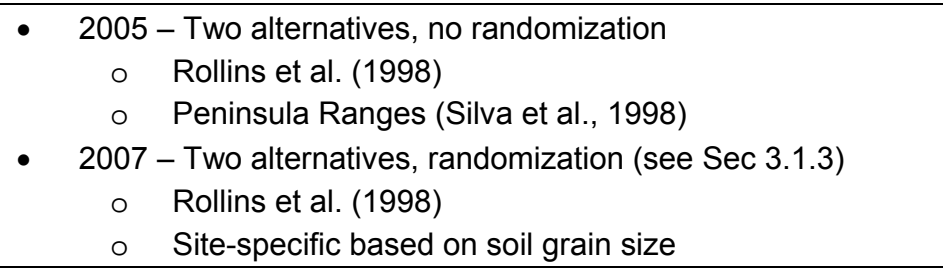 \\
\hline Ringold Median $V_{S}$ & $\begin{array}{l}\text { - } 2005 \text { - Modeled as a single layer with } \mathrm{V}_{\mathrm{S}} \text { either } 2,760 \text { or } 4,000 \\
\text { fps } \\
\text { - } 2007 \text { - Modeled as two layers } \\
0 \quad \text { CCU with } \mathrm{V}_{\mathrm{S}} \text { equal to or slightly less than } \mathrm{H} 3 \\
0 \quad \text { Ringold Unit } A \text { with } \mathrm{V}_{\mathrm{S}}>7,000 \mathrm{fps}\end{array}$ \\
\hline Ringold $G / G_{\max }$ and Damping & $\begin{array}{l}\text { - } 2005 \text { - Two alternatives, no randomization } \\
0 \quad \text { EPRI (1993) } \\
\text { o Peninsula Ranges (Silva et al., 1998) } \\
\text { - } 2007 \text { - CCU Two alternatives, randomization (see Sec 3.1.3) } \\
\text { o Rollins et al. (1998) } \\
\text { o Site-specific based on soil grain size } \\
\text { - } 2007 \text { - Ringold Unit A Peninsula Ranges }\end{array}$ \\
\hline Basalt Median $\mathrm{V}_{\mathrm{S}}$ & $\begin{array}{l}\text { - } 2005 \text { - Range of } \sim 6,200 \text { to } \sim 8,000 \mathrm{fps} \\
0 \quad \text { All layers with same median } V_{S} \\
0 \quad \text { broad flow top gradient } \\
2007-\text { Range } \sim 7,900 \text { to } \sim 8500 \mathrm{fps} \\
0 \quad \text { Individual layer medians included as alternative } \\
0 \quad \text { Flow-specific flow top gradients }\end{array}$ \\
\hline Interbed Median $\mathrm{V}_{\mathrm{S}}$ & $\begin{array}{l}\text { - } 2005 \text { - Range of } \sim 2,300 \mathrm{fps} \text { to } 4,500 \mathrm{fps} \\
0 \quad \text { All layers with same median } V_{\mathrm{S}} \\
\text { - } 2007 \text { - Range of } \sim 2,700 \text { to } \sim 2,950 \mathrm{fps} \\
0 \quad \text { Individual layer medians included as alternative }\end{array}$ \\
\hline Basal and Interbed Damping & $\begin{array}{l}\text { - For both } 2005 \text { and } 2007 \text { models based on distribution of total } \\
\text { site } \kappa .2005 \text { - not randomized, } 2007 \text { - randomized }\end{array}$ \\
\hline
\end{tabular}

\subsection{RELATIVE SITE RESPONSE ANALYSIS}

\subsection{APPROACH}

As described in Appendix A of Geomatrix (1996), in Geomatrix (2003, 2006), and in Rohay and Reidel (2005), a site response analysis is performed to compute the relative response of Hanford site profiles and California soil site profiles to ground motions representative of the site hazard at the specified return period. These site response analyses are performed using outcropping motions for the crustal depth where the California and Hanford sites have 
similar shear wave velocities, which is at a depth of $3 \mathrm{~km}$ (Geomatrix, 1996). These rock motions are then propagated upward through randomized California soil site profiles and randomized Hanford profiles. Geometric mean (mean log) response spectra for the computed surface motions are used to compute the ratio of Hanford surface motions to California soil site motions. This ratio, termed the relative amplification function (RAF) was used by Rohay and Reidel (2005) to adjust the original horizontal design response spectrum developed using California-based empirical ground motion models to represent the ground motions representative of the response of the Hanford WTP site to similar levels of shaking. The approach used by Rohay and Reidel (2005) is followed in this study.

\subsubsection{Rock Motions}

The development of outcrop motions representative of rock motions at a depth of $3 \mathrm{~km}$ is documented in Geomatrix (2006). The motions consist of a set of 16 California rock site motions from magnitude $\mathbf{M} \sim 6$ earthquakes deconvolved through 30 randomized profiles representative of California rock sites. The deconvolved time histories were modified to remove spurious high-frequency motion above $10 \mathrm{~Hz}$ by performing a weak spectral match of the high-frequency portion of the record to a theoretical outcrop response spectrum for $\mathbf{M}$ 6 earthquake ground motions at a depth of $3 \mathrm{~km}$.

\subsubsection{California Soil Sites}

The development of randomized shear wave velocity profiles representative of California soil recording sites is documented in Geomatrix (2006). The set of profiles consisted of 15 profiles representative of northern California conditions and 15 profiles representative of southern California conditions. This study uses those profiles and soil properties with the additional step of randomizing the $\mathrm{G} / \mathrm{G}_{\max }$ and damping relationships. As discussed in Rohay and Reidel (2005) and Geomatrix (2006), EPRI (1993) modulus reduction and damping relationships are used for the Northern California soil sites and Peninsula Ranges modulus reduction and damping relationships are used for southern California soil sites.

\subsubsection{Randomized Velocity Profiles for the WTP Site}

Rohay and Reidel (2005) adopted the site-specific model for velocity variation developed by Silva et al. (1998) for the Savannah River H area to represent the variability in shear wave velocity for the Hanford sediments. In the Silva et al. (1998) model the shear-wave velocities in the sediment layers are modeled as correlated, lognormally distributed variables. The expression for the correlation coefficient between the velocities in two adjacent layers, $\rho$ is given by:

$$
\rho(h, t)=\left(1-\rho_{d}(h)\right) \rho_{t}(t)+\rho_{d}(h)
$$

where $\rho_{d}$ represents the depth-dependent correlation (generally increasing with increasing depth), and $\rho_{t}$ is the thickness-dependent correlation (generally decreasing with increasing layer thickness). The factors $\rho_{d}$ and $\rho_{t}$ are obtained from the expressions:

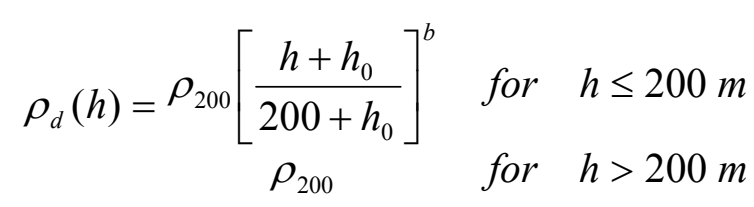

and 


$$
\rho_{t}(t)=\rho_{0} \exp \left[-\left(\frac{t}{\Delta}\right)^{\alpha}\right]
$$

where $h$ is the average of the midpoint depths of layers $i$ and $i-1$, and $t$ is the difference between those midpoint depths. Table 4 lists the parameters of the velocity variability model used for the supra-basalt sediments in the updated site response analysis presented in this report. The Silva et al. (1998) model representative of variability across a large building site was used instead of site-specific data because the site-specific data are too limited to quantify a correlated variability model. The calculated standard deviation $\left(\sigma_{\ln (\mathrm{Vs})}\right)$ of the measured site velocities are generally consistent or somewhat lower than those defined by the generic model.

Table 4: Velocity Variability Model Parameters Used for the Supra-basalt Sediments at the WTP Site

\begin{tabular}{|c|c|}
\hline Parameter & Value \\
\hline$\sigma_{\ln (\mathrm{Vs})}$ at depth $0 \mathrm{ft}$ & 0.26 \\
\hline$\sigma_{\ln (\mathrm{Vs})}$ at depth $5 \mathrm{ft}$ & 0.26 \\
\hline$\sigma_{\ln (\mathrm{Vs})}$ at depth $15 \mathrm{ft}$ & 0.15 \\
\hline$\sigma_{\ln (\mathrm{Vs})}$ at depth $50 \mathrm{ft}$ & 0.17 \\
\hline$\sigma_{\ln (\mathrm{Vs})}$ at depth $100 \mathrm{ft}$ & 0.1 \\
\hline$\sigma_{\ln (\mathrm{Vs})}$ at depth $\geq 200 \mathrm{ft}$ & 0.12 \\
\hline$\rho_{0}$ & 0.001 \\
\hline$\rho_{200}$ & 0.67 \\
\hline$\Delta$ & 5 \\
\hline $\mathrm{h}_{0}$ & 20 \\
\hline $\mathrm{B}$ & 0.64 \\
\hline $\mathrm{A}$ & 1 \\
\hline
\end{tabular}

Layer thickness were randomized using a uniform distribution over the range of $\pm 10 \%$ at shallow depths, increasing to $\pm 20 \%$ at depth. The depth to the $\mathrm{H} 2 / \mathrm{H} 3, \mathrm{H} 3 / \mathrm{CCU}$, $\mathrm{CCU} /$ Ringold Unit A, and Ringold Unit A/Basalt boundaries were randomized using a uniform distribution over the range of depths measured in the site borings. Figure 14 shows the randomized velocity profiles and Figure 15 compares the statistics of the randomized profiles with the target values for median $\mathrm{V}_{\mathrm{S}}$ and $\sigma_{\ln [\mathrm{Vs}]}$. 


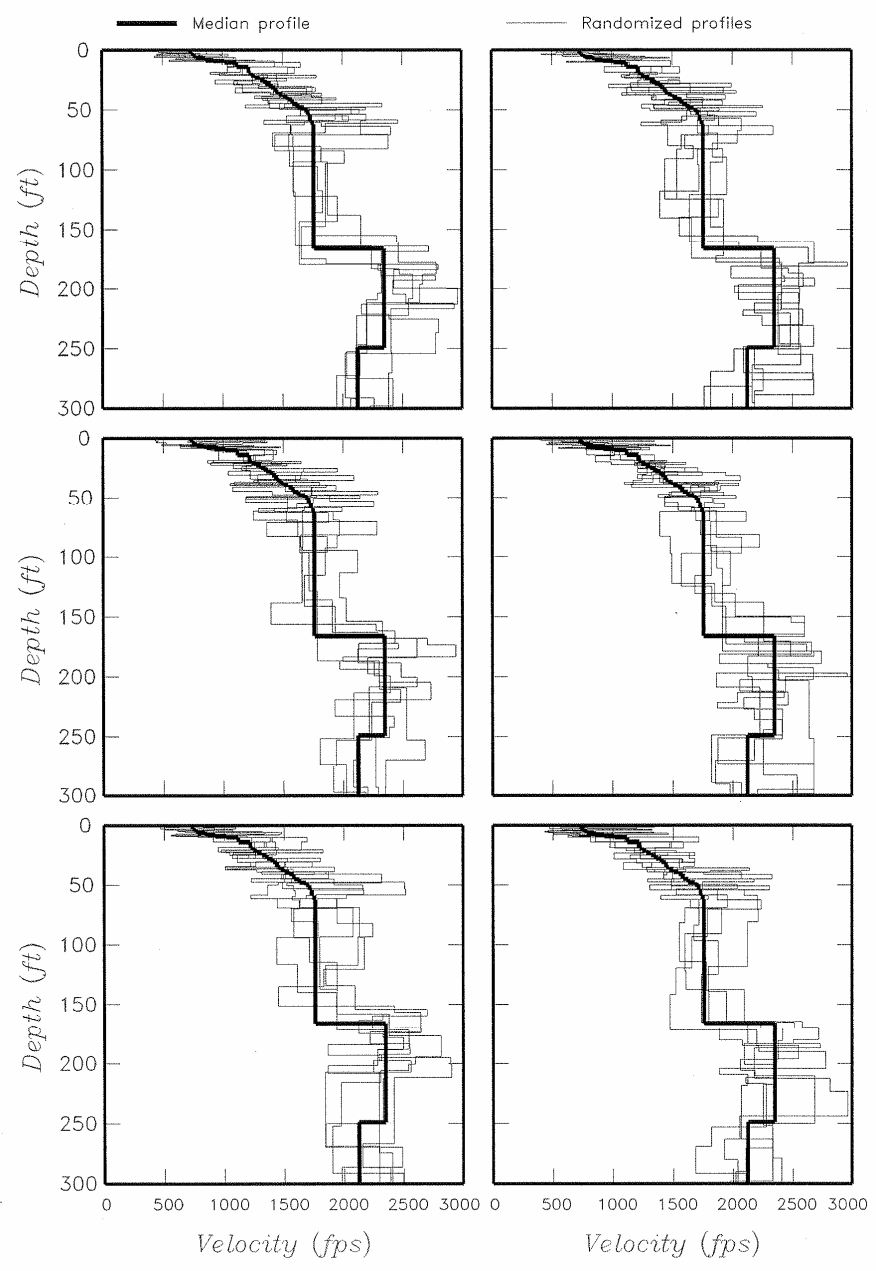

Figure 14: Thirty randomized velocity profiles (five per panel) for the supra-basalt sediments.
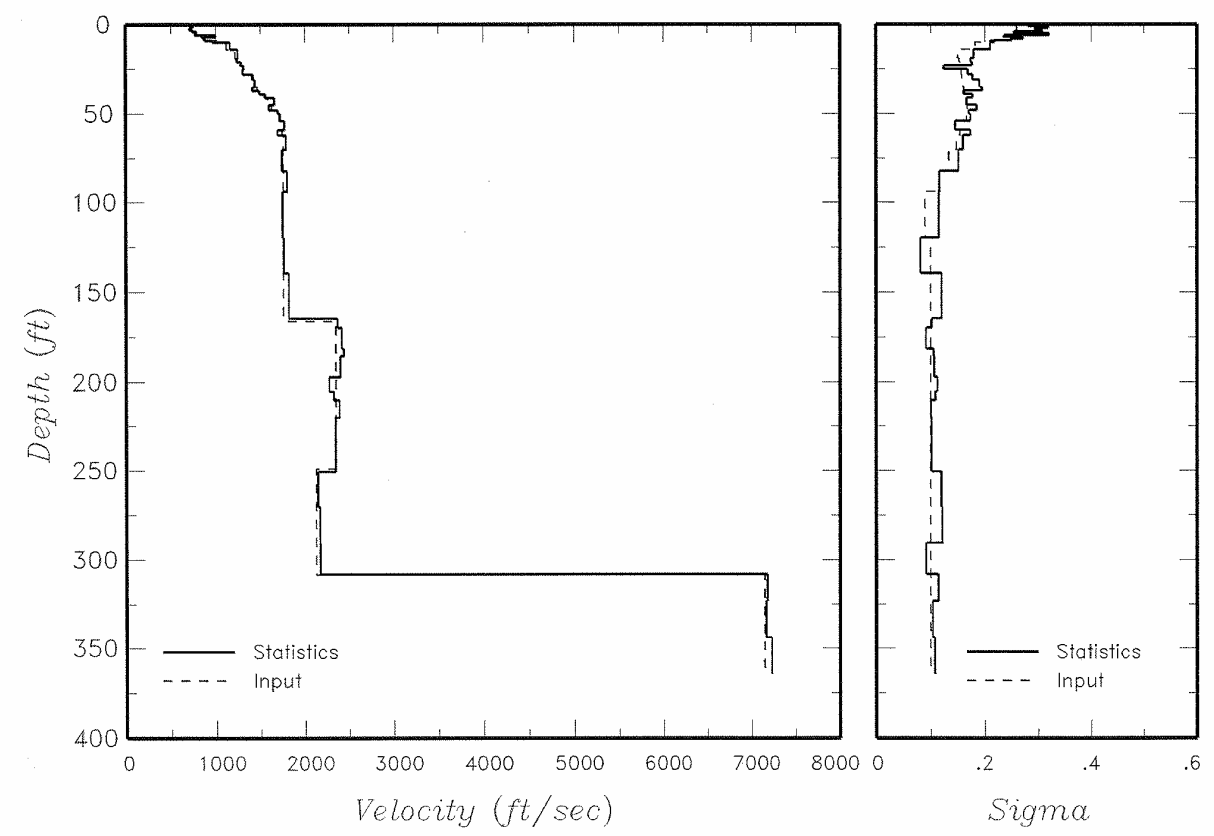

Figure 15: Statistics of randomized velocity profiles for the supra-basalt sediments. 
Randomization of the basalt and interbed velocities was performed using a simple correlation model. The variability in $\ln \left[\mathrm{V}_{\mathrm{S}}\right]$ was modeled assuming a $\sigma_{\ln [\mathrm{Vs}]}=0.1$. This value was selected as representative of velocity variation at large depth. The value is slightly larger than that computed from the measured velocities, but again, the number of site-specific measurements is too limited to obtain a reliable estimate of $\sigma$. The correlation between adjacent layers in basalt was set at 0.95 in order to prevent introducing velocity reversals in the flow top gradients. The correlation between velocity in adjacent basalt and interbed layers was set at zero. The layer thicknesses were randomized using a uniform distribution over the range of thicknesses measured in the four deep borings. Figure 16 shows the randomized basalt and interbed velocity profiles and Figure 17 compares the statistics of the randomized profiles with the target values for median $\mathrm{V}_{\mathrm{S}}$ and $\sigma_{\ln [\mathrm{Vs}]}$.
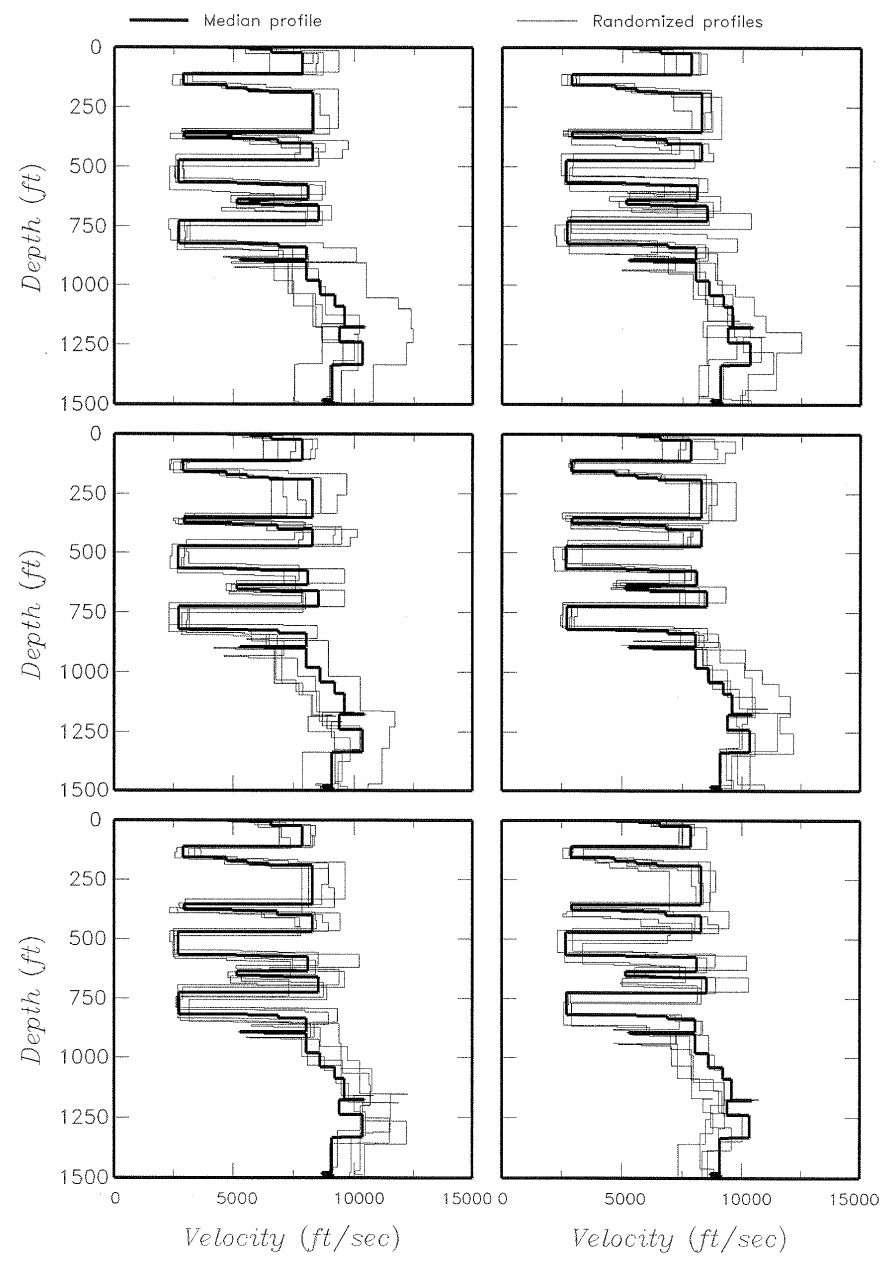

Figure 16: Thirty randomized velocity profiles (five per panel) for the basalts and interbeds. 


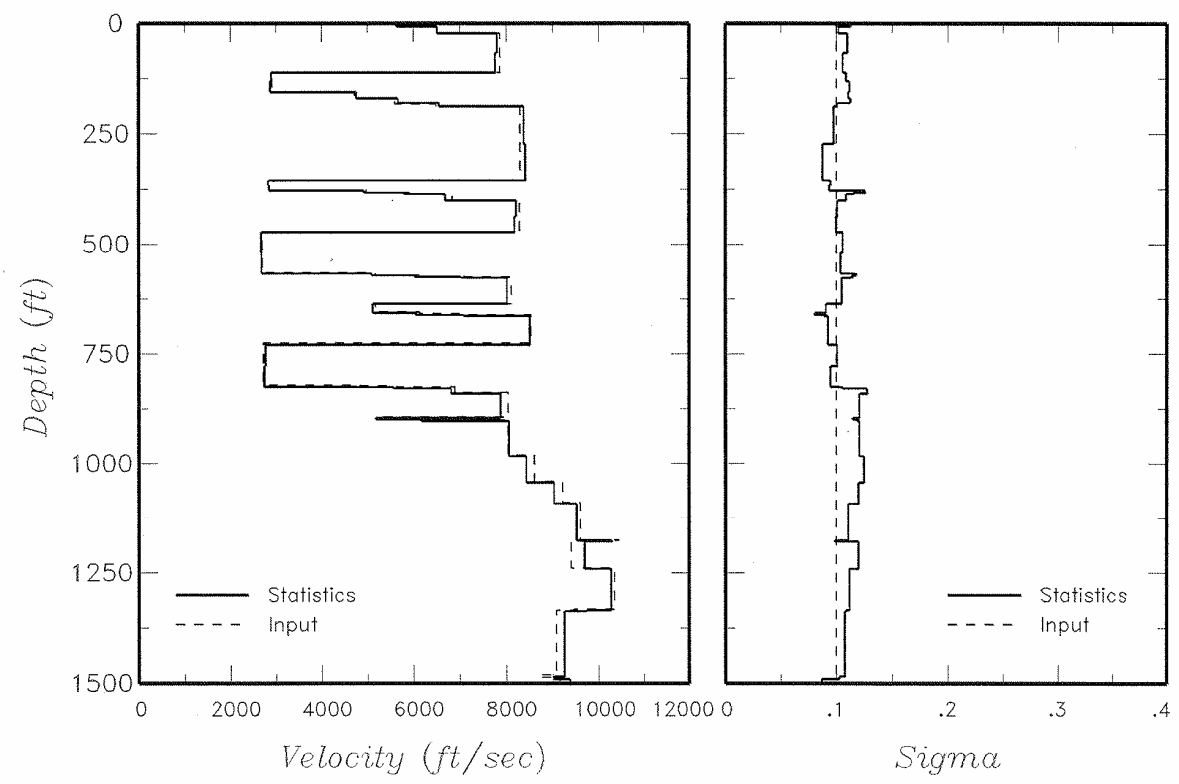

Figure 17: Statistics of randomized velocity profiles for the basalts and interbeds.

\subsubsection{Randomized Modulus Reduction and Damping Relationships}

Two approaches were used to randomize the modulus reduction and damping relationships. The EPRI (1993), Rollins et al. (1998) and Peninsula Ranges curves were randomized as follows. For $\mathrm{G} / \mathrm{G}_{\max }$, a beta distribution for was constructed such that the standard deviation of $\ln \left[\mathrm{G} / \mathrm{G}_{\max }\right]$ approached the target value of 0.15 when $\mathrm{G} / \mathrm{G}_{\max }=\sim 0.5$. Damping was randomized using a lognormal distribution for damping with $\sigma_{\ln [\text { Damping] }}=0.3$ at low strain and decreasing as the damping level increased, with damping limited to a maximum of 15 percent. These target values were based on data presented in Silva et al. (1998). Figure 18 shows the 16 th $\%, 50$ th $\%$ and 84 th\% from 100 simulations of the EPRI (1993) 21-50 ft depth $\mathrm{G} / \mathrm{G}_{\max }$ and damping curves.

The site-specific modulus reduction and damping curves developed using the Menq (2003) model were randomized as follows. The $\mathrm{G} / \mathrm{G}_{\max }$ and damping relationships are both defined in terms of the Darendeli (2001) parameters $\gamma_{R}, a$, and $\mathrm{D}_{\min }$. These parameters are then simulated using lognormal distribution for $\gamma_{R}, a$, and $\mathrm{D}_{\min }$ and a normal distribution for $a$, with standard deviations adjusted to obtain levels of variability similar to those shown in Figure 18. Damping was again limited to a maximum of 15 percent. Figure 19 shows an example of this approach applied to the EPRI (1993) 21-50 ft depth range. These relationships can be fit very closely by the Darendeli (2001) model using the parameters $\gamma_{R}$, $0.052, \sigma_{\ln [\gamma R]}=0.4 ; a=0.935, \sigma_{a}=0.2 ;$ and $D_{\min .}=1.18$. $\sigma_{\ln [\operatorname{Dmin}]}=0.3$.

Sensitivity tests conducted by randomizing the EPRI (1993) and Rollins et al. (1998) curves using both methods showed very similar resulting surface spectra. This is likely due to the fact that, for the shaking levels represented by the WTP design motions, the strain levels are generally near or below 0.01 percent where the variability in the $\mathrm{G} / \mathrm{G}_{\max }$, and damping relationships produced by the two approaches is similar. 


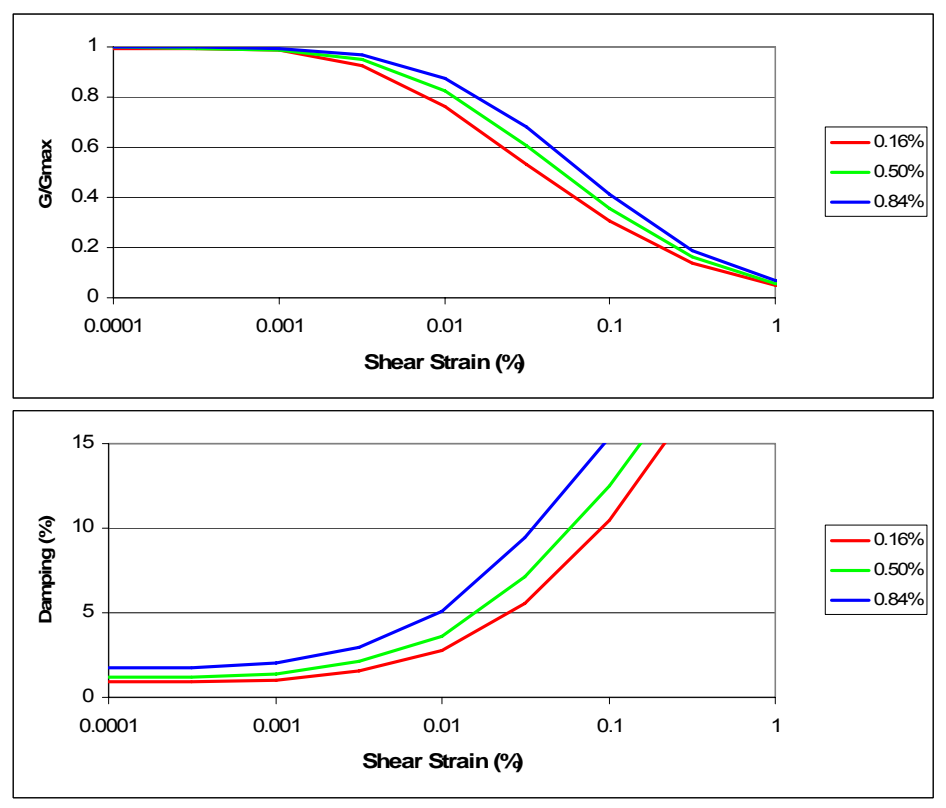

Figure 18: Percentiles of randomized $G / G_{\max }$ and damping relationships based on EPRI (1993) 21-50 $\mathrm{ft}$ depth curves. $\mathrm{G} / \mathrm{G}_{\max }$ is randomized using a beta distribution with strain-dependent parameters and damping is randomized using a lognormal distribution with strain-dependent sigma.

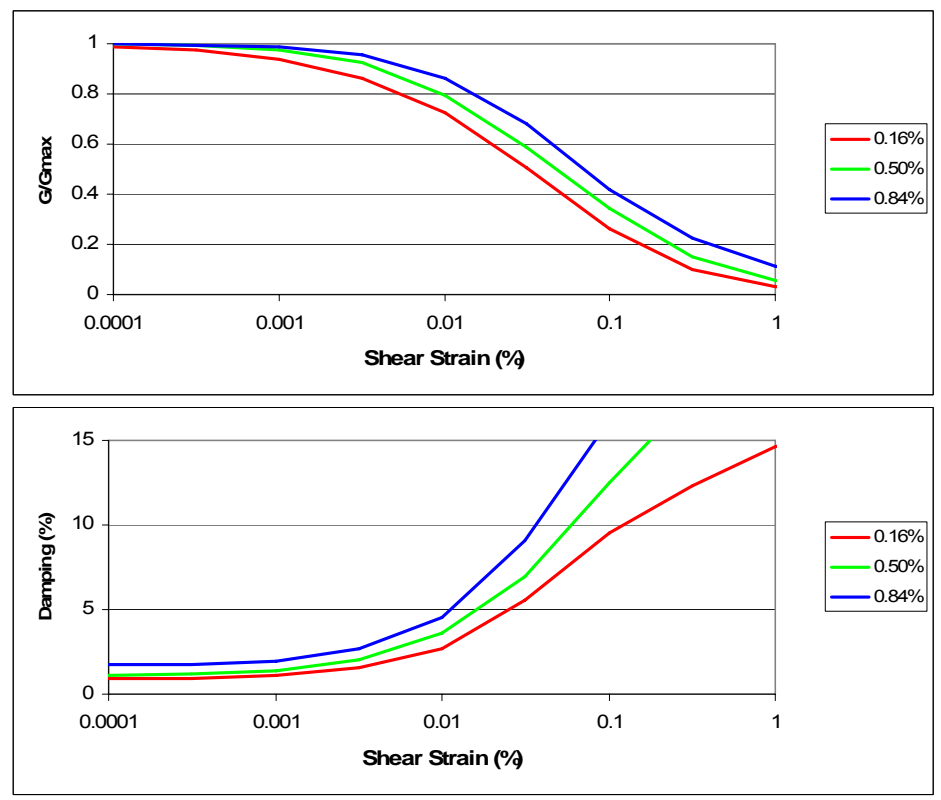

Figure 19: Percentiles of randomized $G / G_{\max }$ and damping relationships based on EPRI (1993) 21-50 $\mathrm{ft}$ depth curves. Curves are first fit with Darendeli (2001) model parameters $\gamma_{R}, a$, and $\mathrm{D}_{\min } . \mathrm{G} / \mathrm{G}_{\max }$ and damping are randomized using randomization of Darendeli (2001) model parameters fit to base case curves.

Basalt and interbed material damping was randomized by randomizing $\kappa$ using $\sigma_{\ln [\kappa]}=0.3$, similar to the assumed variation in slow strain damping in the soils. 


\subsection{SITE RESPONSE ANALYSIS RESULTS}

\subsubsection{Summary of 2005 Results and Sensitivity Using 2005 Site Response Model}

The site response model logic tree developed by Rohay and Reidel (2005), Figure 1, defined a wide range of velocity profiles for the WTP site. Figure 20 shows the resulting distribution of relative amplification functions. The largest contributors to the uncertainty in the relative amplification were uncertainty in the interbed shear wave velocity and the uncertainty in $\kappa$.

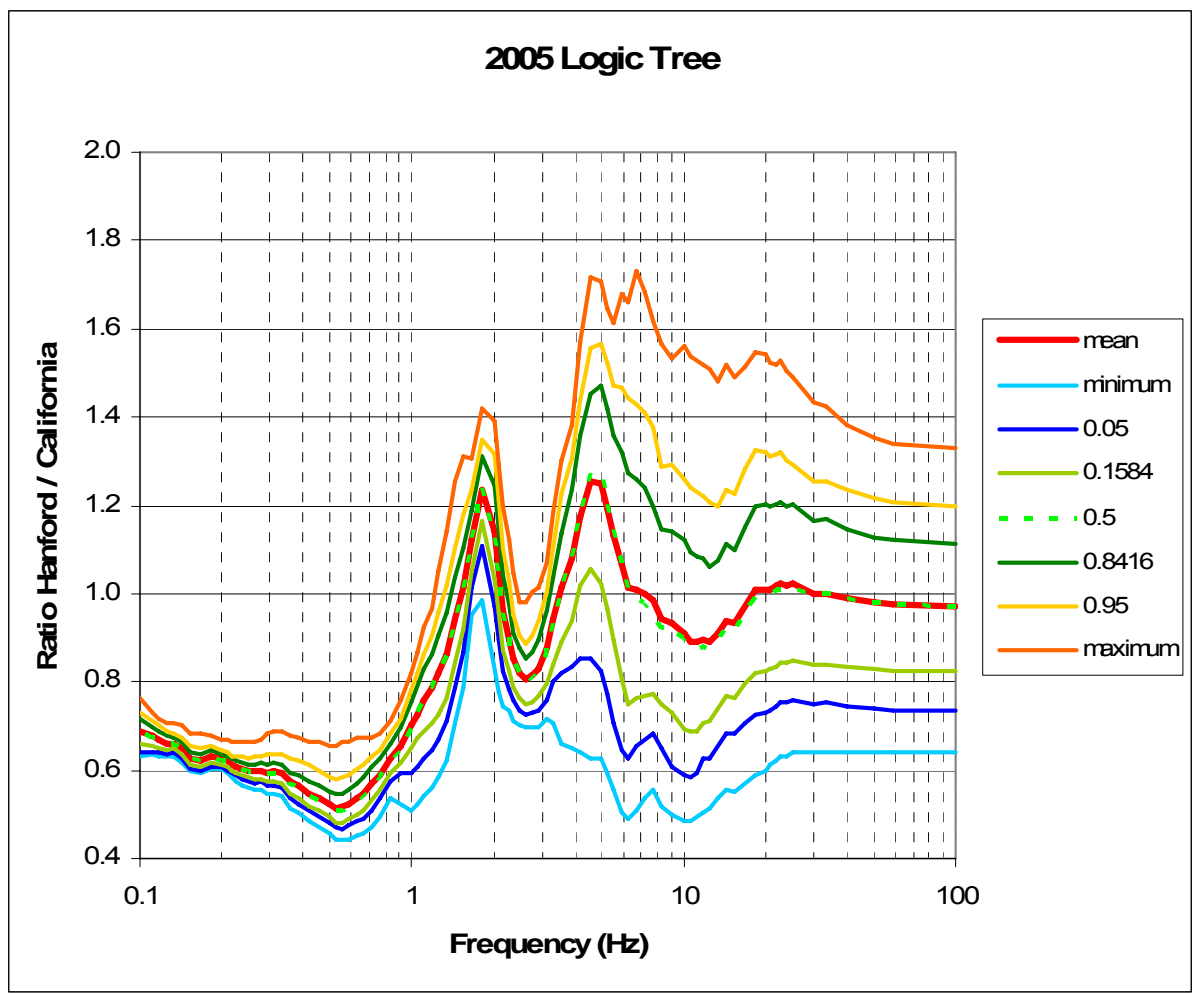

Figure 20: Distribution of relative amplification functions for the WTP site developed by Rohay and Reidel (2005).

The effects of the updated site response model on the relative amplification can be anticipated by modifying the 2005 logic tree shown in Figure 1 to include only those branches that are representative of the updated site response model (Figure 2). Figure 21 shows the reduced Rohay and Reidel (2005) logic tree. The weights assigned to the Ringold unit velocity alternatives produce a weighted average velocity that is equal to the average $V_{S}$ for the combined CCU and Ringold Unit A layers in the updated model, 3,250 fps. A single basalt $V_{P}$ value is used that results in a $V_{S}$ value of $8,045 \mathrm{fps}$, and single values of the interbed $\mathrm{V}_{\mathrm{P}}$ and $\mathrm{V}_{\mathrm{P}} / \mathrm{V}_{\mathrm{S}}$ are used that produce a $\mathrm{V}_{\mathrm{S}}$ value of 2,885 . These values of basalt and interbed $V_{S}$ are near the average values in the updated model. 


\begin{tabular}{|c|c|c|c|c|c|c|}
\hline \multirow{4}{*}{ Kappa } & $\begin{array}{c}\text { Ringold } \\
\text { Vs } \\
(f p s)\end{array}$ & $\begin{array}{c}\text { Gravord } \\
\text { Ringold } \\
\text { G/Gmax and } \\
\text { Damping Curves }\end{array}$ & $\begin{array}{c}\text { Saddle Mt. } \\
\text { Basalt Vp } \\
\text { (fps) }\end{array}$ & $\begin{array}{c}\text { Basalt } \\
V_{p} / V_{s}\end{array}$ & $\begin{array}{c}\text { Saddle Mt. } \\
\text { Interbeds Vp } \\
\text { (fps) }\end{array}$ & $\begin{array}{c}\text { Interbed } \\
V p / V s\end{array}$ \\
\hline
\end{tabular}

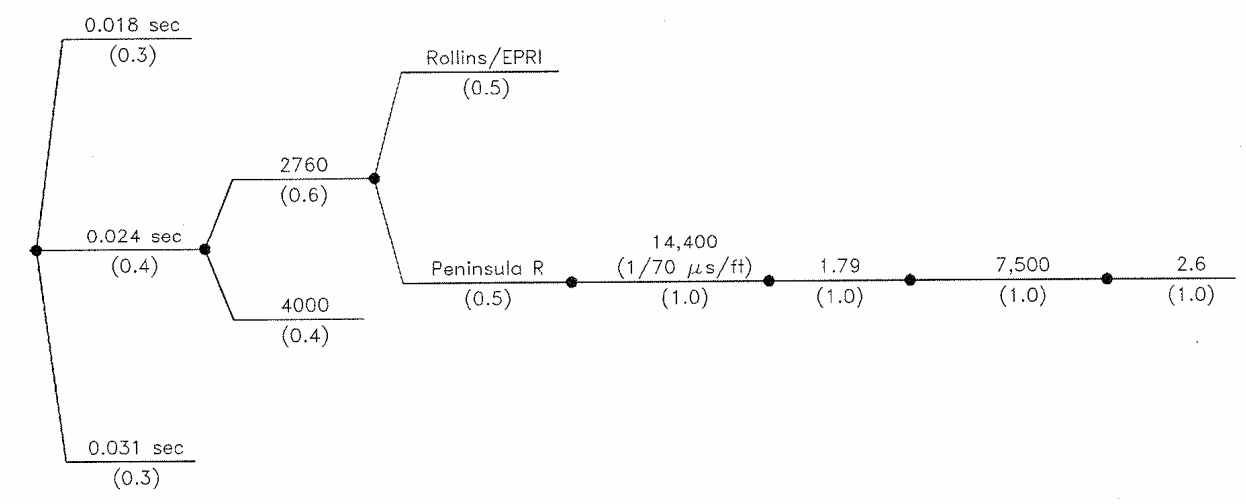

Figure 21: Rohay and Reidel (2005) logic tree reduced to branches consistent with updated site response model.

Figure 22 shows the resulting distribution of relative amplification computed with the reduced logic tree. The range in amplification is greatly reduced due to removal of the largest source of uncertainty, the wide range in interbed shear wave velocity. The mean response is reduced due to the fact that the shear wave velocity data obtained in the basalts and interbeds indicate a large basalt/interbed velocity contrast. Results presented in Rohay and Reidel (2005) show that the relative amplification decreased as the basalt/interbed velocity contrast increased. 


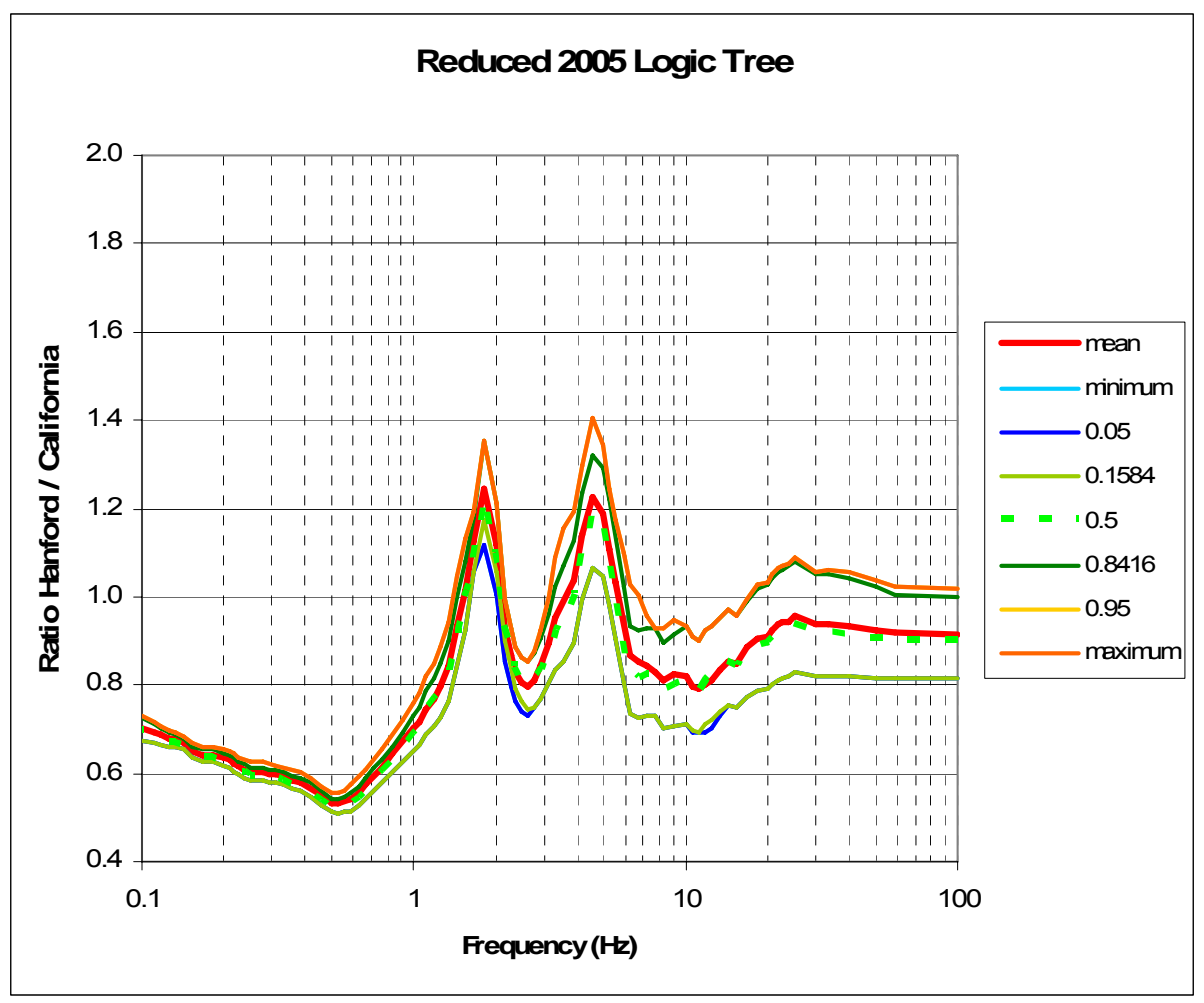

Figure 22: Distribution of relative amplification functions for the WTP site computed using the Rohay and Reidel (2005) site response model logic tree reduced to include only those parameters that are comparable to the updated site response model. (The reduced logic tree is shown in Figure 21.)

\subsubsection{Sensitivity Analyses Using Updated Site Velocities Only}

A first step in examining the impact of the updated site response model was made by computing the distribution of relative amplification considering only the changes in the shear wave velocity profiles. For this analysis, the shear modulus and damping relationships used by Rohay and Reidel (2005) were used - EPRI (1993) for the sand-dominated H2 unit and equal weights given to Rollins et al. (1998) and Peninsula Ranges for the gravel-dominated H3 unit and CCU layers. Only the Peninsula Ranges relationships were used for the Ringold Unit A layer. Modulus reduction and damping relationships were not randomized for this case. Figure 23 shows the resulting distribution of relative amplification for this sensitivity analysis Case 1a. Because the data gathered in 2006 and 2007 have greatly reduced the largest source of uncertainty, the range in velocity of the interbeds, the resulting range in relative amplification is also greatly reduced. As indicated above, the results shown in Rohay and Reidel (2005) indicate that the relative amplification decreases as the ratio of basalt to interbed velocity increases. The velocity contrast between the interbeds and the basalts in the updated velocity model is in the upper range of the models developed by Rohay and Reidel (2005). As a result, the updated relative amplifications lie in the lower range of the values obtained by Rohay and Reidel (2005). The results are similar to those shown in Figure 22 for the reduced Rohay and Reidel model (2005). 


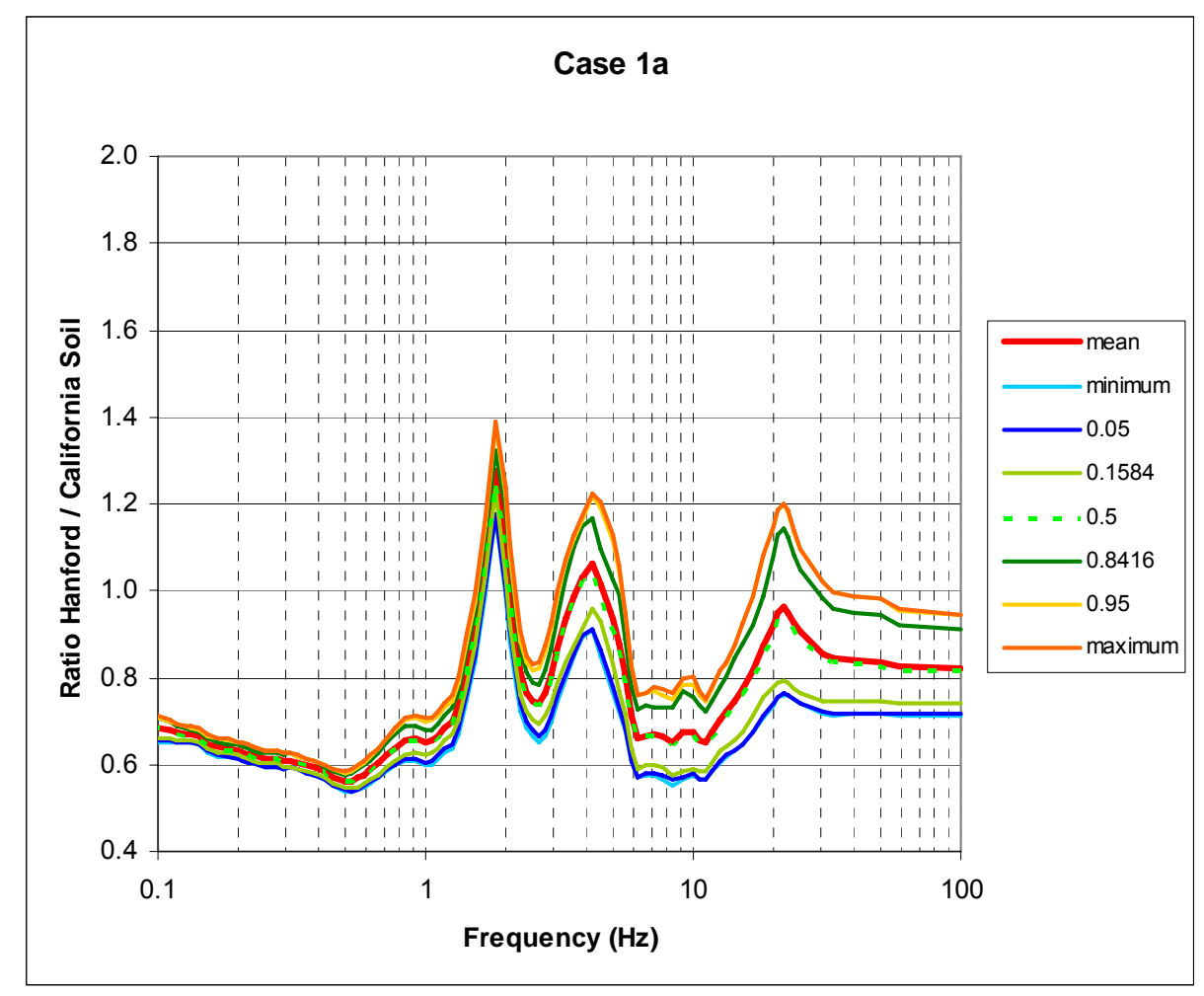

Figure 23: Distribution of relative amplification functions computed using the updated WTP velocity models and the Rohay and Reidel (2005) sets of modulus reduction and damping relationships (without randomization of $\mathrm{G} / \mathrm{G}_{\max }$ and damping).

Figure 24 shows the results of repeating the analysis presented in Figure 23 including randomization of the modulus reduction and damping relationships. The use of randomized $\mathrm{G} / \mathrm{G}_{\max }$ and damping relationships produces very similar response to that obtained using the same set of relationships for all randomized velocity profiles.

Figure 25 shows the effect on site response of using median velocities for the basalts and interbeds based on the suspension logging data. The relative amplification functions computed using the suspension logging-based median velocities are compared to those developed using down-hole velocity-based median velocities for the individual basalt and interbed layers. The higher basalt median velocities based on suspension logging data produce slightly lower response, consistent with the effect of decreasing response with increasing basalt velocity reported in Rohay and Reidel (2005). 


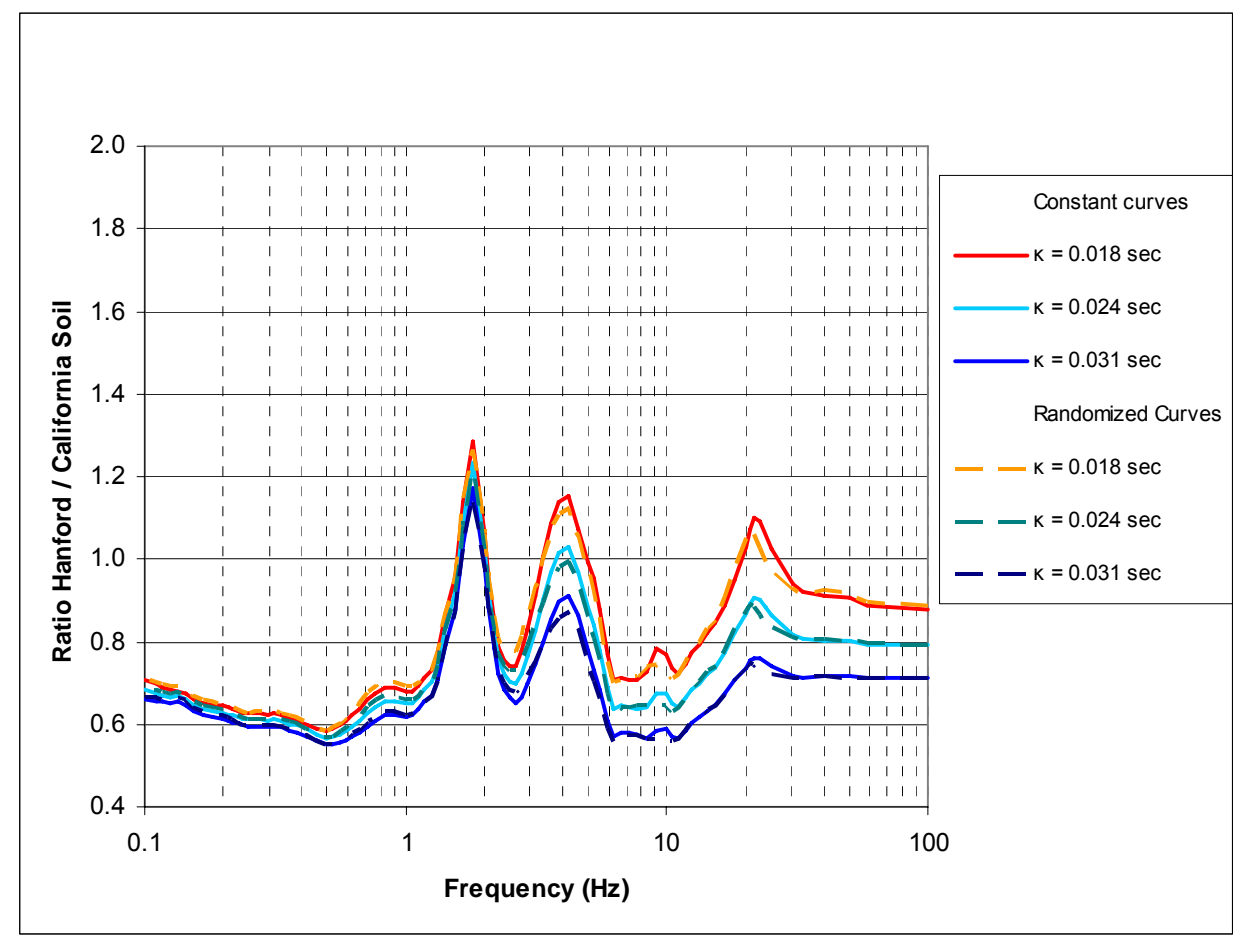

Figure 24: Comparison of distributions of relative amplification functions computed using the updated WTP velocity models and the Rohay and Reidel (2005) sets of modulus reduction and damping relationships with and without randomization. Ratios are shown for the $\mathrm{CCU}=\mathrm{H} 3$ velocity case.

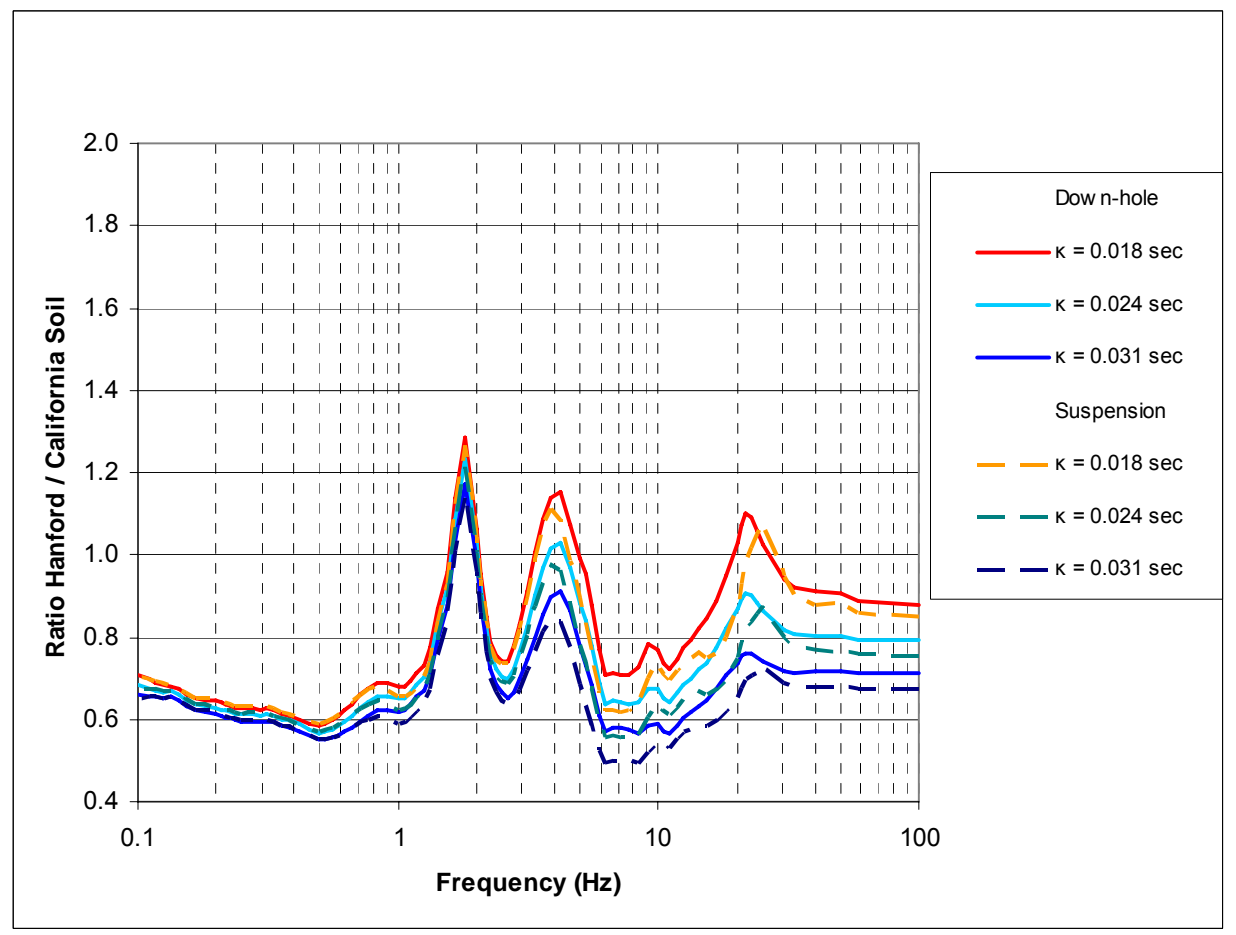

Figure 25: Comparison of relative amplification functions computed using the updated WTP basalt and interbed velocity models based on down-hole velocity measurements and those computed with basalt and interbed velocities based on the suspension logging data. Ratios are shown for the $\mathrm{CCU}=\mathrm{H} 3$ velocity case with EPRI (1993) and Rollins et al. (1998) $\mathrm{G} / \mathrm{G}_{\max }$ and damping relationships. 


\subsubsection{Sensitivity Analyses Using Complete Updated WTP Site Model}

Figures 26 through 32 show the sensitivity of the relative amplification function to the uncertainties at each level of the updated site response model logic tree shown in Figure 2.

Figure 26 shows the effect of the alternative $\kappa$ values on the relative response. The individual label curves represent conditional mean amplifications. For example, the curve labeled " $\kappa=0.018 \mathrm{sec}$ " is computed by assigning a weight of 1.0 to the logic tree branch for $\kappa=$ $0.018 \mathrm{sec}$ and zero to the other two branches. The plotted curve is the weighted mean relative amplification computed over the uncertainty in the remaining levels of the site response model logic tree. The uncertainty in $\kappa$ remains an important contributor to the uncertainty in relative amplification.

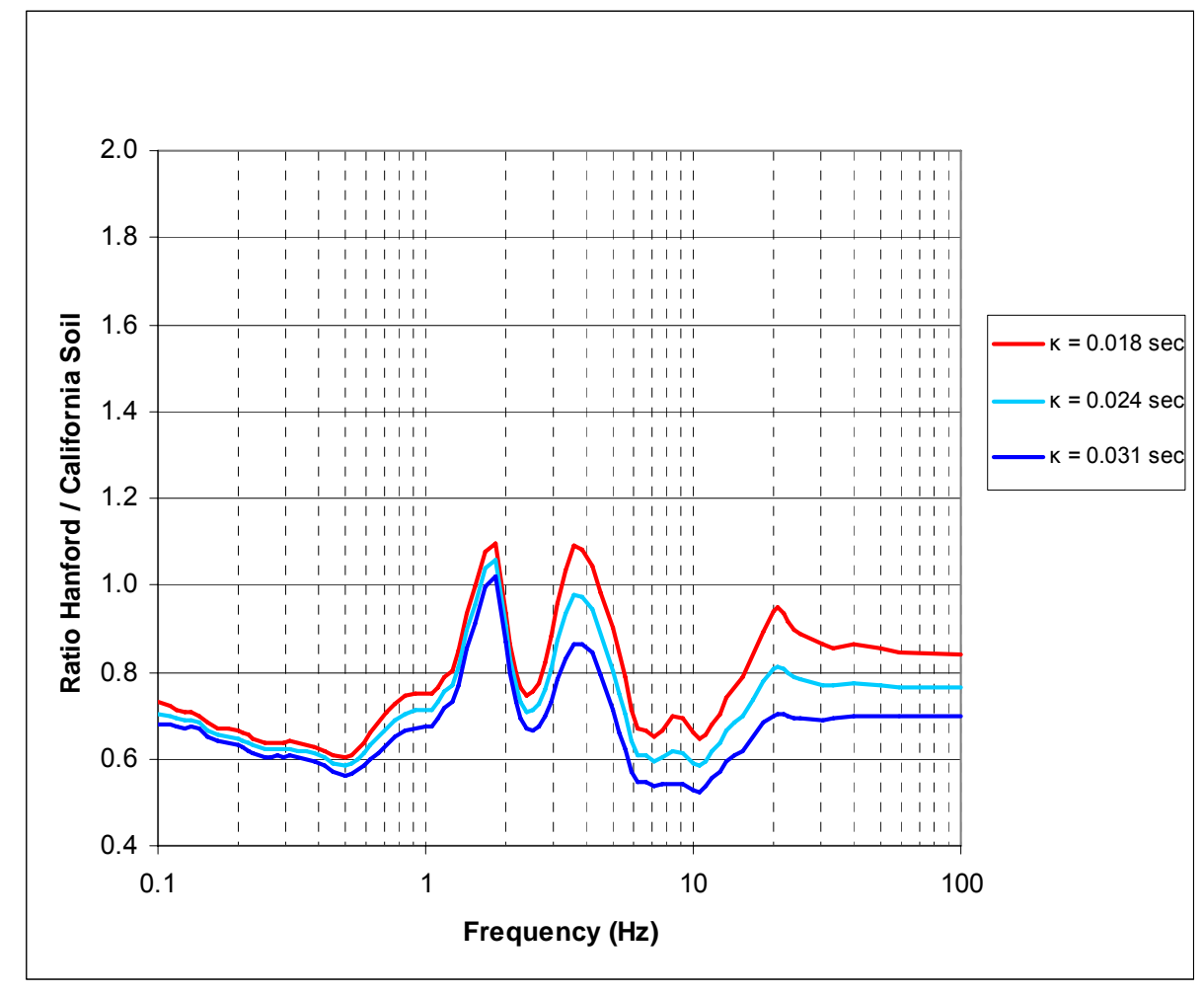

Figure 26: Effect of $\kappa$ on relative response for the updated site response model (Figure 2).

Figure 27 shows the effect of the alternative velocity models for the H3 and CCU layers and Figure 28 shows the effect of the alternative velocity models for the basalts and interbeds. The alternative $\mathrm{H} 3 / \mathrm{CCU}$ velocities have little impact on the relative response. The use of common median velocities for the interbeds and basalts produces slightly higher response than the use of individual layer velocities. This is likely due to the slightly greater velocity contrasts for the individual layer velocity model (see Figure 4). 


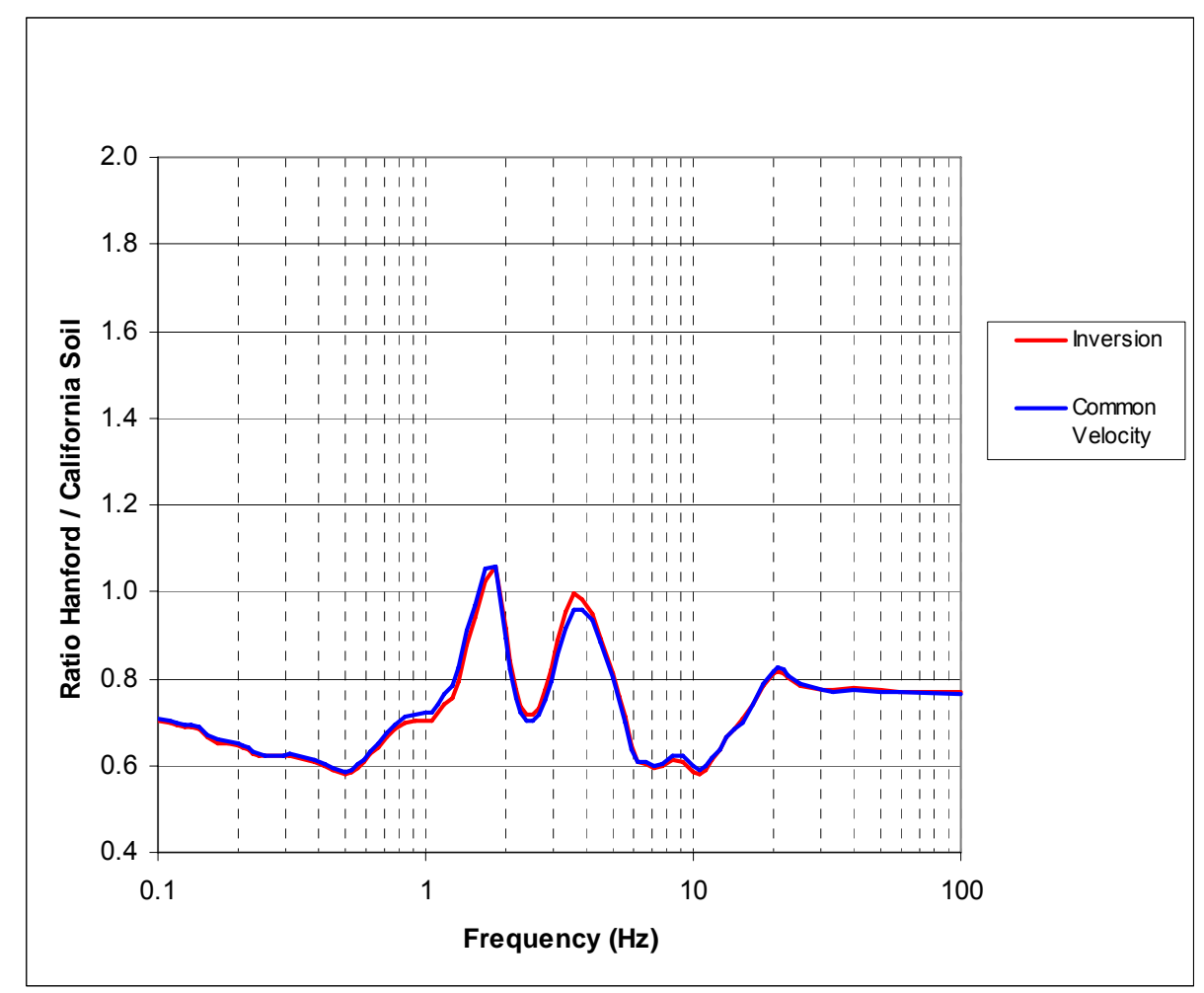

Figure 27: Effect of $\mathrm{H} 3 / \mathrm{CCU}$ velocity model on relative response for the updated site response model (Figure 2).

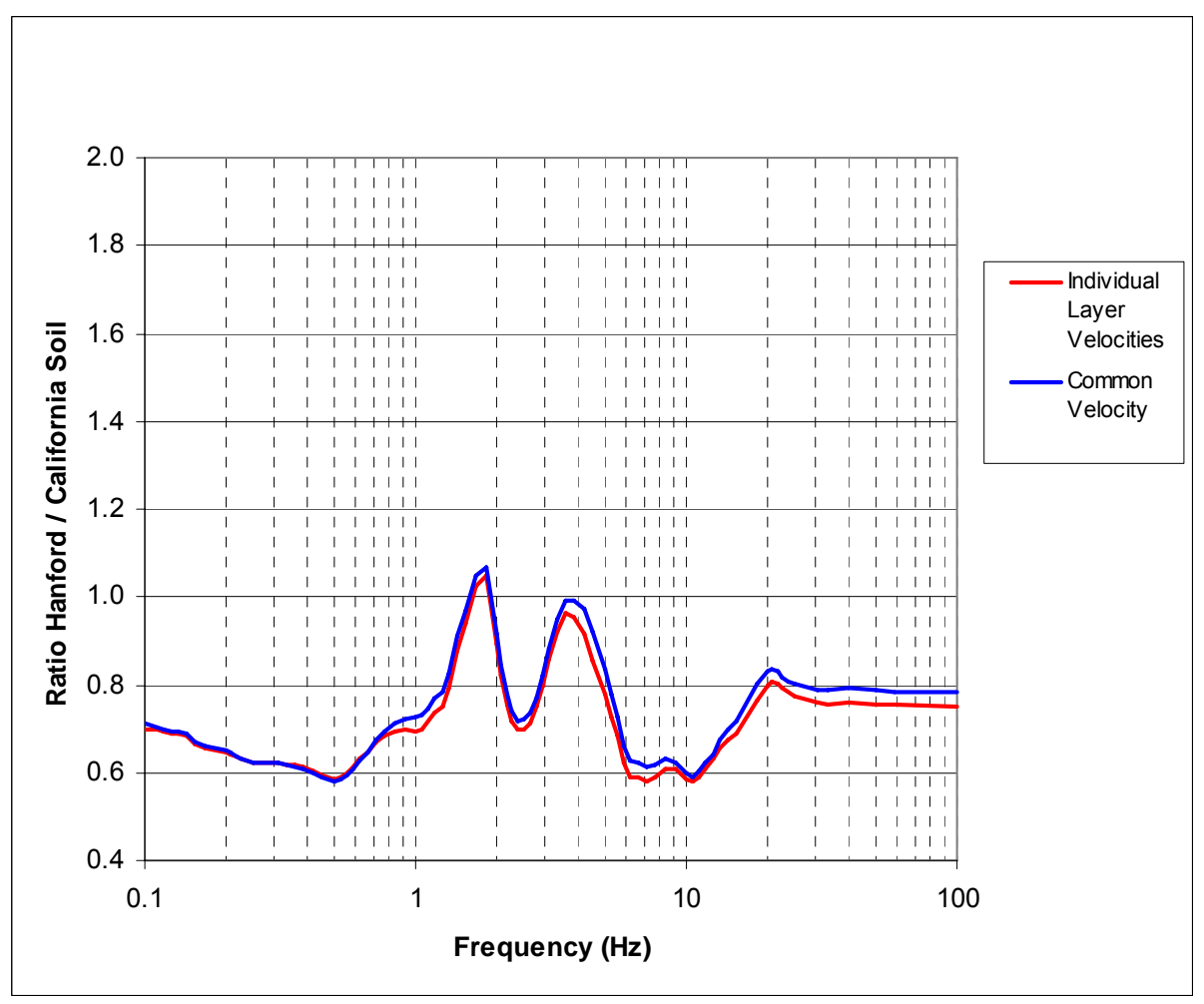

Figure 28: Effect of basalt and interbed velocity model on relative response for the updated site response model (Figure 2). 
Figure 29 shows the effect of the alternative approach used for defining the $G / G_{\max }$ and damping relationships for the supra-basalt sediments. The use of generic relationships produces higher relative response for frequencies above about $1.7 \mathrm{~Hz}$ because these relationships exhibit more linear behavior. Use of the site-specific relationships produces slightly higher response for lower frequencies and a shift to lower frequency in the peaks of the relative amplification due to greater softening of the sediments.

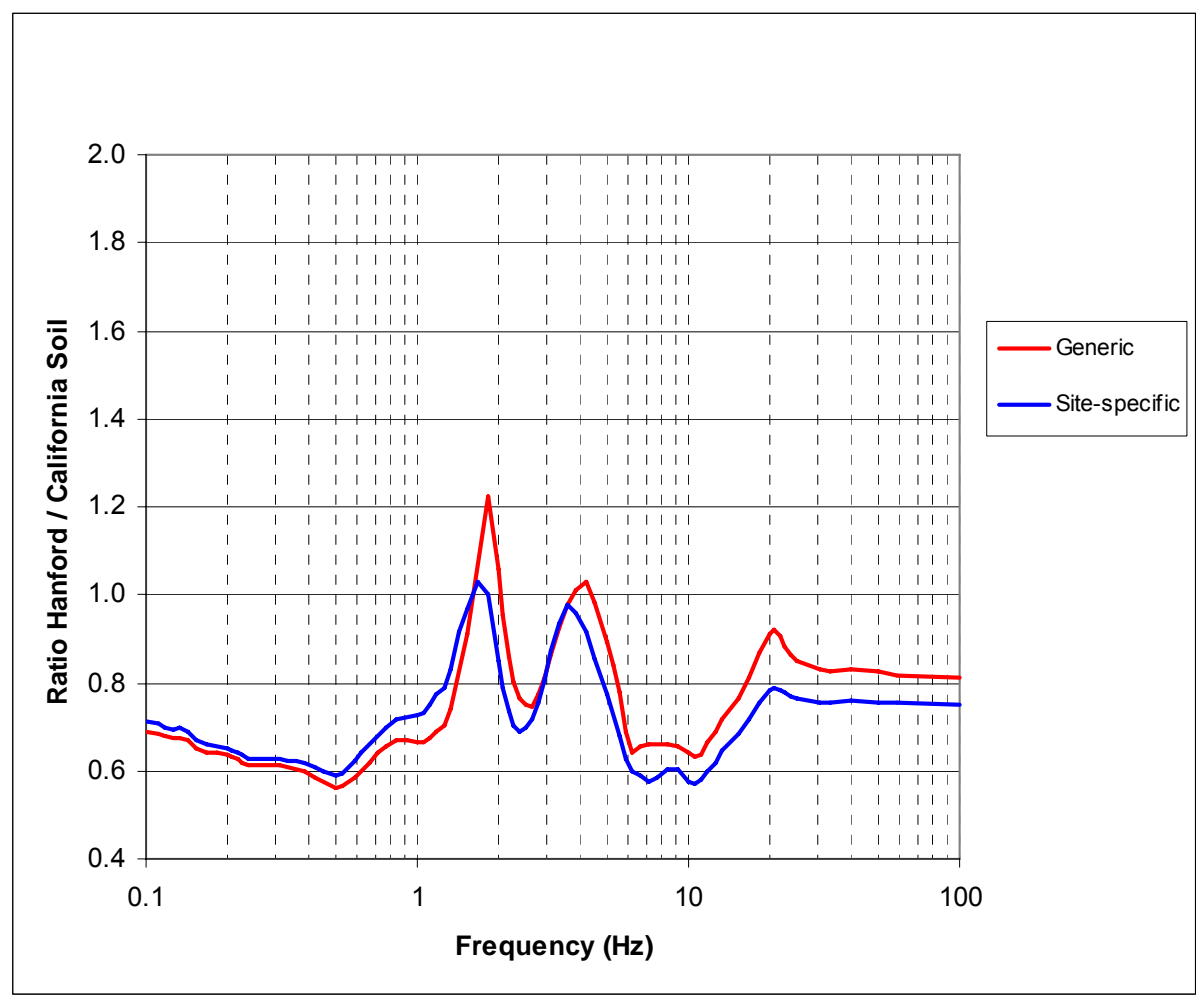

Figure 29: Effect of alternative approaches for specification of the $G / G_{\max }$ and damping relationships for the supra-basalt sediments on relative response for the updated site response model (Figure 2).

Figures 30, 31, and 32 show the effect on relative amplification of the alternative sets of modulus reduction and damping relationships for the sand-dominated $\mathrm{H} 2$ unit, the graveldominated $\mathrm{H} 3$ unit, and gravel-dominated $\mathrm{CCU}$, respectively. As expected, the relative response decreases as the degree of non-linearity increases. The alternative relationships for the CCU gravels have the largest effect on the relative response due to the concentration of strain in this layer near the contact with the high velocity Ringold Unit A horizon. 


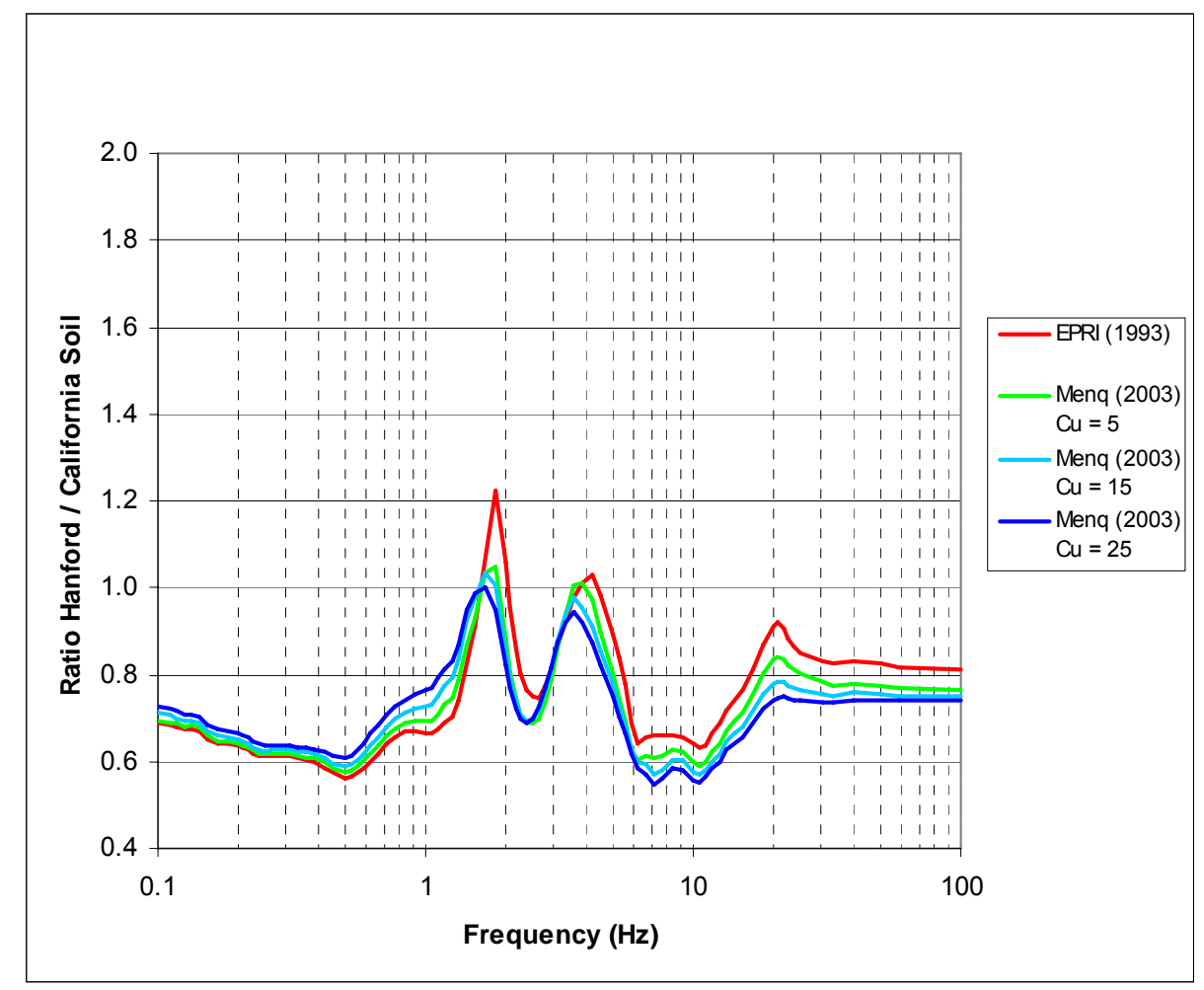

Figure 30: Effect of alternative $\mathrm{G} / \mathrm{G}_{\max }$ and damping relationships for the $\mathrm{H} 2$ unit on relative response for the updated site response model (Figure 2).

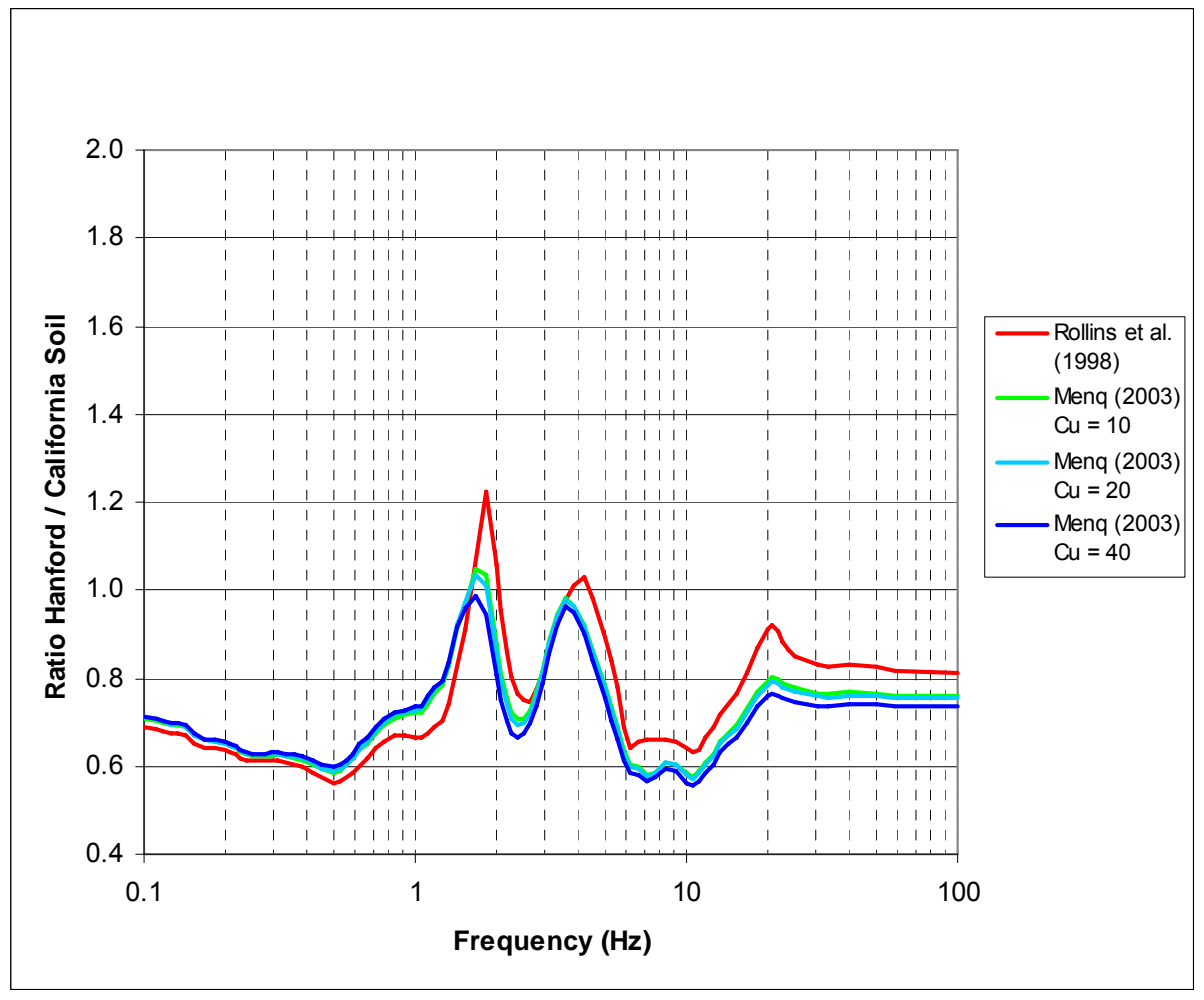

Figure 31: Effect of alternative $\mathrm{G} / \mathrm{G}_{\max }$ and damping relationships for the $\mathrm{H} 3$ unit on relative response for the updated site response model (Figure 2). 


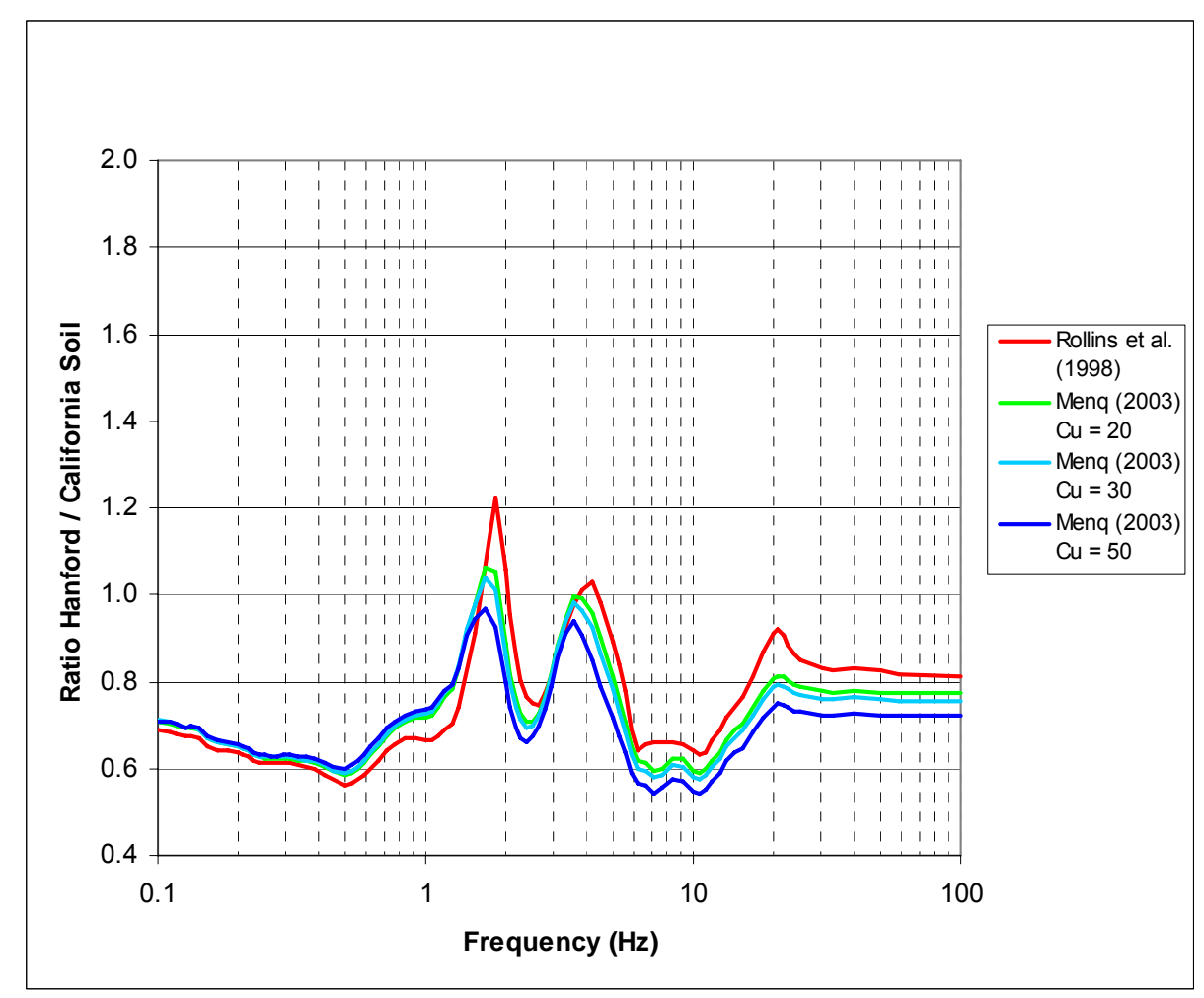

Figure 32: Effect of alternative $\mathrm{G} / \mathrm{G}_{\max }$ and damping relationships for $\mathrm{CCU}$ layer on relative response for the updated site response model (Figure 2).

\subsubsection{Statistics of Relative Amplification Functions}

Figure 30 shows the distribution of relative amplification obtained from the updated site response model logic tree (Figure 2). The primary contributors to the uncertainty in the relative amplification in order of importance are uncertainty in $\kappa$, uncertainty in the approach for selecting modulus reduction and damping relationships, and uncertainty in defining the average grain size distribution for the sediments for use in the Menq (2003) model. 


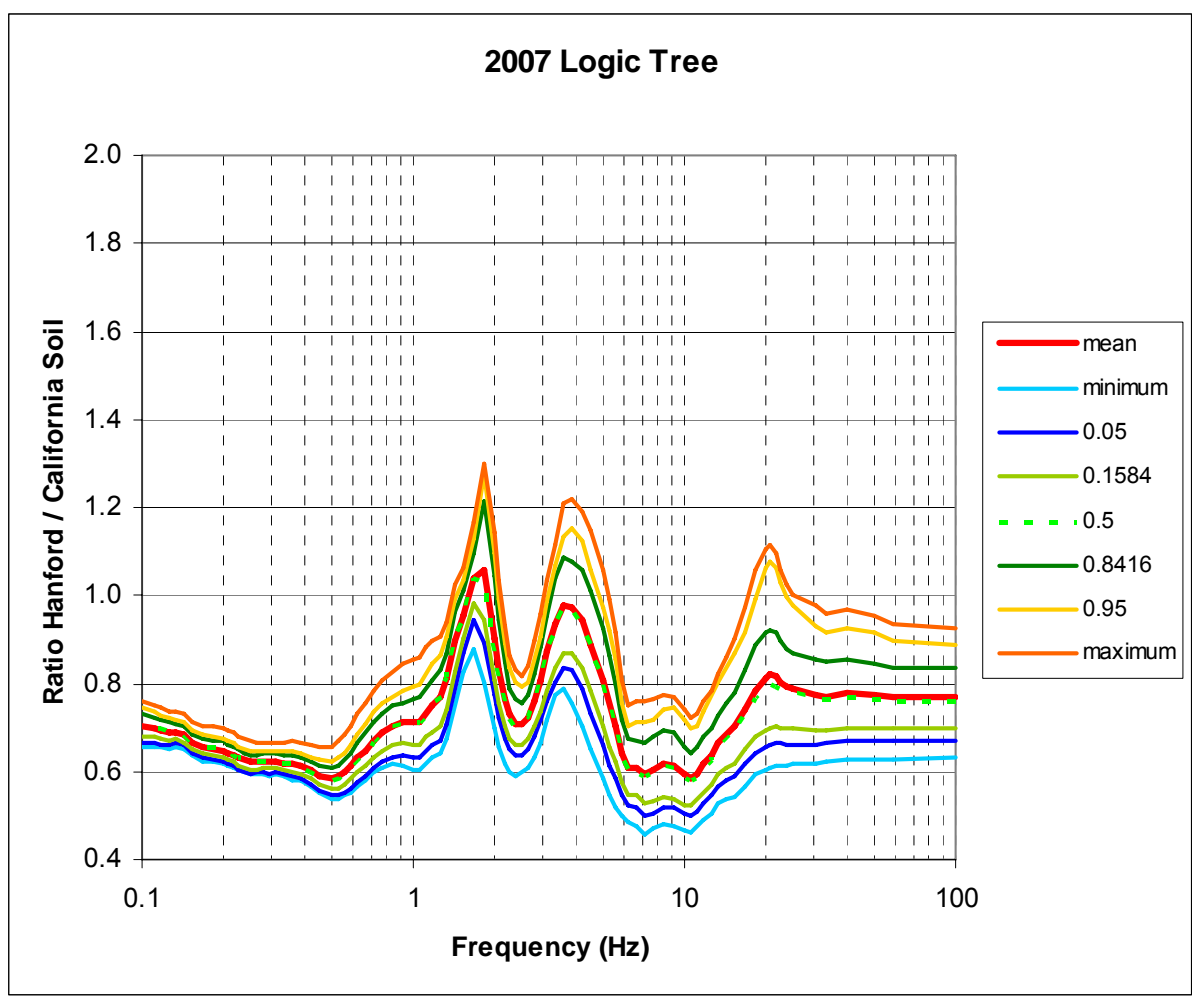

Figure 33: Distribution of relative amplification functions for the WTP site computed using the updated site response model (Figure 2).

\subsection{EFFECT OF PEER-NGA GROUND MOTION MODELS ON SITE HAZARD}

The WTP design spectra are based on the results of a site-wide PSHA study conducted for the DOE Hanford site by Geomatrix (1996). That study used empirical ground motion models for western US earthquakes based primarily on data from firm soil sites in California. Recently, the Pacific Earthquake Engineering Research Center (PEER) has sponsored a study to develop updated empirical ground motion models appropriate for active tectonic regions, principally California. This study is called the Next Generation Attenuation (NGA) study. Five teams are in the process of developing ground motion models based on an extensive data base of strong ground motion data. Three of the initial models are currently being used by the U.S. Geological Survey (USGS) to develop the next round of national seismic hazard maps. These models are those developed by Boore and Atkinson (2006), Campbell and Bozorgnia (2006), and Chiou and Youngs (2006), published on the PEER-NGA web site ${ }^{6}$. These models along with a preliminary model developed by Dr. I.M. Idriss for rock sites only were subjected to an extensive review by the USGS.

The three documented PEER-NGA models were used to recompute the seismic hazard at the WTP site to assess the potential impact of updated ground motion models on the selection of design ground motions. The model developed by Dr. Idriss was not used as it applies only to rock sites. In addition, a preliminary version of the fifth PEER-NGA model being developed by Abrahamson and Silva, provided by Dr. N. Abrahamson (personal communication, 2007) was used. The four PEER-NGA models define the site conditions in terms of average shear wave velocity for the top 30 meters of the site velocity profile, $V_{\mathrm{S} 30}$. In order to compare 
directly with the 1996 hazard results, the average velocity was computed from the generic Califorina soil profile used to represent California deep soil sites. The resulting value of 285 $\mathrm{m} / \mathrm{sec}(936 \mathrm{ft} / \mathrm{sec})$ was used in computing the hazard with the four PEER-NGA models.

In addition to the new PEER-NGA ground motion models, there have been several recently published ground motion models for subduction zone earthquakes. The Cascadia subduction zone interface source was found to be an important contributor to the hazard for frequencies of $1-\mathrm{Hz}$ and less in the Geomatrix (1996) study. Three recently developed models were used to compute the hazard from this source as well as intraslab seismicity associated with the subducting Juan de Fuca plate: Youngs et al. (1997), which is an update of one of the models used by Geomatrix (1996), Gregor et al. (2002), and Atkinson and Boore (2003). The Youngs et al. (1997) and Gregor et al. (2002) models are for firm soil conditions. The Atkinson and Boore (2003) model provides ground motions for National Earthquake Hazards Reduction Program (NEHRP) site classes and their site class D model was used.

PSHA calculations were performed using the seismic source model developed in Geomatrix (1996). One set of calculations was performed for a location in 200 West Area using the 1996 set of ground motion models. This calculation is used as a reference point because the WTP design spectra are based on the site-wide hazard results, which were in turn governed by the hazard at 200 West Area. A second set of calculations was performed for the WTP site location using the 1996 set of ground motion models to assess the effect of the WTP location on the hazard. A third set of calculations was performed for the WTP site using the four PEER-NGA models for the crustal sources (Yakima folds, shallow basalt, and basement sources), the three subduction zone interface models for the Cascadia megathrust source, and the Atkinson and Boore (2003) and Youngs et al. (1997) models for the Juan de Fuca plate source.

Figure 34 compares the results from these three calculations for PGA and spectral accelerations of 5, 2, and $1 \mathrm{~Hz}$. The hazard results using the 1996 ground motion models are slightly lower at the WTP site than at the 200 West site, reflecting a slightly greater distance from the more active sources. The hazard results obtained using the new ground motion models at the WTP site are similar to those obtained using the 1996 set of ground motion models. The results for $1-\mathrm{Hz}$ spectral acceleration indicate a small increase in the 2,000 -year ground motion level. The higher hazard at this spectral frequency is due primarily to the use of the updated subduction zone earthquake ground motion models. However, as shown in Figure 33, the relative amplification function for the WTP site is well below 1.0 for spectral frequencies near and below $1 \mathrm{~Hz}$.

${ }^{6}$ http://peer.berkeley.edu/products/nga_project.html 

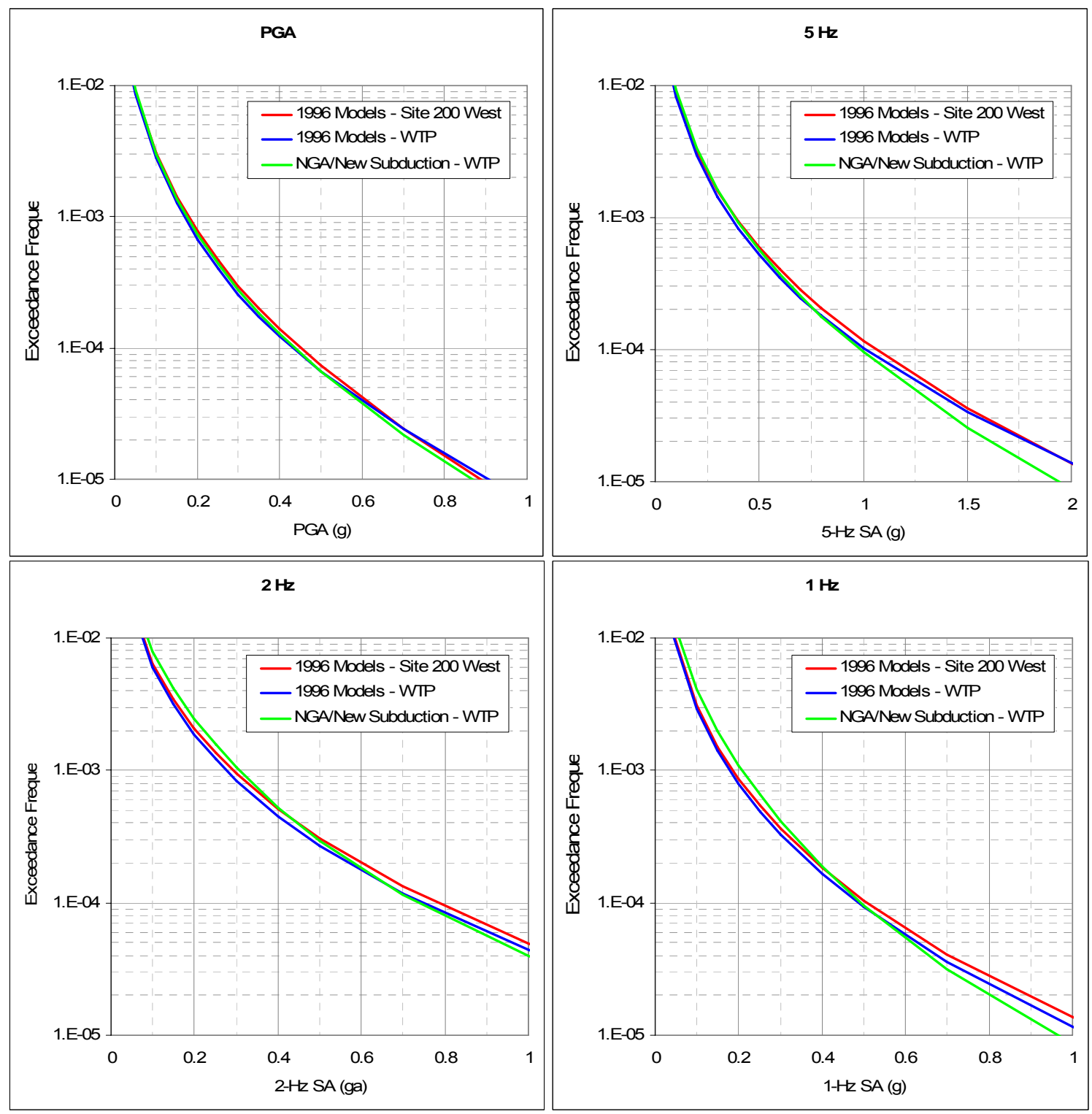

Figure 34: Comparison of total hazard curves (peak ground acceleration [PGA] and spectral acceleration [SA]) computed for: the 200 West site location using 1996 ground motion models, the WTP site location using 1996 ground motion models, and the WTP site location using PEER-NGA and new subduction zone earthquake ground motion models.

\subsection{DEVELOPMENT OF WTP SITE-SPECIFIC DESIGN RESPONSE SPECTRA}

This section describes the development of updated WTP site-specific design response spectra based on the results presented in Section 3.

\subsection{Horizontal Spectrum}

Rohay and Reidel (2005) developed an interim horizontal design response spectrum for the WTP site by multiplying the original WTP horizontal design response spectrum (based on the 1996 PSHA results) by a relative amplification function (RAF) derived from relative site response analyses. As described in Section 1 of this report, a site response model logic tree 
(Figure 1) was developed to represent the epistemic uncertainty in characterizing the dynamic properties of the WTP site. Figure 20 shows the distribution of relative amplification obtained by Rohay and Reidel (2005) from relative response analyses for all of the alternative WTP site response models defined by the logic tree shown in Figure 1. For conservatism in the final design recommendation, Rohay and Reidel (2005) used the 84th percentile relative amplifications from the full logic tree analysis to develop the interim design response spectrum. The selection of the $84^{\text {th }}$-percentile relative amplification was guided by examination of the mean relative amplification computed for selected branches of the logic tree that resulted in higher relative amplification. The $84^{\text {th }}$-percentile relative amplification obtained from the full logic tree analysis was found to envelop the mean response for these branches and was thus considered to be a reasonably conservative estimate of the RAF.

Figure 35 shows the process used to develop the 2005 WTP interim horizontal design response spectrum presented in Rohay and Reidel (2005). The light blue curve (1996 DRS) shows the original WTP design response spectrum developed from the 1996 PSHA results. The green dashed and solid curves show the 1996 spectrum multiplied by the mean and 84thpercentile RAF, respectively, developed from the full distribution of relative response (Figure 20). A smooth envelope of the spectrum obtained using 84th-percentile RAF was constructed (red curve). The narrow, sharp peak at $5 \mathrm{~Hz}$ was lowered slightly and broadened to produce the recommended interim horizontal design response spectrum, also known as the revised ground motion design response spectrum (RGM).

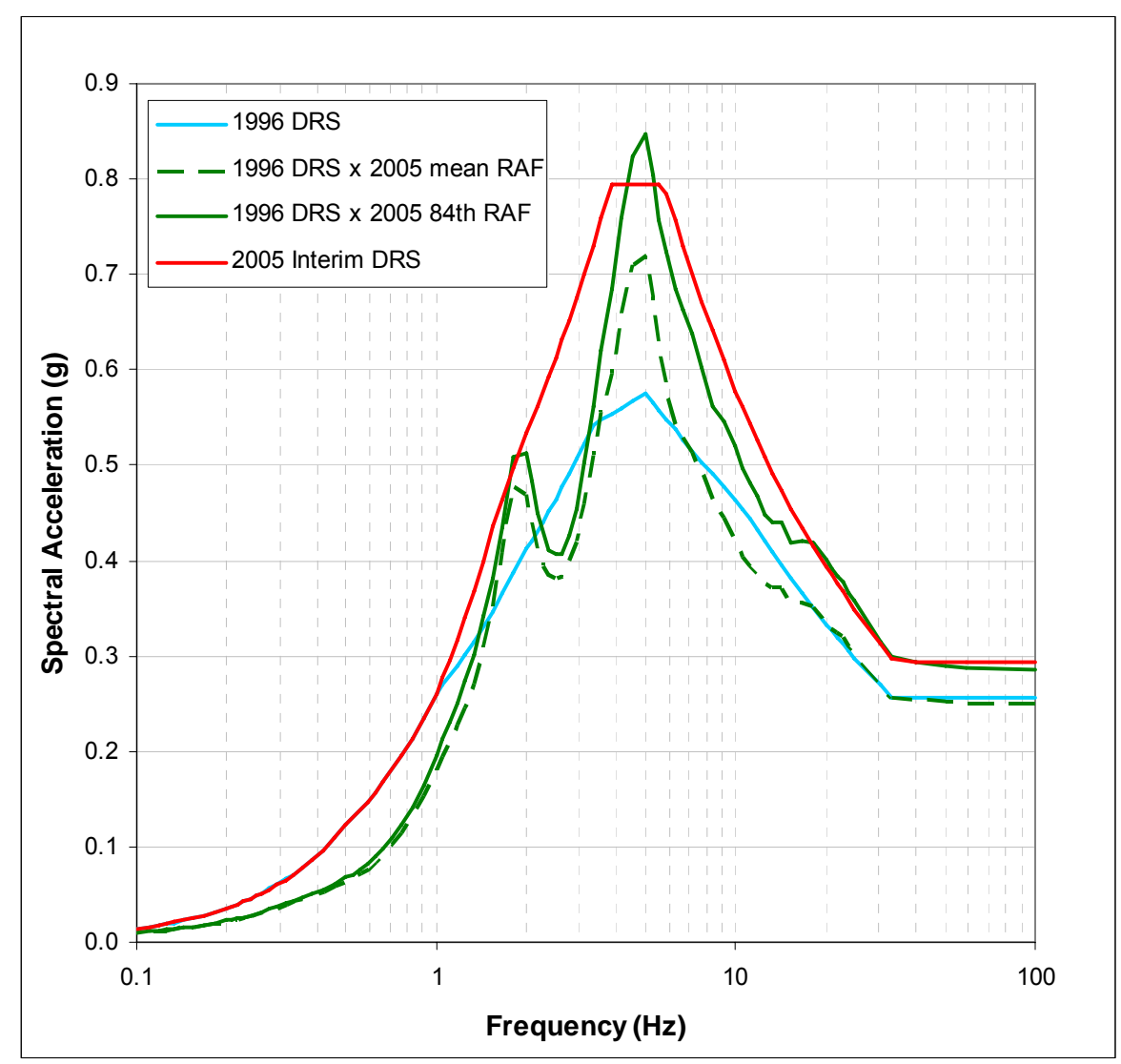

Figure 35: Development of 2005 interim WTP horizontal design response spectrum (2005 Interim DRS) presented in Rohay and Reidel (2005) compared to the original horizontal design response spectrum (1996 DRS) 
The updated WTP site-specific horizontal design response spectrum was developed following the same approach used by Rohay and Reidel (2005). Figure 36 compares response spectra developed by multiplying the original design response spectrum by the mean and 84th-percentile relative amplification functions developed by Rohay and Reidel (2005) to those developed by multiplying the original design response spectrum by the updated relative amplification functions developed in this study (Figure 33). Also shown in the figure are response spectra developed using the relative amplification functions produced for Case 1a (Figure 23). Case 1a is considered to be a conservative case because the site response analyses utilize modulus reduction and damping relationships for the $\mathrm{H} 3$ and $\mathrm{CCU}$ layers that are likely more linear than the behavior of these materials as derived from the sitespecific initial laboratory test. As indicated in Figure 36, the spectrum developed using the 84th-percentile RAF from the 2007 site response model logic tree envelops the spectrum developed using the mean RAF from the conservative Case la.

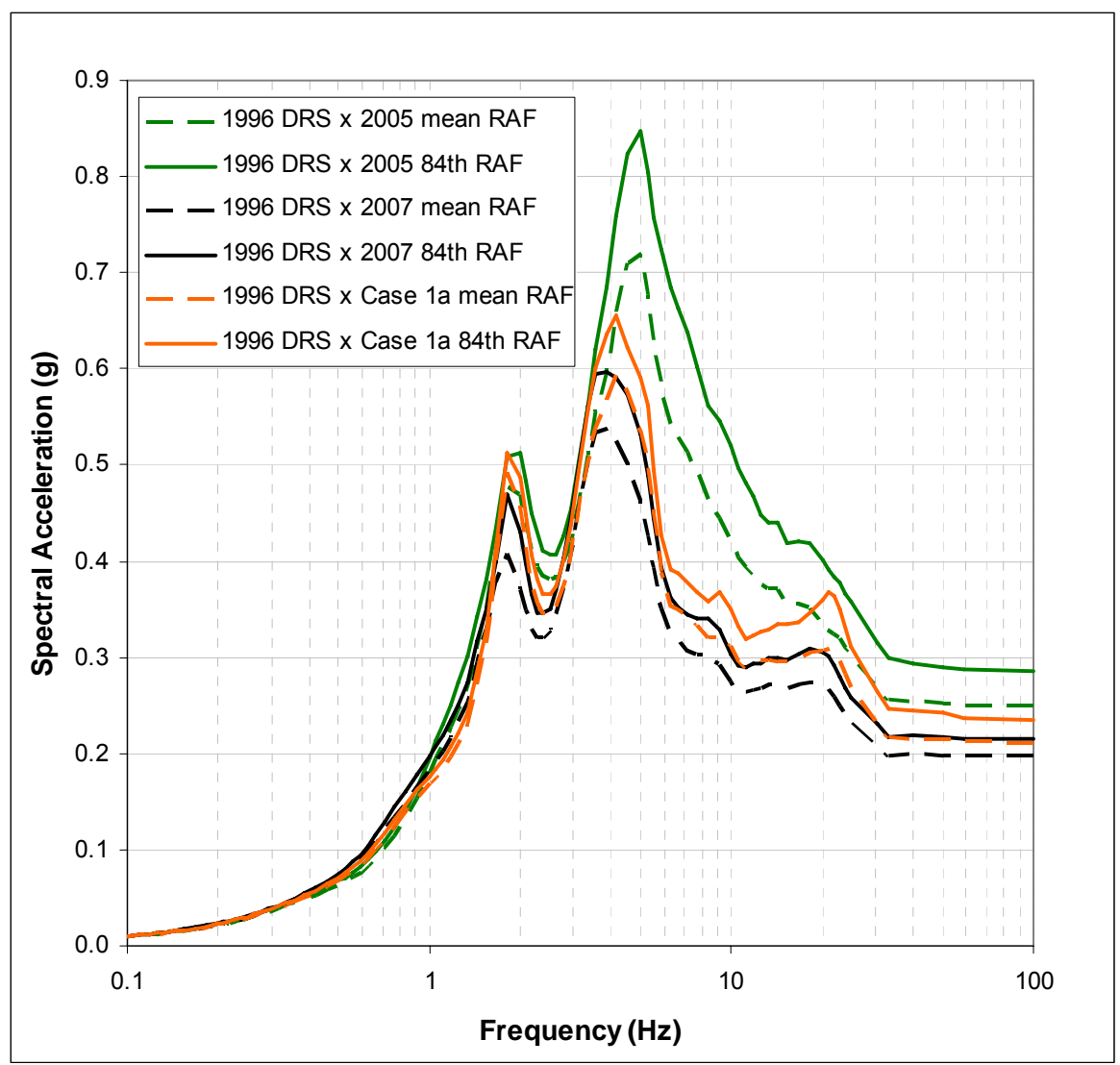

Figure 36: Mean and 84th percentile response spectra developed using 2005 and 2007 relative amplification functions. The 2005, 2007, and Case 1a relative amplification functions are shown in Figures 20,33, and 23, respectively.

Figure 37 shows the updated WTP site-specific horizontal design response spectrum. This spectrum was developed by smoothly enveloping the spectrum produced using the $84^{\text {th }}$ percentile RAF from the updated site response model and the original design response spectrum. The spectrum was also constructed to have a broad peak. Figure 38 compares the updated WTP site-specific response spectrum to spectra developed using spectral amplification factors developed by Newmark and Hall (1978). The spectral accelerations of the updated WTP site-specific design response spectrum are listed in Table 5. 


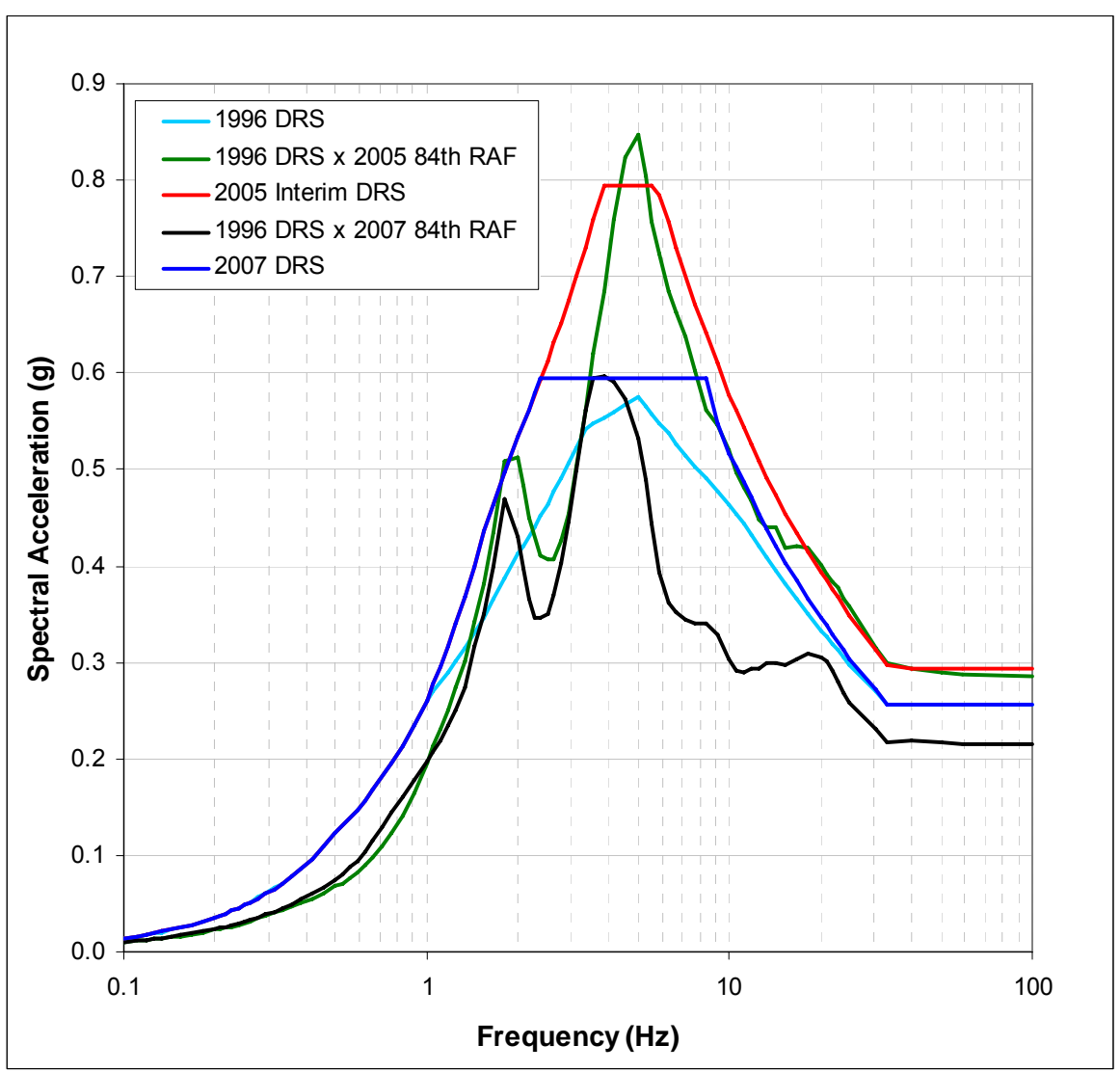

Figure 37: Development of updated site-specific horizontal design response spectrum for the WTP site. Also shown are the original design response spectrum (1996 DRS), the original design response spectrum multiplied by the 2005 84th-percentile RAF, and the 2005 interim DRS. 


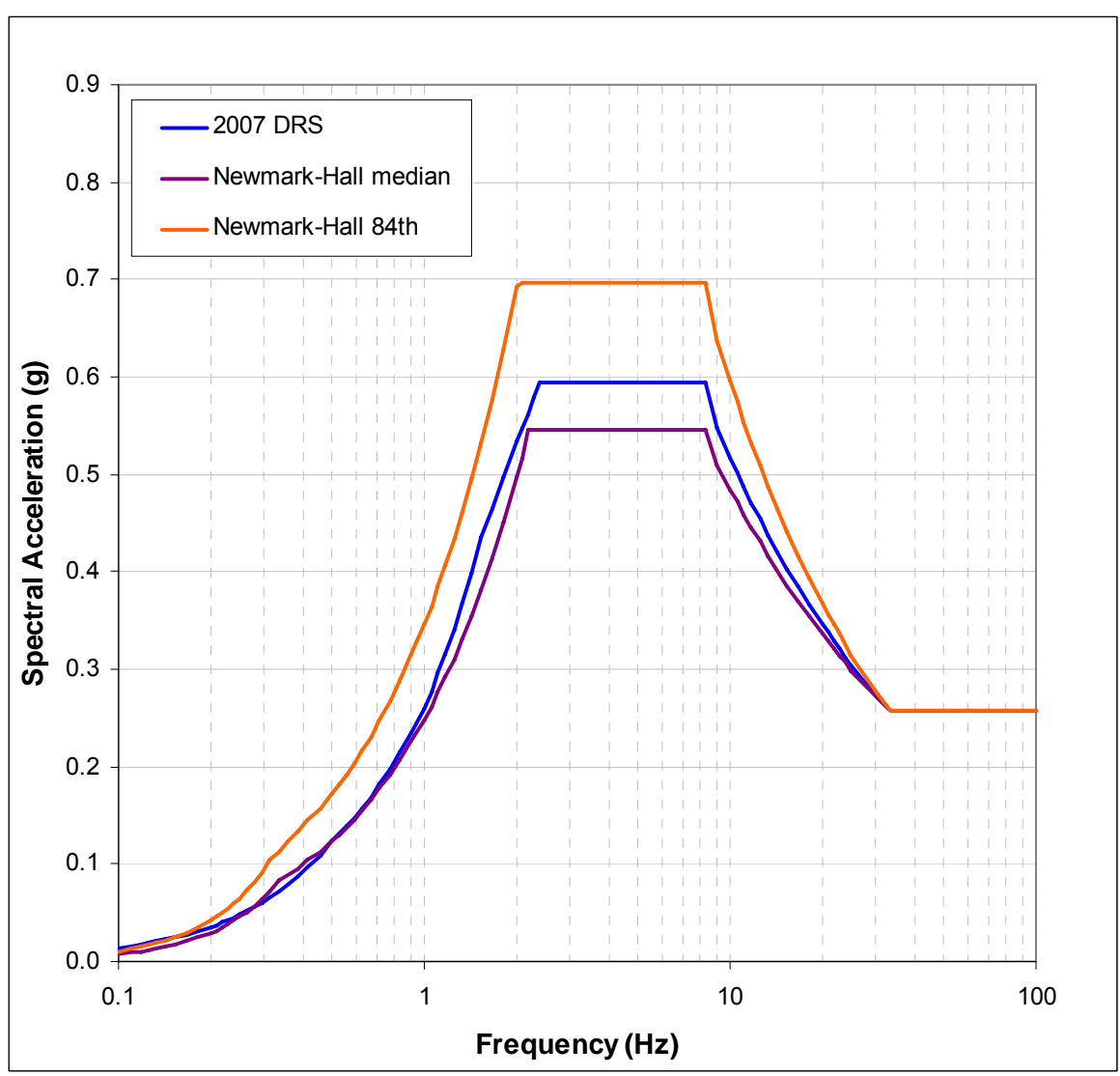

Figure 38: Comparison of the updated WTP site-specific horizontal design response spectrum to spectra developed using the Newmark and Hall (1978) median and $84^{\text {th }}$-percentile spectral amplification factors.

\subsection{Vertical Spectrum}

The original vertical design response spectrum for the WTP site was based on vertical/horizontal $(\mathrm{V} / \mathrm{H})$ spectral ratios developed from empirical ground motion models used in the 1996 seismic hazard study (Geomatrix, 1996). Rohay and Reidel (2005) developed updated vertical/horizontal $(\mathrm{V} / \mathrm{H})$ spectral ratios using more recently published ground motion models. The updated V/H ratios developed by Rohay and Reidel (2005) were used together with the 2007 horizontal spectrum shown in Figure 37 to construct an updated WTP site-specific vertical design response spectrum. The peak of the updated vertical spectrum was broadened in a similar manner to the 2005 interim vertical spectrum. The updated spectrum is shown in Figure 39 along with the updated horizontal spectrum and the interim spectra developed by Rohay and Reidel (2005). The spectral accelerations of the update vertical spectrum are listed in Table 5.

The combined 2007 horizontal and vertical design response spectra shown in Figure 39 and listed in Table 5 represent the updated WTP site-specific ground motion design response spectra (WSGM). 


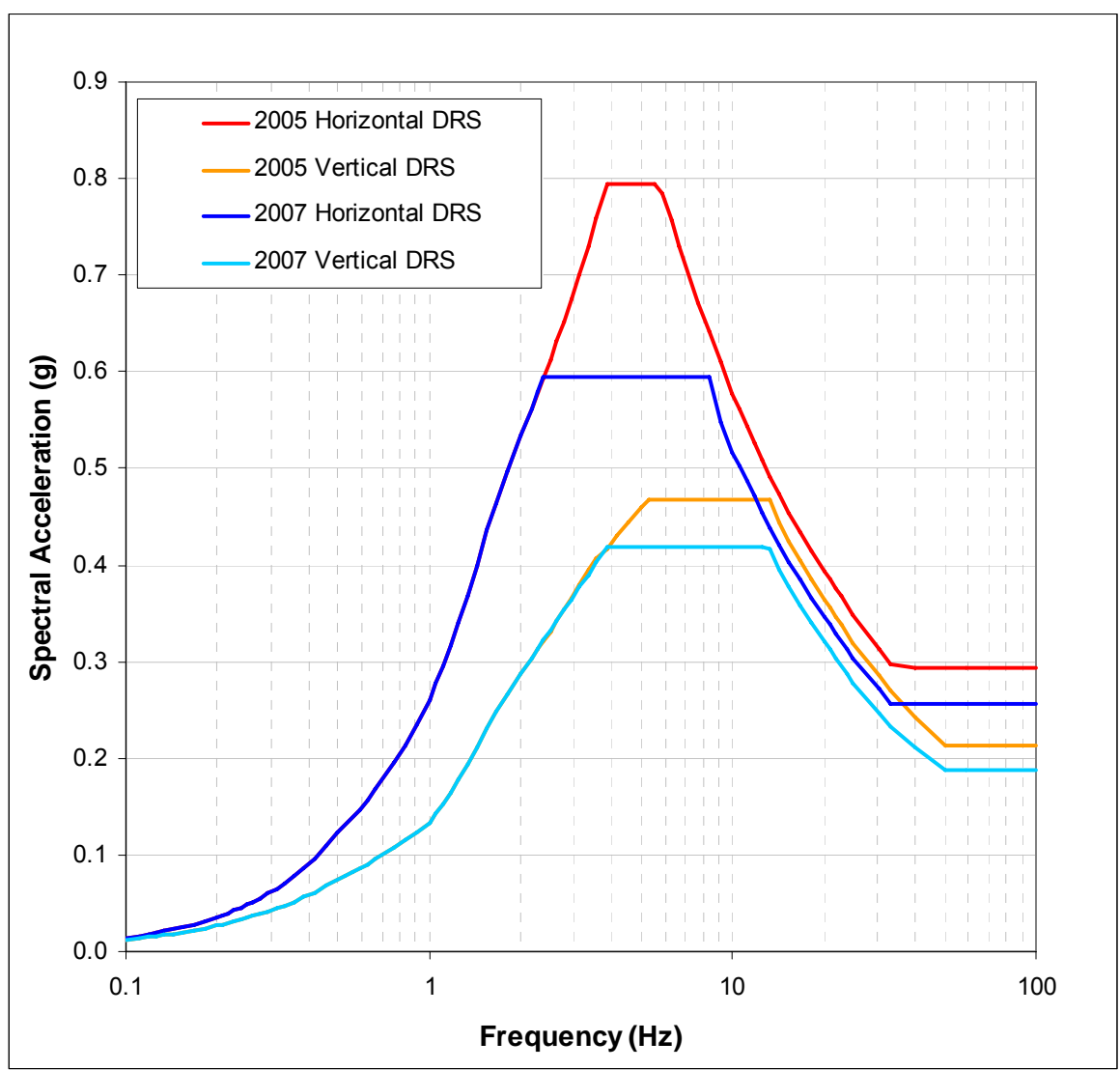

Figure 39: The updated WTP site-specific design response spectra compared to the interim design response spectra developed by Rohay and Reidel (2005).

Table 5: Updated WTP Site-Specific Design Response Spectra

\begin{tabular}{|c|c|c|}
\hline $\begin{array}{c}\text { Frequency } \\
\mathbf{( H z})\end{array}$ & $\begin{array}{c}\text { Horizontal Spectral Acceleration } \\
\mathbf{( g )}\end{array}$ & $\begin{array}{c}\text { Vertical Spectral Acceleration } \\
\mathbf{( g )}\end{array}$ \\
\hline 100.0000 & 0.2570 & 0.1873 \\
\hline 58.8240 & 0.2570 & 0.1873 \\
\hline 50.0000 & 0.2570 & 0.1873 \\
\hline 40.0000 & 0.2570 & 0.2113 \\
\hline 33.3330 & 0.2570 & 0.2332 \\
\hline 30.3030 & 0.2716 & 0.2474 \\
\hline 25.0000 & 0.3038 & 0.2787 \\
\hline 23.8100 & 0.3125 & 0.2873 \\
\hline 22.7270 & 0.3211 & 0.2957 \\
\hline 21.7390 & 0.3295 & 0.3040 \\
\hline 20.8330 & 0.3378 & 0.3122 \\
\hline 20.0000 & 0.3459 & 0.3202 \\
\hline 18.1820 & 0.3656 & 0.3396 \\
\hline 16.6670 & 0.3845 & 0.3585 \\
\hline 15.3850 & 0.4029 & 0.3768 \\
\hline 14.2860 & 0.4205 & 0.3943 \\
\hline & & \\
\hline
\end{tabular}


Table 5: Updated WTP Site-Specific Design Response Spectra (cont'd)

\begin{tabular}{|c|c|c|}
\hline $\begin{array}{l}\text { Frequency } \\
\quad(\mathrm{Hz})\end{array}$ & $\begin{array}{l}\text { Horizontal Spectral Acceleration } \\
\text { (g) }\end{array}$ & $\begin{array}{c}\text { Vertical Spectral Acceleration } \\
(\mathbf{g})\end{array}$ \\
\hline 13.3330 & 0.4379 & 0.4169 \\
\hline 12.5000 & 0.4546 & 0.4187 \\
\hline 11.7650 & 0.4710 & 0.4187 \\
\hline 11.1110 & 0.4868 & 0.4187 \\
\hline 10.5260 & 0.5022 & 0.4187 \\
\hline 10.0000 & 0.5175 & 0.4187 \\
\hline 9.0910 & 0.5470 & 0.4187 \\
\hline 8.3330 & 0.5950 & 0.4187 \\
\hline 7.6920 & 0.5950 & 0.4187 \\
\hline 7.1430 & 0.5950 & 0.4187 \\
\hline 6.6670 & 0.5950 & 0.4187 \\
\hline 6.2500 & 0.5950 & 0.4187 \\
\hline 5.8820 & 0.5950 & 0.4187 \\
\hline 5.5560 & 0.5950 & 0.4187 \\
\hline 5.2630 & 0.5950 & 0.4187 \\
\hline 5.0000 & 0.5950 & 0.4187 \\
\hline 4.5450 & 0.5950 & 0.4187 \\
\hline 4.1670 & 0.5950 & 0.4187 \\
\hline 3.8460 & 0.5950 & 0.4187 \\
\hline 3.5710 & 0.5950 & 0.4035 \\
\hline 3.3330 & 0.5950 & 0.3895 \\
\hline 3.1250 & 0.5950 & 0.3771 \\
\hline 2.9410 & 0.5950 & 0.3645 \\
\hline 2.7780 & 0.5950 & 0.3532 \\
\hline 2.6320 & 0.5950 & 0.3421 \\
\hline 2.5000 & 0.5950 & 0.3319 \\
\hline 2.3810 & 0.5950 & 0.3220 \\
\hline 2.2730 & 0.5790 & 0.3133 \\
\hline 2.1740 & 0.5613 & 0.3036 \\
\hline 2.0830 & 0.5469 & 0.2957 \\
\hline 2.0000 & 0.5334 & 0.2882 \\
\hline 1.8180 & 0.4970 & 0.2667 \\
\hline 1.6670 & 0.4644 & 0.2476 \\
\hline 1.5380 & 0.4363 & 0.2312 \\
\hline 1.4290 & 0.3993 & 0.2105 \\
\hline 1.3330 & 0.3676 & 0.1928 \\
\hline 1.2500 & 0.3402 & 0.1775 \\
\hline 1.1760 & 0.3163 & 0.1643 \\
\hline 1.1110 & 0.2954 & 0.1528 \\
\hline 1.0530 & 0.2769 & 0.1427 \\
\hline 1.0000 & 0.2603 & 0.1336 \\
\hline
\end{tabular}


Table 5: Updated WTP Site-Specific Design Response Spectra (cont'd)

\begin{tabular}{|c|c|c|}
\hline $\begin{array}{l}\text { Frequency } \\
\quad(\mathrm{Hz})\end{array}$ & $\begin{array}{l}\text { Horizontal Spectral Acceleration } \\
\text { (g) }\end{array}$ & $\begin{array}{c}\text { Vertical Spectral Acceleration } \\
(\mathrm{g})\end{array}$ \\
\hline 0.9090 & 0.2351 & 0.1235 \\
\hline 0.8330 & 0.2141 & 0.1149 \\
\hline 0.7690 & 0.1965 & 0.1075 \\
\hline 0.7140 & 0.1815 & 0.1011 \\
\hline 0.6670 & 0.1686 & 0.0955 \\
\hline 0.6250 & 0.1573 & 0.0906 \\
\hline 0.5880 & 0.1474 & 0.0861 \\
\hline 0.5560 & 0.1387 & 0.0822 \\
\hline 0.5260 & 0.1309 & 0.0786 \\
\hline 0.5000 & 0.1239 & 0.0753 \\
\hline 0.4550 & 0.1088 & 0.0676 \\
\hline 0.4170 & 0.0967 & 0.0613 \\
\hline 0.3850 & 0.0867 & 0.0560 \\
\hline 0.3570 & 0.0784 & 0.0515 \\
\hline 0.3330 & 0.0714 & 0.0476 \\
\hline 0.3130 & 0.0654 & 0.0443 \\
\hline 0.2940 & 0.0603 & 0.0414 \\
\hline 0.2780 & 0.0557 & 0.0387 \\
\hline 0.2630 & 0.0518 & 0.0365 \\
\hline 0.2500 & 0.0483 & 0.0344 \\
\hline 0.2380 & 0.0452 & 0.0326 \\
\hline 0.2270 & 0.0424 & 0.0309 \\
\hline 0.2170 & 0.0400 & 0.0295 \\
\hline 0.2080 & 0.0377 & 0.0280 \\
\hline 0.2000 & 0.0357 & 0.0268 \\
\hline 0.1820 & 0.0313 & 0.0240 \\
\hline 0.1670 & 0.0279 & 0.0218 \\
\hline 0.1540 & 0.0250 & 0.0199 \\
\hline 0.1430 & 0.0226 & 0.0183 \\
\hline 0.1330 & 0.0206 & 0.0170 \\
\hline 0.1250 & 0.0188 & 0.0157 \\
\hline 0.1180 & 0.0174 & 0.0147 \\
\hline 0.1110 & 0.0161 & 0.0138 \\
\hline 0.1000 & 0.0139 & 0.0122 \\
\hline
\end{tabular}




\subsection{REFERENCES}

Atkinson, G.M. and D.M. Boore, 2003, Empirical ground motions for subduction zone earthquakes and their application to Cascadia and other regions, Bulletin of the Seismological Society of America, v. 93, p. 1703-1729.

Barnett D.B., B.N. Bjornstad, K.R. Fecht, D.C. Lanigan, S.P. Reidel, and C.F. Rust, 2007, Geology of the Waste Treatment Plant Seismic Boreholes, PNNL-16407 Revision 1, Report prepared by Pacific Northwest National Laboratory for the U.S. Department of Energy, Office of River Protection, under Contract DE-AC05-76RL01830, May.

Boore, D.M., and G.M. Atkinson, 2006, Boore-Atkinson provisional NGA empirical ground-motion model for the average horizontal component of PGA, PGV and SA at spectral periods of $0.05,0.1,0.2,0.3,0.5,1,2,3,4$, and 5 seconds, October, http://peer.berkeley.edu/products/Boore-Atkinson-NGA_11-13-06.html

Campbell, K.W, and Y. Bozorgnia, 2006, Campbell-Bozorgnia NGA empirical ground motion model for the average horizontal component of PGA, PGV, PGD and SA at selected spectral periods ranging from 0.01-10.0 seconds (Version 1.1), December, http://peer.berkeley.edu/products/Campbell-Bozorgnia_NGA.html

Chiou, B.S.-J., and R.R. Youngs, 2006, Chiou and Youngs PEER-NGA empirical ground motion model for the average horizontal component of peak acceleration and pseudo-spectral acceleration for spectral periods of 0.01 to 10 seconds, July, http://peer.berkeley.edu/products/Chiou_Youngs_NGA_2006.html

Darendeli, B.M., 2001, Development of a new family of normalized modulus reduction and material damping curves, Ph.D. Dissertation, University of Texas, Austin, 362 p.

Electric Power Research Institute (EPRI), 1993, Guidelines for determining design basis ground motions: EPRI TR-102293, Project 3302, 5 vol., November.

Geomatrix, 1996, Probabilistic seismic hazard analysis, DOE Hanford Site Washington: Westinghouse Hanford Company report WHC-SD-W236-TI-002, Revision 1a, October.

Geomatrix, 2003, Updated relative site response study for Hanford: Calculation package prepared for Bechtel National, San Francisco California, March 21, 2003.

Geomatrix, 2005, Site Response Software Validation Reports: Unpublished report prepared for Pacific Northwest National Laboratory, Geomatrix Project 10406, December, 2005.

Geomatrix, 2006, Site Response Analyses for the Waste Treatment Plant, Hanford, Washington, Calculation 9995-001, Rev 1, March 2, 2006, 55 p.

Gregor, N.J,. W.J. Silva, I.G. Wong, and R.R. Youngs, 2002, Ground-motion attenuation relationships for Cascadia subduction zone megathrust earthquakes based on a stochastic finite-fault model, Bulletin of the Seismological Society of America, v. 92, p. 1923-1932.

Menq, F.-Y., 2003, Dynamic properties of sandy and gravely soils, Ph.D. Dissertation, University of Texas, Austin, May, 364 p.

Newmark, N. M., and W.J. Hall, 1978, Development of Criteria for Seismic Review of Selected Nuclear Power Plants, Report NUREG/CR-0098, U.S. Nuclear Regulatory Commission, Rockville, Maryland. 
Rockhold, M.L., M.J. Fayer, and P.R. Heller, 1993, Physical and Hydraulic Properties of Sediments and Engineered Materials Associated with Grouted Double-Shell Tank Waste Disposal at Hanford. PNL-8813: Report prepared by Pacific Northwest Laboratory for the U.S. Department of Energy, under Contract DE-AC05-76RL01830, September.

Rohay, A.C., and T.M. Brouns, 2007, Site-specific Velocity and Density Model for the Waste Treatment Plant, Hanford, Washington, PNNL-16652: Report prepared by Pacific Northwest National Laboratory for the U.S. Department of Energy, Office of River Protection, under Contract DE-AC05-76RL01830, June.

Rohay, A.C., and S.P. Reidel, 2005, Site-specific seismic site response model for the Waste Treatment Plant, Hanford, Washington, PNNL-15089: Report prepared by Pacific Northwest National Laboratory for the U.S. Department of Energy, Office of River Protection, under Contract DE-AC05-76RL01830, March.

Rollins, K.M., M.D. Evans, N.B. Diehl, and W.D. Daily III, 1998,. Shear modulus and damping relationships for gravels: ASCE Journal of Geotechnical and Geoenvironmental Engineering, v. 124, n.5.

Schnabel, P.B., Lysmer, J., and Seed, H.B. 1972, SHAKE - a computer program for earthquake response analysis of horizontally layered sites, Earthquake Research Center, University of California, Berkeley, CA, EERC 72-12.

Shannon \& Wilson, Inc., 2000, Final Report, Geotechnical Investigation, River Protection ProjectWaste Treatment Plant. Project No. DE-AC06-96RL-13308, Subcontract No. W375WTSC99-1036, 200 East Area, Hanford Site, Richland, Washington, report prepared for British Nuclear Fuels, Ltd.

Silva, W.J. and R. Darragh, 1995, Engineering characterization of earthquake strong ground motion recorded at rock sites: Electric Power Research Institute TR-102261. Palo Alto, California.

Silva, W.C., Abrahamson, N., Toro, G., and Costantino, C., 1998, Description and validation of the stochastic ground motion model: Report submitted to Brookhaven National Laboratory, Associated Universities, Inc., New York.

Youngs, R.R., S.-J. Chiou, W.J. Silva, and J.R. Humphrey, 1997, Strong ground motion attenuation relationships for subduction zone earthquakes, Seismological Research Letters, v. 68, p. 5873. 


\section{Distribution}

No. of

\section{Copies}

OFFSITE

C. J. Costantino

4 Rockingham Road

Spring Valley, NY 10977

J. A. McCloskey

U.S. Department of Energy

Headquarters, EM-23

19901 Germantown Road

Germantown, MD 20874

B. B. Redpath

Redpath Geophysics

P.O. Box 540

Murphys, CA 95247

K. H. Stokoe II

University of Texas at Austin

Department of Civil Engineering

College of Engineering

1 University Station C1700

Austin, TX 78712

6 U.S. Army Corps of Engineers

Seattle District

P.O. Box 3755

Seattle, WA 98124-3755

ATTN: A. P. Dimbirs (4)

R. O. Garrison

R. E. Smith

E. A. Mann

Micro-g LaCoste

1401 Horizon Ave.

Lafayette, CO 80026

S. P. Reidel

7207 West Old Inland Empire Highway

Benton City, WA 99320
No. of

Copies

ONSITE

7 DOE Office of River Protection

W. Abdul

H6-60

J. R. Eschenberg H6-60

T. R. Hoertkorn H6-60

L. F. Miller H6-60

Correspondence Control (3) H6-60

2 Bechtel National, Inc.

L. T. Lamm MS4-A2

M. R. Braccia MS 5-K

EnergySolutions

M. G. Gardner

G1-62

5 Fluor Hanford, Inc.

D. B. Barnett E6-35

S. A. Fargo H8-60

D. G. Horton K6-75

S. H. Worley E6-35

$\begin{array}{ll}\text { C. S. Wright E6-35 } & \end{array}$

Washington Closure Hanford, LLC

K. R. Fecht H4-21

Washington State Department of Ecology

J. A. Caggiano H0-57

11 Pacific Northwest National Laboratory

B. N. Bjornstad K6-81

T. M. Brouns (5) K9-69

D. C. Lanigan K6-75

A. C. Rohay K6-75

Information Release (3) P8-55 